\title{
Solimar Ferrari
}

\section{Câncer na gestação:}

\section{avaliação de depressão, ansiedade, autoestima e vínculo materno-fetal}

Tese apresentada à Faculdade de Medicina da Universidade de São Paulo para obtenção do título de Doutor em Ciências

Programa de Obstetrícia e Ginecologia Orientadora: Prof. ${ }^{a}$ Dr. $\stackrel{\text { a }}{ }$ Gláucia Rosana Guerra Benute

São Paulo

2018 


\section{Dados Internacionais de Catalogação na Publicação (CIP)}

Preparada pela Biblioteca da

Faculdade de Medicina da Universidade de São Paulo

Creprodução autorizada pelo autor

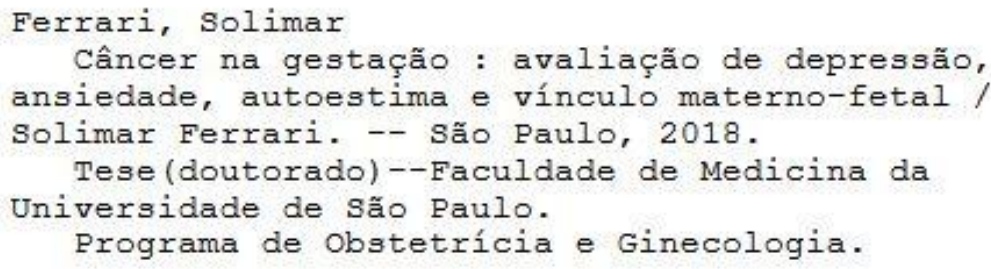

Descritores: 1.Gravidez 2. Neoplasias 3.Depressão 4.Ansiedade 5.Autoestima 6. Relações materno-fetais 7.Apego materno-fetal $8 . V$ ínculo materno-fetal

$\mathrm{USP} / \mathrm{FM} / \mathrm{DBD}-394 / 18$

Responsável: Erinalva da Conceição Batista, CRB-8 6755 
Ao meu pai Rubens (in memorian) e à minha irmã Luciane (in memorian), pela certeza de um amor eterno. 
Ao Prof. Dr. Marcelo Zugaib, Professor Titular do Departamento de Obstetrícia e Ginecologia da FMUSP, pela oportunidade acadêmica concedida.

À Prof. ${ }^{a}$ Dr. ${ }^{a}$ Rossana Pulcineli Vieira Francisco pelo incentivo constante à pesquisa, pela oportunidade de realização deste trabalho e pelas valiosas contribuições no exame de qualificação.

À Prof. ${ }^{a}$ Dr. a Gláucia Rosana Guerra Benute, minha orientadora, por todo o aprendizado neste trabalho e no tempo que convivemos na Divisão de Psicologia do ICHC-FMUSP, por ser uma referência de profissional e pesquisadora.

À Dr. ${ }^{\underline{a}}$ Eliane Azeka pelo profissionalismo e responsabilidade ao conduzir o atendimento às gestantes com câncer do Ambulatório de Tumores na Gestação da Divisão de Clínica Obstétrica do HC-FMUSP.

À Dr. ${ }^{\text {a }}$ Maria de Lourdes Brizot pela clareza de suas pontuações no exame de qualificação e pela dedicação ao ensino, pesquisa e formação de profissionais da saúde.

Ao Dr. Niraldo de Oliveira Santos pelo que representa para a Psicologia no Brasil e pelas ricas contribuições no exame de qualificação.

À Agatha Rodrigues pelo aprendizado e contribuição em seus ensinamentos.

Aos colegas da Pós-Graduação pela troca de experiências, em especial à Mariana Rebello, Fabiana Chaves Maia e Débora Cristina N. Bordini.

À Lucinda Cristina Pereira, secretária do Curso de Pós-Graduação em Obstetrícia e Ginecologia pela disponibilidade e atenção em todos os momentos.

A todos os médicos e médicas da Clínica Obstétrica da FMUSP pelo compromisso com a excelência no atendimento às gestantes.

À Dr. a Mara Cristina Souza De Lucia por todas as oportunidades que me ofereceu, inclusive a realização deste trabalho. 
Às amigas Denise Cunha Coutinho, Cláudia Laham e Maria Rita Polo Gáscon, pelo apoio e amizade sincera.

Às pacientes que puderam, de maneira generosa, contribuir para este trabalho compartilhando suas experiências e sentimentos.

À minha mãe Ignês $A$. Ferrari pela resiliência em tempos tão árduos e porque sempre nos ensinou a acreditar na força do bem.

À minha cunhada Rosana Schiavetti e à minha sogra Dulce $\mathrm{H}$. Schiavetti pelo afeto sempre presente.

À minha irmã Célia Ferrari, alma gêmea, pelo privilégio da tua amizade e cumplicidade, sempre.

Ao meu irmão André Luiz Ferrari, pela sua luta, que me faz ter a certeza que existe a possibilidade de um mundo melhor.

Às pequenas Maria Cecília Ferrari e Alice Ferrari, sobrinhas, pela renovação, alegria e encantamento que trouxeram para nossas vidas.

Ao meu companheiro Flávio Schiavetti, por todos os caminhos desbravados e ainda a conhecer, por me ensinar a não ter medo, por estar ao meu lado sempre, pela cumplicidade e amor. 
A força que nunca seca (Chico César e Vanessa da Mata) Já se pode ver ao longe A senhora com a lata na cabeça Equilibrando a lata vesga Mais do que o corpo dita Que faz o equilíbrio cego A lata não mostra O corpo que entorta Pra lata ficar reta.

Pra cada braço uma força De força não geme uma nota A lata só cerca, não leva A água na estrada morta E a força nunca seca Pra água que é tão pouca 
Normatização Adotada

Esta tese está de acordo com as seguintes normas, em vigor no momento desta publicação:

Referências: adaptado de International Committee of Medical Journals Editors (Vancouver).

Universidade de São Paulo. Faculdade de Medicina. Divisão de Biblioteca e Documentação. Guia de apresentação de dissertações, teses e monografias. Elaborado por Anneliese Carneiro da Cunha, Maria Julia de A. L. Freddi, Maria F. Crestana, Marinalva de Souza Aragão, Suely Campos Cardoso, Valéria Vilhena. 3a ed. São Paulo: Divisão de Biblioteca e Documentação; 2011.

Abreviaturas dos títulos dos periódicos de acordo com List of Journals Indexed in Index Medicus. 


\section{SUMÁRIO}

Lista de Siglas

Lista de Tabelas

Lista de Figuras

Resumo

Summary

Resumen

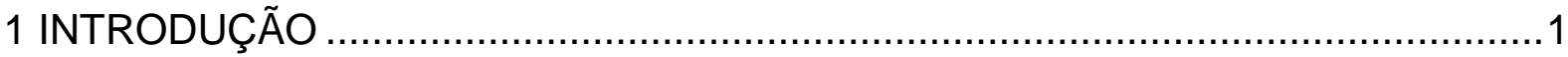

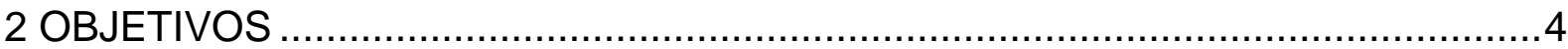

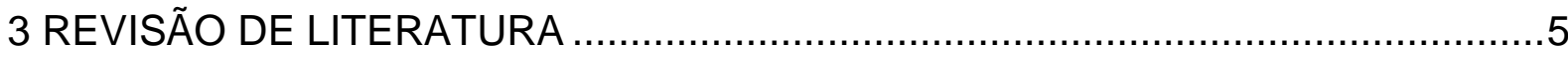

3.1 Câncer na gestação ..........................................................................

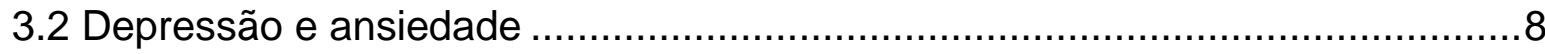

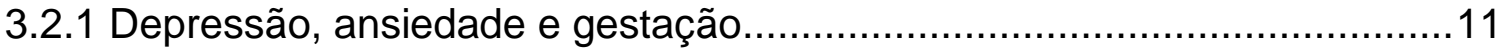

3.2.2 Depressão, ansiedade e câncer ............................................... 13

3.2.3 Dimensões psicológicas da vivência de adoecimento por câncer na

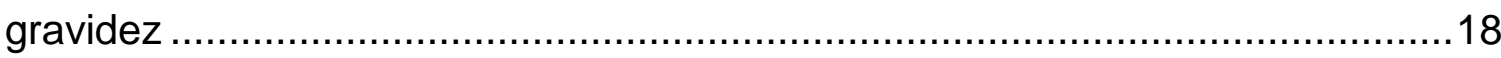

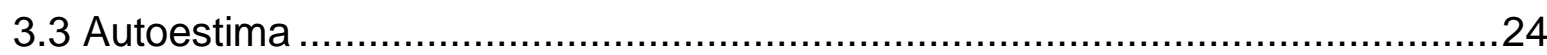

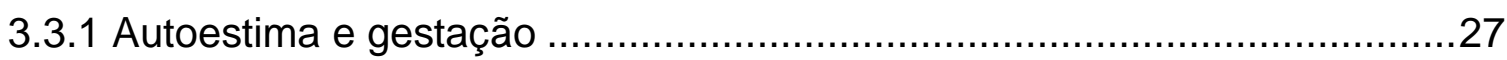

3.3.2 Autoestima e câncer .........................................................................29

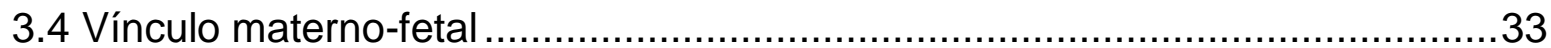

4 MÉTODO

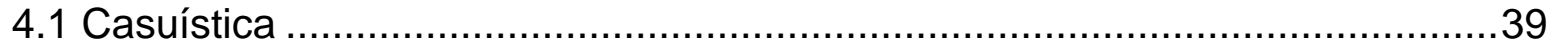

4.2 Local do Estudo .............................................................................

4.3 Critérios de inclusão........................................................................

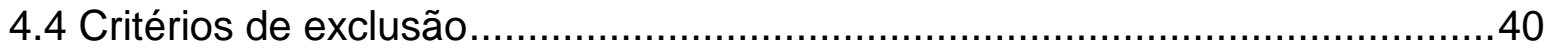

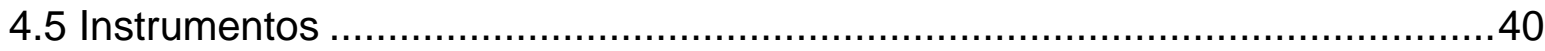

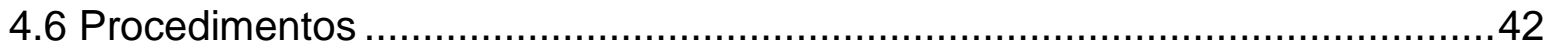


4.7 Análise dos dados

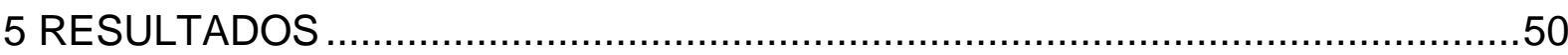

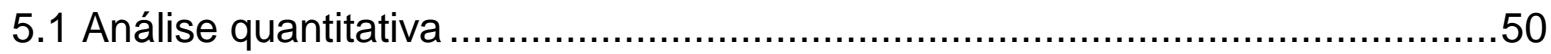

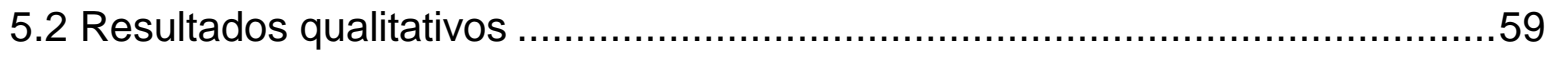

5.2.1 Entrevistas realizadas com as gestantes com diagnóstico de câncer e sem

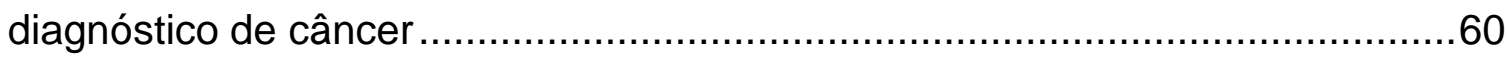

5.2.1.1 Descoberta da gestação ...............................................................6

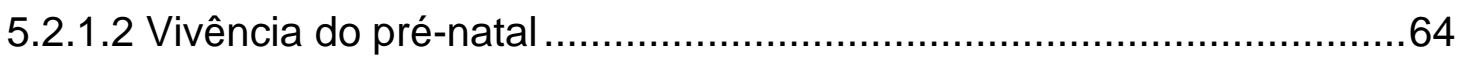

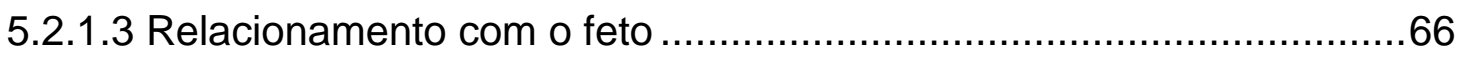

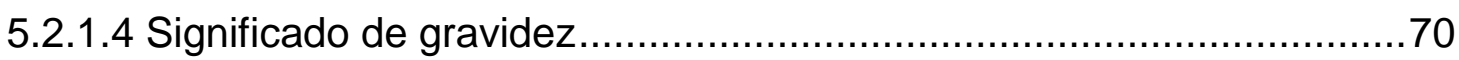

5.2.2 Entrevistas realizadas com as gestantes com diagnóstico de câncer ........72

5.2.2.1 Descoberta do câncer.................................................................. 72

5.2.2.2 Vivência do tratamento do câncer .....................................................74

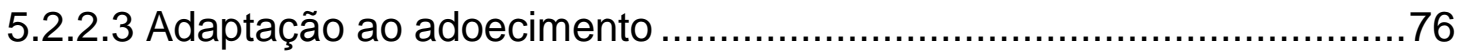

5.2.2.4 Crenças sobre o relacionamento com o feto .................................... 80

5.2.2.5 Vivência do câncer na gestação ....................................................82

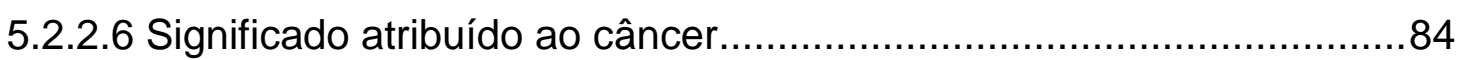

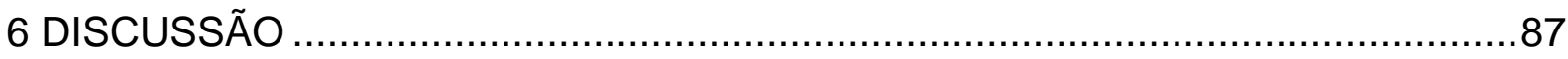

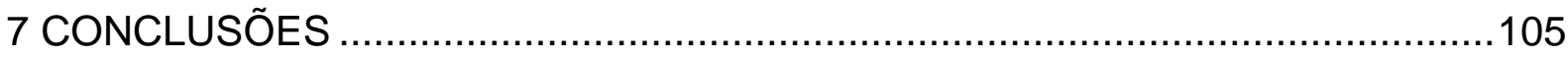

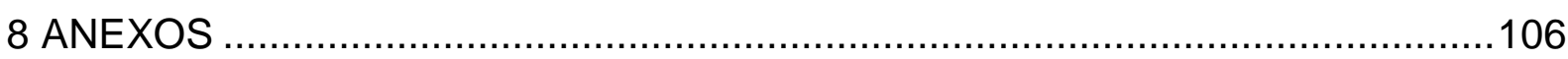

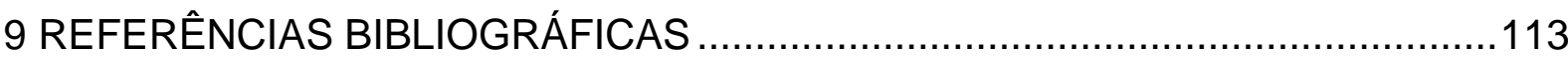




\section{LISTA DE SIGLAS}

BEDS Brief Edinburgh Depression Scale

BSI-18 Brief Symptom Inventory-18

CAPPesq Comissão de Ética para Análise de Projetos de Pesquisa

CERQ Cognitive Emotion Regulation Questionnaire

CES-D The Center for Epidemiologic Studies Scale on Depression

CPQ Cancer and Pregnancy Questionnaire

DSM-V Manual Diagnóstico e Estatístico dos Transtornos Mentais

EORTC European Organization for Research and Treatment of C30 -

QLQ C-30 Cancer Quality-of-Life Questionnaire

HADS Escala Hospitalar de Ansiedade e Depressão

HC-FMUSP Hospital das Clínicas da Faculdade de Medicina da USP

HSCL-25 Hopkins Symptom Checklist

IES Impact of Event Scale

MFAS Escala de apego materno-fetal

NCCN National Comprehensive Cancer Network

OMS Organização Mundial da Saúde

PPP Prenatal Psychosocial Profile

RCOG Royal College of Obstetricians and Gynecologists

TDM Transtorno Depressivo Maior 


\section{LISTA DE TABELAS}

Tabela 1 - Descrição dos estudos que investigaram as dimensões psicológicas da vivência de adoecimento por câncer na gravidez, de acordo com o ano, país, o que foi investigado, amostra e instrumentos utilizados.

Tabela 2 - Descrição dos estudos que investigaram a associação de autoestima e adoecimento por câncer, de acordo com o ano, país, o que foi investigado, e amostra.

Tabela 3 - Apresentação da categorização das respostas obtidas na entrevista semidirigida, para análise qualitativa: gestantes com diagnóstico de câncer e sem diagnóstico de câncer.

Tabela 4 - Apresentação da categorização das repostas obtidas por meio de entrevista semidirigida para análise qualitativa: somente gestantes com diagnóstico de câncer.

Tabela 5 - Associação entre a presença e ausência de diagnóstico de câncer com variáveis sociodemográficas.

Tabela 6 - Associação entre a presença e ausência de diagnóstico de câncer com escolaridade, paridade, crença de fé, trabalho remunerado e abortamentos anteriores.

Tabela 7 - Distribuição dos casos de acordo com o tipo de câncer e o momento do diagnóstico

Tabela 8 - Associação entre presença ou ausência de diagnóstico de câncer e presença ou ausência de depressão.

Tabela 9 - Associação entre presença ou ausência de diagnóstico de câncer com ansiedade, autoestima e apego materno-fetal.

Tabela 10 - Associação dos dados de acordo com média, desvio padrão, mediana, mínimo e máximo da idade; idade gestacional; renda per capita e a combinação de diagnóstico de câncer e depressão

Tabela 11 - Associação dos dados de acordo com média, mediana, desvio padrão, mediana, mínimo e máximo da pontuação obtida nas escalas de ansiedade, autoestima e apego materno-fetal e a combinação de diagnóstico de câncer e depressão.

Tabela 12 - Valores $p$ dos modelos de regressão linear para ansiedade, autoestima e apego. 
Tabela 13 - Distribuição dos dados de acordo com presença ou ausência de diagnóstico de câncer na gestação e a percepção sobre a descoberta da gestação.

Tabela 14 - Distribuição dos dados de acordo com presença ou ausência de diagnóstico de câncer na gestação e a percepção sobre a vivência do prénatal.

Tabela 15 - Distribuição dos dados de acordo com presença ou ausência de diagnóstico de câncer na gestação e a percepção sobre o relacionamento com o feto.

Tabela 16 - Distribuição dos dados de acordo com presença ou ausência de diagnóstico de câncer na gestação e o significado atribuído à gravidez.

Tabela 17 - Distribuição dos dados de acordo com presença de diagnóstico de câncer na gestação e a percepção sobre a descoberta do câncer.

Tabela 18 - Distribuição dos dados de acordo com presença de diagnóstico de câncer na gestação e a percepção sobre a vivência do tratamento.

Tabela 19 - Distribuição dos dados de acordo com presença de diagnóstico de câncer na gestação e a percepção sobre a adaptação ao adoecimento.

Tabela 20 - Distribuição dos dados de acordo com presença de diagnóstico de câncer na gestação e as crenças sobre o relacionamento com o feto

Tabela 21 - Distribuição dos dados de acordo com presença de diagnóstico de câncer na gestação e a vivência da doença com a gestação.

Tabela 22 - Distribuição dos dados de acordo com presença de diagnóstico de câncer na gestação e o significado atribuído ao câncer. 


\section{LISTA DE FIGURAS}

Figura 1 - Gráfico das medianas (símbolo) e respectivos intervalos com 95\% de confiança para mediana (barras) dos escores da escala de ansiedade para a combinação de diagnóstico de câncer e depressão.

Figura 2 - Gráfico das medianas (símbolo) e respectivos intervalos com 95\% de confiança para mediana (barras) dos escores da escala de autoestima para a combinação de diagnóstico de câncer e depressão.

Figura 3 - Gráfico das medianas (símbolo) e respectivos intervalos com 95\% de confiança para mediana (barras) dos escores da escala de apego materno-fetal para a combinação de diagnóstico de câncer e depressão. 


\section{Resumo}

Ferrari S. Câncer na gestação: avaliação de depressão, ansiedade, autoestima e vínculo materno-fetal [tese]. São Paulo: Faculdade de Medicina, Universidade de São Paulo; 2018.

Introdução: Atualmente, estima-se que uma em cada mil mulheres grávidas sejam portadoras de câncer. A associação do diagnóstico de câncer ao de gestação coloca a mulher numa condição vulnerável para o desenvolvimento de transtornos psicológicos. Objetivo: Comparar e avaliar a associação entre sintomatologia de depressão, ansiedade, autoestima e vínculo materno-fetal entre gestantes com diagnóstico de câncer e gestantes sem diagnóstico de câncer. Propõe-se também a realizar a análise do discurso da vivência do período gestacional com e sem o diagnóstico de câncer. Método: Foi realizado estudo transversal com 63 gestantes com diagnóstico de câncer atendidas no Ambulatório de Tumores na Gestação de um hospital universitário terciário e 72 gestantes sem diagnóstico de câncer atendidas no Ambulatório de Pré-Natal de baixo risco do mesmo serviço. Foram utilizadas as escalas de Apego Materno-Fetal (MFAS), Hospital Anxiety and Depression (HAD), Subescala de Autoestima do Prenatal Psychosocial Profile (PPP) e entrevista semidirigida que investigou questões relacionadas à gravidez e ao adoecimento por câncer. Os testes Mann-Whitney, Kruskal-Wallis, de Dunn, quiquadrado de Pearson e o teste exato de Fisher foram utilizados. O nível de significância adotado foi de $5 \%$. A análise qualitativa foi realizada por meio da Técnica de Análise de Conteúdo. Resultados: Neste estudo constatou-se presença de sintomatologia depressiva em 33,3\% das gestantes com câncer e em 18,1\% nas gestantes sem câncer. Observou-se que as gestantes com diagnóstico de câncer quando comparadas às gestantes sem diagnóstico de câncer apresentaram menor renda per capita $(p>0,001)$, menor escolaridade $(p=0,001)$, maior paridade $(p<0,001)$, menor trabalho remunerado $(p=0,015)$, maior prevalência de depressão $(p=0,041)$, ansiedade $(p=0,039)$ e autoestima rebaixada $(p<0,001)$. Na análise feita por meio da combinação de diagnóstico de câncer e de depressão, evidenciou-se que a ansiedade estava associada à depressão e não com o diagnóstico de câncer. Com relação à autoestima, na combinação dos grupos evidenciou-se que 0 rebaixamento da autoestima estava relacionado à presença de câncer e não com a depressão. Aos resultados qualitativos foram atribuídas categorias em ambos os grupos: Descoberta da gestação, Vivência pré-natal, Relacionamento com o feto e Significado da gravidez. Em relação às entrevistas somente com as gestantes com câncer foram definidas as categorias: Como foi a descoberta da doença, Vivência do tratamento do câncer, Adaptação ao adoecimento, Crenças sobre o relacionamento com o feto, Vivência do câncer na gestação e Significado atribuído ao câncer. Conclusão: Este estudo evidenciou diferenças significativas entre presença de sintomatologia depressiva, ansiosa e baixa autoestima entre gestantes com diagnóstico de câncer quando comparadas com as sem o diagnóstico. $\mathrm{Na}$ análise qualitativa, constatou-se que com relação ao relacionamento com o feto foram identificadas as seguintes categorias: Conversa, Bom relacionamento, Medo, Alegria, Milagre e Não se relaciona. Com relação à Vivência do câncer na gestação foram evidenciadas as categorias: Enfoque negativo, Enfoque positivo, Dualidade e Normal. Sobre o significado da gravidez, as categorias foram: Enfoque positivo, 
Responsabilidade e Não sabe explicar. Em relação ao significado atribuído ao câncer, as categorias demonstradas foram: Morte/sofrimento, Cura/tratamento, Superação e Causa.

Descritores: Gravidez; Neoplasias; Depressão; Ansiedade; Autoestima; Relações materno-fetais; Apego materno-fetal; Vínculo materno-fetal. 


\section{SUMMARY}

Ferrari S. Cancer in pregnancy: evaluation of depression, anxiety, self-esteem, and maternal-fetal attachment [thesis]. São Paulo: "Faculdade de Medicina, Universidade de São Paulo"; 2018.

Introduction: Currently, it is estimated that one in every thousand pregnant women are suffering from cancer. The association of the diagnosis of cancer with that of pregnancy puts a woman in a vulnerable condition for the development of psychological disorders. Objective: This Doctoral thesis aimed to evaluate and verify the association between symptoms of depression, anxiety, self-esteem and maternalfetal bond among pregnant women diagnosed with cancer and pregnant women without a cancer diagnosis. It also proposed to understand the discourse of the experience of the gestational period with and without the diagnosis of cancer. Method: A cross-sectional study was performed with 63 pregnant women diagnosed with cancer, assisted at the Clinic of Tumors in Pregnancy of a tertiary university hospital and 72 pregnant women without a cancer diagnosis, assisted at the Clinic of Low-risk Prenatal care of the same service. These scales were used: MFAS for maternal-fetal bonding, Hospital Anxiety and Depression (HAD), self-esteem subscale of Prenatal Psychosocial Profile (PPP) and a semi-structured interview that investigated issues related to pregnancy and illness due to cancer. The MannWhitney, Kruskal-Wallis, Dunn, Pearson's chi-square and Fisher's exact tests were used. The level of significance was $5 \%$. The qualitative analysis was performed by means of the Content Analysis Technique. Results: In this study, the presence of depressive symptoms was found in $33.3 \%$ of pregnant women with cancer and in $18.1 \%$ pregnant women without cancer. It was observed that the pregnant women diagnosed with cancer when compared to pregnant women without a cancer diagnosis presented lower per capita income $(p>0.001)$, lower level of schooling $(p=0.001)$; higher number of pregnancies $(p<0.001)$, lower paid job $(p=0.015)$, higher prevalence of depression $(p=0.041)$, anxiety $(p=0.039)$ and lowered self-esteem $(p<0.001)$. In the analysis made through the combination of cancer diagnosis and depression, it was shown that anxiety was associated with depression and not with the diagnosis of cancer. Regarding the self-esteem, the combination of the groups showed that the lowering of self-esteem is related to the presence of cancer and not with depression. These categories were attributed to the qualitative results in both groups: Pregnancy discovery, Prenatal experience, Relationship with the fetus and Meaning of pregnancy. With respect to the interviews only with the pregnant women with cancer, the following categories were defined: How was the discovery of the disease, Cancer treatment experience, Adaptation to the illness, Beliefs about the relationship with the fetus, Cancer experience during pregnancy and Meanings attributed to cancer. Conclusion: This study showed significant differences between the presence of depressive symptomatology, anxiety and low self-esteem among pregnant women diagnosed with cancer when compared to those without the diagnosis. In the qualitative analysis, it was found that with regard to the relationship with the fetus the following categories were identified: Chatting, Good relationship, Fear, Joy, Miracle and Not related. Regarding the Cancer experience during pregnancy, the following categories were highlighted: Negative focus, Positive focus, Duality and Normal. About the meaning of pregnancy, the categories were: Positive 
focus, Responsibility and Cannot explain. In relation to the meaning attributed to cancer, the categories shown were: Death/suffering, Healing/treatment, Overcoming and Cause.

Descriptors: Pregnancy; Neoplasms; Depression; Anxiety; Self-esteem; Selfconcept; Maternal-fetal relationship; Maternal-fetal attachment; Maternal-fetal bonding. 


\section{RESUMEN}

Ferrari S. Cáncer en el embarazo: evaluación de depresión, ansiedad, autoestima y vínculo materno fetal [tesis]. São Paulo: Faculdade de Medicina, Universidade de São Paulo; 2018.

Introducción: En la actualidad se estima que una cada mil mujeres embarazadas son portadoras de cáncer. El diagnóstico de cáncer asociado con el de embarazo lleva a la mujer a una condición de vulnerabilidad para el desarrollo de trastornos psicológicos. Objetivo: Comparar y evaluar la asociación entre sintomatología de depresión, ansiedad, autoestima y vínculo materno fetal entre embarazadas con diagnóstico de cáncer y embarazadas sin diagnóstico de cáncer. Asimismo, se plantea el análisis del discurso de vivencia del período de embarazo con y sin un diagnóstico de cáncer. Método: El estudio transversal se llevó a cabo con 63 gestantes con diagnóstico de cáncer atendidas en el Centro de salud de tumores en el embarazo de un hospital universitario terciario y 72 gestantes sin diagnóstico de cáncer atendidas en el Centro de salud prenatal de bajo riesgo del mismo servicio. Fueron utilizadas las escalas de Apego Materno Fetal (MFAS), Hospital Anxiety and Depression (HAD), Subescala de Autoestima del Prenatal Psychosocial Profile (PPP) y entrevista semidirigida que investigó cuestiones relacionadas con el embarazo y la enfermedad por cáncer. Los test Mann-Whitney, Kruskal-Wallis, de Dunn, cuicuadrado de Pearson y el test exacto de Fisher fueron utilizados. El nivel de significación adoptado fue del $5 \%$. El análisis cualitativo se llevó a cabo por medio de la Técnica de Análisis de Contenido. Resultados: En este estudio se constató la presencia de sintomatología depresiva en un $33,3 \%$ de las embarazadas con cáncer y en un $18,1 \%$ de las embarazadas sin cáncer. Se observó que al comparar a las embarazadas con diagnóstico de cáncer y las de diagnóstico sin cáncer, las primeras presentaron menor renta per capita $(p>0,001)$, menor nivel de escolaridad $(p=0,001)$, mayor paridad $(p<0,001)$, menor trabajo remunerado $(p=0,015)$, mayor prevalencia de depresión $(\mathrm{p}=0,041)$, ansiedad $(\mathrm{p}=0,039)$ y autoestima rebajada $(p<0,001)$. En el análisis hecho por medio de la combinación de diagnóstico de cáncer y de depresión, se evidenció que la ansiedad estaba asociada a la depresión y no con el diagnóstico de cáncer. Con relación a la autoestima, en la combinación de los grupos se evidenció que la baja en autoestima estaba relacionada con la presencia del cáncer y no con la depresión. A los resultados cualitativos se les atribuyeron categorías en ambos grupos: Descubrimiento del embarazo, Vivencia prenatal, Relación con el feto y Significado del embarazo. Respecto a las entrevistas sólo con las embarazadas con cáncer fueron definidas las siguientes categorías: Cómo se descubrió la enfermedad, Vivencia del tratamiento del cáncer, Adaptación

a la enfermedad, Creencias sobre la relación con el feto, Vivencia del cáncer en el embarazo y Significado atribuido al cáncer. Conclusión: Este estudio evidenció diferencias significativas entre la presencia de sintomatología depresiva, ansiosa y baja autoestima entre embarazadas con diagnóstico de cáncer cuando comparadas con aquellas que no tienen ese diagnóstico. En el análisis cualitativo se constató que respecto a la relación con el feto fueron identificadas las siguientes categorías: Conversación, Buena relación, Miedo, Alegría, Milagro y No se relaciona. Respecto a la Vivencia del cáncer en el embarazo fueron evidenciadas las categorías: Enfoque negativo, Enfoque positivo, Dualidad y Normal. Sobre el significado del embarazo, 
las categorías fueron: Enfoque positivo, Responsabilidad y No sabe explicar. Respecto al significado atribuido al cáncer, las categorías demostradas fueron: Muerte/sufrimiento, Cura/tratamiento, Superación y Causa.

Descriptores: embarazo; neoplasias; depresión; ansiedad; autoestima; relación materno fetal; apego materno fetal; vínculo materno fetal. 


\section{INTRODUÇÃO}

Considerado questão importante de saúde pública dada a magnitude do problema, o adoecimento pelo câncer leva a óbito 8,8 milhões de pessoas a cada ano ${ }^{1}$. Em torno de 14 milhões de pessoas desenvolvem câncer por ano e estima-se que esse número suba para mais de 21 milhões até $2030^{1}$.

Quando considerado o período gestacional, o diagnóstico de câncer pode ocorrer durante a gestação até um ano após o parto². É considerado pouco frequente, estimando-se que ocorra um em cada 1000 gestações $^{3,4}$. A literatura aponta que os tipos de câncer mais comuns diagnosticados na gravidez são: mama ${ }^{5,6}$, melanoma $^{5,6}$, câncer de colo de útero ${ }^{5,6}$, linfoma ${ }^{5,6} \mathrm{e}$ leucemia ${ }^{6}$.

A associação do diagnóstico de câncer ao de gestação torna a gravidez de alto risco. Nestes casos, a gestante necessita de cuidado especial no prénatal, uma vez que aumentam as chances de consequências desfavoráveis do ponto de vista orgânico e, consequentemente, do ponto de vista relacional e emocional ${ }^{7}$.

No que diz respeito às questões emocionais, o adoecimento por câncer é considerado um evento impactante por si só. Quando este acometimento ocorre simultaneamente com a gravidez, são potencializados os sentimentos de medo, culpa, ansiedade e depressão ${ }^{8}$.

A literatura aponta que a depressão em mulheres com gestação de alto risco apresentam índices entre 9 e $45 \%^{9-12}$ e sintomas de ansiedade entre 16 e $25 \%{ }^{13}$.

Uma das preocupações decorrente dos altos índices de sintomatologia de depressão ${ }^{14}$ e ansiedade ${ }^{15}$ está relacionada à influência que estas alterações de humor podem exercer no vínculo materno-fetal, já que este último é considerado preditor para ocorrência de problemas no desenvolvimento infantil ${ }^{14,16}$.

Os estudos ${ }^{17}$ sobre depressão e ansiedade em gestantes com câncer são escassos. A maioria dos estudos ${ }^{19-23}$ versam sobre a dimensão psicológica da vivência de adoecimento por câncer na gravidez. Foram encontrados oito estudos que discorreram sobre as dimensões psicológicas do adoecimento por 
câncer na gestação. Dois ${ }^{17,18}$ deles utilizaram metodologia quantitativa e avaliaram os níveis de sofrimento psicológico neste contexto. Os outros ${ }^{8,19-23}$ seis avaliaram, por meio de metodologia qualitativa, as representações sociais sobre a correlação da doença com a gravidez, as repercussões emocionais desta condição, os modos de enfrentamento e a caracterização das experiências por meio de relatos.

Um único estudo ${ }^{17}$ avaliou depressão em 74 gestantes com diagnóstico de câncer. Os resultados evidenciaram níveis significativos de ansiedade (mediana=52,7), mas não de depressão (mediana=49,0). O índice de depressão foi uma das variáveis que fizeram parte de uma investigação mais ampla sobre o sofrimento psicológico em gestantes com câncer, utilizando os questionários autoadministrados: Impact of Event Scale (IES) e Brief Symptom Inventory-18 (BSI-18).

Os resultados obtidos com os estudos ${ }^{8,19-23}$ qualitativos identificaram sentimentos de frustração de expectativas por ser uma vivência que representa uma interrupção no curso natural da vida ${ }^{8,24}$ a necessidade de adaptação ${ }^{22}$, o conflito entre receber o melhor tratamento para sua doença e colocar em risco a vida do bebêt ${ }^{20-22}$ e a importância da comunicação com a equipe de saúde ${ }^{20}$. Outros achados referiram-se à experiência da gravidez como uma possibilidade de superar o sofrimento causado pela doença ${ }^{23}$ ao dar perspectivas positivas de futuro para as mulheres nesta situação ${ }^{19}$.

A avaliação de autoestima em gestantes também é muito importante, pois a baixa autoestima pode prejudicar a adesão a comportamentos positivos de saúde, impactar nos resultados da gravidez ${ }^{25}$ e consequentemente prejudicar a formação do vínculo com o filho ${ }^{26}$.

Autoestima é o conceito que o indivíduo tem sobre si mesmo, manifestado por pensamentos e sentimentos que podem ser positivos ou negativos $^{27-30}$. A autoestima pode ser considerada alta, média ou baixa ${ }^{31} \mathrm{e}$ refere-se a um processo em constante modificação diante de situações externas positivas ou negativas ${ }^{32}$.

Em indivíduos com câncer, é importante avaliar a autoestima devido aos inúmeros fatores adversos a que aqueles se encontram expostos, tais como: alterações na rotina diária, mudanças corporais, perdas importantes, e o 
estigma da doença ${ }^{33}$. Não foram encontrados estudos sobre a avaliação de autoestima em gestantes com diagnóstico de câncer.

Outro aspecto importante a ser considerado é o vínculo materno-fetal compreendido como o relacionamento que os pais estabelecem com o feto $\mathrm{e}$ que vai ser continuado após o nascimento ${ }^{34,35}$. O estabelecimento do vínculo ainda na gestação pode predizer a qualidade da relação que se estabelecerá com o filho após o nascimento ${ }^{36,37}$.

Um estilo de vínculo seguro é aquele no qual os pais dão condições aos filhos de estabelecerem relações de confiança permitindo que os mesmos internalizem este modelo e o reproduzam em outros relacionamentos ${ }^{38}$.

A associação entre depressão e ansiedade no período gestacional e os efeitos negativos sobre a qualidade do vínculo mãe-bebê estão descritas na literatura ${ }^{39-41}$. Da mesma forma, há associação entre autoestima e vínculo estabelecido com o feto ou com o filho após o nascimento ${ }^{42-44}$; no entanto, não foram encontrados estudos que avaliam e associam estas variáveis.

Assim, este estudo se propôs investigar a depressão, ansiedade, autoestima e vínculo materno-fetal em gestantes com diagnóstico de câncer e a associação entre estas variáveis de maneira a auxiliar no planejamento de ações, com foco em uma perspectiva psicológica, que possam subsidiar a assistência à saúde da mulher que vivencia esta condição. 


\section{OBJETIVOS}

O presente estudo envolvendo gestantes com câncer e sem câncer tem por objetivo avaliar entre os grupos:

- Sintomatologia de depressão e ansiedade;

- Autoestima;

- Vínculo materno-fetal estabelecido;

- Verificar a associação entre sintomatologia de depressão e ansiedade, autoestima e vínculo materno-fetal;

Propõe-se ainda a realizar análise do discurso sobre a vivência do período gestacional com e sem o diagnóstico de câncer. 


\section{REVISÃO DE LITERATURA}

\subsection{Câncer na gestação}

Atualmente, estima-se que uma em cada 1.000 mulheres grávidas são portadoras de câncer, considerando que este diagnóstico pode ser realizado do primeiro dia da gestação até um ano após o parto ${ }^{45,46}$.

O câncer de mama associado à gestação é a neoplasia com maior incidência, ocorrendo numa relação de um caso para 3.000 a 10.000 partos $^{47,48}$, dependendo do país estudado. A gestação tardia, principalmente nos casos de primeira gravidez acima dos 35 anos de idade, tem sido considerada como fator de risco para o diagnóstico de câncer de mama ${ }^{3}$.

Com relação aos outros tipos de neoplasias, o melanoma é provavelmente o câncer mais agressivo na gestação e representa entre 0,14 e 2,8 casos para 1.000 gestações, ou seja, $8 \%$ de todas as neoplasias malignas que ocorrem na gravidez ${ }^{49,50}$. O câncer de colo de útero aparece em 0,8-1,5 por 10.000 nascimentos ${ }^{51}$. A leucemia aguda está presente na relação de um caso para 75.000 a 100.000 gestações $^{50}$ e os linfomas estão presentes em gestações na proporção 1: 1000-1: $6000^{52}$. O linfoma de Hodgkin é a neoplasia hematológica mais frequente na gravidez, sendo que aproximadamente $3 \%$ dos linfomas de Hodgkin estão associados à gestação ${ }^{52}$.

Sekine et al. $^{53}$ salientam os benefícios dos exames pré-natais na detecção do câncer na gravidez. Em um estudo ${ }^{53}$ realizado pelos autores com a população japonesa, cujo método de investigação foi um questionário aplicado para hospitais de níveis secundário e terciário, observou-se a prevalência de cânceres ginecológicos. A detecção do câncer ginecológico na gestação, segundo os autores, pode ser beneficiada pelos exames pré-natais desde que eles sejam realizados de maneira precoce. Neste estudo os cânceres mais prevalentes foram: o câncer do colo do útero $(71,4 \%)$, ovário $(7,0 \%)$ e câncer de mama $(6,6 \%)$, sendo que as malignidades ginecológicas representaram $79 \%$. 
Os estudos ${ }^{2,3}$ nesta área são restritos e os que existem são controversos sobre os efeitos da progressão do câncer na gravidez e o seu prognóstico ${ }^{55}$.

Um estudo ${ }^{46}$ de coorte populacional realizado na Austrália no período de 1994 a 2008 por meio da obtenção de informações a partir de três bancos de dados (Perinatal Data Collection, Central Cancer Registry, e Admitted Patient Data Collection) evidenciou 499 casos de câncer associados à gravidez. Neste período, a taxa bruta de câncer associado à gravidez aumentou de 112,3 para 191,5 por 100.000 nascidos vivos $(p<0,001)$. Além disso, outros achados evidenciados foram: altas taxas de indução de parto $(28,5 \%)$, quando comparadas com as gestantes sem diagnóstico de câncer neste mesmo período; aumento do número de cesáreas nestes casos (40\%) e parto prematuro planejado (19,7\%). A idade gestacional média no parto foi de 37,7 semanas e as internações pré-natais foram mais frequentes nestes casos. Para os autores ${ }^{46}$, o aumento da incidência do câncer na gravidez pode estar associado à evolução tecnológica das técnicas diagnósticas.

Um estudo ${ }^{54}$ de coorte descritivo que analisou registros epidemiológicos de 16 países ao longo de 20 anos identificou mudanças nas características associadas ao câncer na gestação, demonstrando que a proporção de gravidezes que terminaram em nascidos vivos aumentou em relação ao uso mais frequente do tratamento com quimioterapia durante a gravidez, sem resultados de malformações nestes casos. Em consonância com o uso crescente de quimioterapia, a frequência de bebês nascidos PIG (pequenos para a idade gestacional) também aumentou para cada período de 5 anos do estudo. Entre os países estudados estavam a Bélgica, que teve a maior número de doentes (27\%), seguida dos Países Baixos (24\%), Itália (15\%), Rússia (12\%) e República Checa (9\%).

De Haan et al. ${ }^{55}$ salientaram a importância do diagnóstico precoce do câncer na gestação de maneira a viabilizar o planejamento do tratamento adequado, levando em consideração a saúde da mãe e do feto, e melhorar o prognóstico materno.

A evolução do câncer pode levar à necessidade de antecipação do parto com vistas ao desenvolvimento do tratamento materno, e com isso o feto pode ter consequências no desenvolvimento devido à prematuridade ${ }^{55}$. 
Apesar dos estudos sobre mortalidade materna decorrente do câncer serem raros, destaca-se que este é o desfecho mais grave relacionado à condição do câncer na gravidez ${ }^{55}$. Um estudo ${ }^{55}$ holandês verificou esta condição por meio de dados obtidos no Dutch Maternal Mortality Committee cujo resultado foi 1,23 mortes maternas por câncer para mil nascidos vivos no período de 2001 a 2012. Uma limitação deste estudo é de que os dados do comitê são fornecidos voluntariamente, podendo, então, ocorrer uma subnotificação por parte das equipes de saúde.

Sobre a natimortalidade, um estudo ${ }^{56}$ de base populacional com dados obtidos em banco de dados na Suécia avaliou o impacto do câncer materno durante a gravidez nos riscos de natimortos. Foram evidenciados 8,2 casos por mil nascimentos natimortos nos casos de câncer materno diagnosticado durante a gravidez. O câncer materno diagnosticado durante a gravidez também neste estudo se associou positivamente ao parto prematuro, especialmente ao parto muito prematuro (28 a 31 semanas). Os autores ${ }^{56}$ ressaltam a importância do monitoramento cuidadoso do crescimento fetal e a tomada de decisão cautelosa sobre as escolhas de tratamento e momento do parto prematuro induzido.

Para o tratamento, indica-se uma estreita colaboração entre obstetra, oncologista e perinatologista a fim de se realizar uma análise de risco/benefício individual, tendo em conta a saúde materna e a fetal. Os procedimentos de planejamento do tratamento devem ser discutidos em equipe médica com o objetivo de reduzir os efeitos tóxicos sobre o feto da exposição à radiação ou quimioterápicos ${ }^{57}$.

A quimioterapia e a radioterapia por muito tempo foram consideradas incompatíveis para o uso na gravidez, devido aos riscos para o desenvolvimento fetal. Isto resultou em interrupções da gravidez ou tratamentos abaixo do que seria ideal para as mulheres. Houve um avanço neste sentido, e por meio de estudos e relatos de casos, progressos na terapêutica e consenso entre as equipes multiprofissionais ${ }^{58}$.

A gestão do câncer na gravidez, portanto, acaba por representar um desafio importante tanto para as equipes de saúde, como para a própria mulher e sua família ${ }^{56}$. Por este motivo deve-se privilegiar a discussão nas equipes e 
com a paciente, uma vez que prioridades conflitantes entre a sua saúde e a saúde do feto podem prejudicar a adesão daquela ao tratamento ${ }^{59}$.

\subsection{Depressão e ansiedade}

A depressão é considerada um problema de saúde pública dada sua prevalência, gravidade, os elevados custos para os serviços de saúde ${ }^{56}$ e sua relação com fatores de vulnerabilidade social ${ }^{60}$.

Trata-se do transtorno mais comum na população geral, tendo prevalência mundial estimada entre 2,2 e $10,4 \%{ }^{60}$, acometendo aproximadamente duas vezes mais mulheres do que homens ${ }^{61}$. No Brasil, a prevalência da depressão na população geral está estimada em 4,1\% ${ }^{62}$.

A Organização Mundial da Saúde (OMS) calcula que o transtorno seja a principal patologia em 2030, sendo mais intensa em países de baixa e média renda ${ }^{63}$.

Os critérios utilizados para o diagnóstico e classificação dos estados depressivos se encontram no Manual Diagnóstico e Estatístico dos Transtornos Mentais $(\mathrm{DSM}-\mathrm{V})^{64}$. O DSM- $\mathrm{V}^{64}$ inclui vários tipos de transtornos depressivos, sendo que a característica comum entre eles é a presença de humor triste, vazio ou irritável, que podem vir acompanhados de alterações somáticas e cognitivas que afetam significativamente a capacidade funcional do indivíduo.

O Transtorno Depressivo Maior (TDM) representa a condição clássica deste tipo de transtorno. É caracterizado por episódios distintos de pelo menos duas semanas de duração envolvendo alterações nítidas no afeto e na cognição. Deve ser feita uma diferenciação entre o TDM e o que se considera como tristeza ou luto normal. O luto apesar de representar um sofrimento intenso não necessariamente provoca um transtorno e o prognóstico é melhor. Quando o luto leva a um TDM, outras condições de vulnerabilidade psíquica do indivíduo estão presentes ${ }^{64}$.

A conceituação de depressão na psicanálise é complexa e explorada de maneira diferente da nosologia psiquiátrica do DSM- ${ }^{64}$. Alguns expoentes da Psicanálise ${ }^{65,66}$ contribuíram para sua delimitação como fenômeno inerente ao 
psiquismo. Não há a pretensão de esgotar tal complexidade terminológica, mas apenas apresentá-la enquanto sintomatologia depressiva, que é utilizada neste trabalho.

Freud $^{65}$ em um dos seus textos clássicos e desdobrados inúmeras vezes para auxiliar na conceituação relacionada à depressão diferenciou dois fenômenos psicológicos que ele denominou de luto e melancolia. O luto, para Freud $^{65}$, é um processo normal diante da perda, que obriga a pessoa a um desinvestimento afetivo necessário para a continuidade da vida e de outras relações. Significa um trabalho doloroso de perceber, paulatinamente, que o objeto perdido não está mais presente. Para isso é necessária uma dupla tarefa: aceitar a perda em si e também reconhecer o que se perde com esta perda.

O luto patológico seria o que Freud ${ }^{65}$ denominou de melancolia. Ou seja, um estado depressivo em que a perda de algo ou alguém estaria impregnada de elementos psíquicos do próprio indivíduo. Este perderia parte de si mesmo colocada no outro, sem conseguir discriminar estes elementos. O resultado deste processo levaria a sentimentos de culpa por causa dos sentimentos negativos advindos com a perda, como raiva, e dirigidos ao objeto externo. A dificuldade em administrar estes sentimentos levaria a sentimentos de luto patológico, ou seja, de melancolia.

Para Winnicott ${ }^{66}$, o manejo clínico da depressão depende da sua compreensão a partir da história de vida da pessoa e da maneira como ela consegue, ou não, lidar com seus próprios impulsos agressivos ou hostis, sem que se desorganize por meio de sentimentos de culpa. Somente quando o indivíduo conseguisse lidar com os sentimentos bons ou ruins que povoam seu mundo interno, ele estaria apto a utilizar um mecanismo que ele chama de integração. $O$ estado depressivo nestas pessoas estaria dentro do que se pode chamar de uma normalidade. Ou seja, na capacidade de lidar com as vicissitudes do mundo interno em consonância com os estímulos, também positivos ou negativos do mundo externo, de maneira a sofrer e suportar seu próprio sofrimento. Para Winnicott ${ }^{66}$, uma imagem que condensa esta ideia de integração, é a do bebê que consegue, a partir de uma função de maternagem exercida pela mãe ou cuidador, agregar os mecanismos hostis e repará-los de 
maneira que esta reparação alimente sua esperança no relacionamento com o mundo.

Neste caso, a pessoa estaria recolhida em seu processo depressivo, mas temporariamente, e em um processo de reintegração de um todo, onde haveriam partes positivas e negativas, sem que uma aniquilasse a outra ${ }^{66}$. Assim, a depressão ocorre como um padrão de defesa quando a pessoa não consegue fazer o movimento de integração de seus pensamentos e afetos inconscientes bons e ruins e está em desequilíbrio com a realidade.

Esta conceituação psicanalítica da depressão serve para atentar para 0 fato de que esta condição, apesar do sofrimento, pode servir, quando tratada, de uma condição de autoconhecimento e poder de transformação do indivíduo. Porém existem casos em que esta integração não pode ser realizada e teria impacto na vida relacional do indivíduo ${ }^{66}$.

A ansiedade é um sentimento inerente ao desenvolvimento humano, vivenciado de maneira única e pessoal. De um modo geral, é um sentimento que pode auxiliar o indivíduo a lidar com as situações adversas da vida utilizando de maneiras criativas e propícias a encontrar soluções. Ainda sendo vista de uma maneira que permite a adaptação ao mundo, também contribui como proteção da pessoa na medida em que serve de alerta diante de sinais de perigo iminente ${ }^{67}$.

A ansiedade patológica é um distúrbio psíquico caracterizado por preocupação antecipada quanto ao futuro, fruto de uma interpretação de uma situação de possível perigo. Deve ser diferenciada da sensação de medo, que é uma resposta ao perigo iminente que aponta para a real necessidade de uma ação defensiva ${ }^{64}$.

Geralmente está associada a sintomas físicos, como: aumento da frequência cardíaca, sudorese, alterações gastrointestinais, tremores e desmaio; sintomas psíquicos como impaciência, frustração, nervosismo, irritabilidade, hipervigilância para ameaça; sintomas cognitivos, como: falta de concentração; e sintomas comportamentais, como: fuga, esquiva, agitação, busca de segurança e dificuldade para falar ${ }^{64}$.

Também é importante diferenciar a ansiedade como sintoma e o Transtorno de Ansiedade, que é um quadro psiquiátrico. Os sintomas ansiosos 
passam a ser reconhecidos como patológicos quando são desproporcionais em relação ao estímulo e interferem com a qualidade de vida e desempenho nas atividades diárias do indivíduo. O diagnóstico de transtorno ansioso se dá quando se trata de quadro clínico com sintomas primários, ou seja, não são derivados de outras condições psiquiátricas (depressões, psicoses, transtornos do desenvolvimento) ${ }^{64}$.

As mulheres apresentam maior risco de desenvolver transtornos ansiosos ao longo da vida do que os homens ${ }^{68}$, e esses transtornos surgem no início da vida adulta ${ }^{69}$. Os sintomas estão geralmente associados às comorbidades psiquiátricas, principalmente à depressão e outras comorbidades clínicas, causando um impacto importante na qualidade de vida desses indivíduos ${ }^{70}$.

Freud $^{71}$ desenvolveu o conceito de ansiedade ao longo dos anos e faz uma diferença entre a ansiedade que funciona como um alerta, e a ansiedade patológica. Na primeira, o sintoma prepara o sujeito para o perigo, funcionando como um sinal, uma resposta frente uma ameaça de que algo de ruim ocorra. $\mathrm{Na}$ segunda, a ansiedade neurótica, é menos adaptativa, a resposta é inadequada e não corresponde à intensidade da ameaça externa. É como se o sinal de perigo estivesse constantemente presente.

Além dos fatores genéticos, biológicos, psicológicos e psicossociais que encontram-se envolvidos no desenvolvimento da ansiedade, atualmente as condições sociais, econômicas e culturais têm sido associadas ao aumento da sintomatologia ansiosa, devido às condições de vida cada vez mais complexas, tecnológicas e competitivas, uma vez que os sintomas são desencadeados a partir da necessidade de adaptação dos indivíduos para lidar com as demandas cotidianas ${ }^{72}$.

\subsubsection{Depressão, ansiedade e gestação}

A depressão perinatal ou pré-natal é considerada um transtorno multifatorial, onde condições psicológicas, sociais e biológicas se interpõem, 
causando extremo sofrimento psíquico para a mulher e podendo levar a consequências prejudiciais para o recém-nascido ${ }^{73}$.

Por um longo período considerou-se que durante a gestação as mulheres estivessem protegidas de qualquer distúrbio psíquico. No entanto, atualmente considera-se que existe no período gestacional uma vulnerabilidade para o aparecimento destes transtornos, sendo, portanto, a fase do desenvolvimento em que se encontra maior incidência de distúrbios emocionais ${ }^{74,75}$. Assim, está indicado que os profissionais de saúde realizem rastreios para sua detecção ${ }^{76,77}$ e desenvolvam ações que visem a prevenir possíveis problemas na vinculação pós-natal ou na adaptação à nova condição da maternidade ${ }^{74,75}$.

Além disso, é um período de alto risco para internação psiquiátrica, particularmente em mulheres com afecções bipolares ${ }^{78}$, e o risco de suicídio materno é significativamente elevado entre as mulheres com depressão perinatal representando de 5 a $14 \%$ de todas as mortes no pós-parto ${ }^{79,80}$.

A literatura sobre a prevalência da depressão perinatal tem ampla variabilidade, entre 9 e 30\% ${ }^{81}$, sendo maior em mulheres com antecedentes de transtorno depressivo. Além disso, mulheres que apresentam depressão no período gestacional têm maior probabilidade de desenvolver depressão pósparto $^{82,83}$.

Alguns fatores de risco podem ser identificados para o desenvolvimento da depressão no período gestacional. Com relação às variáveis sociodemográficas podem-se destacar: baixo nível educacional e socioeconômico $^{84}$, ausência do companheiro, idade avançada da mãe ${ }^{, 85,86}$, idade precoce da mãe na primeira gestação ${ }^{87}$, falta de apoio familiar ou social $^{85,86}$ e complicações obstétricas ${ }^{87,88}$.

Quanto aos fatores individuais de risco para a depressão na gestação estão: falta de planejamento da gravidez ${ }^{89}$; gravidez não desejada ${ }^{89}$; uso de álcool e drogas $^{90}$; histórico de violência doméstica ${ }^{73}$, incluindo violência psicológica $^{22}$ e história de maus tratos na infância ${ }^{91,92}$.

A presença de doença psiquiátrica anterior à gestação ${ }^{93}$ também é considerado um fator de risco para a depressão pré-natal, em especial os episódios depressivos prévios ${ }^{92}$. 
Mulheres cuja gestação foi definida como de alto risco podem apresentar índices mais elevados de depressão, sendo que a prevalência varia na literatura de 9 a $45 \%{ }^{9-12}$. Isto ocorre por estarem mais expostas a agentes estressores devido a alterações em sua saúde ou do feto. Quando as complicações são com o feto, o risco de depressão é maior do que quando o problema detectado é com a gestante ${ }^{94}$.

Os sintomas de depressão na gestação muitas vezes estão associados com outros sintomas psicológicos, como por exemplo, transtornos de ansiedade ${ }^{95}$ e a baixa autoestima ${ }^{96}$.

Estima-se que na gestação a prevalência de sintomas de ansiedade esteja entre $16^{97}$ e $25 \%{ }^{98,99}$. Nestes, os níveis de ansiedade demonstraram serem maiores durante a gravidez, quando comparados ao período pósparto $^{100,101}$.

Quando no período gravídico puerperal existe uma condição materna ou fetal que coloque risco para a mãe ou para o feto, a sintomatologia ansiosa tende a aumentar e pode se prolongar para o período pós-parto ${ }^{94}$. Assim, em mulheres que vivenciam uma gestação de alto risco, os níveis de ansiedade estão aumentados devido às incertezas quanto a sua saúde e do feto; e na medida em que as condições de alto risco se tornam mais críticas, a ansiedade tende a aumentar ${ }^{102}$.

Mulheres com histórias de aborto espontâneo, nascimento prematuro ou perda fetal têm mais sintomas de depressão e ansiedade nas gestações subsequentes quando comparadas às mulheres sem estes antecedentes ${ }^{103}$.

\subsubsection{Depressão, ansiedade e câncer}

O adoecimento provoca no indivíduo uma interrupção dos padrões habituais de vida e exige a necessidade de se ajustar a uma nova condição, muitas vezes limitada pela rotina de exames e tratamentos. Tira a pessoa da condição a que estava habituada e a obriga a examinar as suas capacidades de enfrentamento de situações de crise ${ }^{104}$. 
A nova condição é ainda mais complexa quando ocorre um diagnóstico de câncer, principalmente pelo fato desta doença estar associada às ideias de sofrimento, dor e morte, mesmo com todo o avanço de medidas terapêuticas existentes $^{105}$.

A vivência do câncer causa um impacto emocional importante, afetando o equilíbrio psicológico e a qualidade de vida ${ }^{106,107}$ do indivíduo. O sofrimento psicológico diante do diagnóstico de câncer pode provocar sintomas ou estados clínicos de depressão e ansiedade frequentemente relatados na literatura. Destaca-se que "depressão e ansiedade são comorbidades frequentes e geralmente encontram-se associadas" 107 .

Uma revisão sistemática ${ }^{107}$ que objetivou apontar o sofrimento psicológico relacionado ao câncer identificou como os mais frequentes indicadores: a depressão e a ansiedade. Dos 36 estudos relacionados, 20 tratavam de depressão e 09 tratavam de depressão e ansiedade. Dos estudos relacionados à depressão, 04 avaliaram mudanças na intensidade deste sintoma ao longo do tempo desde o diagnóstico de câncer.

Um estudo ${ }^{108}$ americano sobre história de depressão autorreferida realizada com pacientes com diagnóstico de câncer investigou 6079 indivíduos onde Ihes foi feita a seguinte pergunta: "Um médico ou outro profissional de saúde lhe disse que você tem um transtorno depressivo, incluindo depressão, depressão maior, distimia ou depressão menor?" Apesar de algumas limitações neste estudo, como a utilização de questionário autorreferido e não de escalas para investigar sintomas de depressão e ansiedade, 21,7\% dos entrevistados foram considerados como tendo histórico de depressão ao responderem à questão de maneira afirmativa.

Um estudo ${ }^{109}$ realizado na Malásia que avaliou a prevalência de ansiedade e depressão em uma população de renda média, com uma amostra de 1490 indivíduos diagnosticados com câncer, utilizando a Escala Hospitalar de Ansiedade e Depressão (HADS) observou alta prevalência de depressão e ansiedade inclusive após um ano do diagnóstico. Observou-se ansiedade moderada ou grave $(>=11)$ no diagnóstico, após 3 meses e após 1 ano, respectivamente: $38,9 \%, 51,0 \%$ e $53,9 \%$. Depressão moderada ou grave ( $>=$ 11) no diagnóstico, após 3 meses e após 1 ano respectivamente: $24,3 \%, 28,3 \%$ 
e $27,1 \%$. Este estudo constatou prevalência de ansiedade sobre a de depressão.

Um estudo ${ }^{110}$ descritivo italiano que avaliou 1147 pacientes internados por câncer de diversos tipos encontrou prevalência de depressão em 13,9\% dos indivíduos. O instrumento utilizado nesta pesquisa foi a escala The Center for Epidemiologic Studies Scale on Depression (CES-D).

Um estudo ${ }^{111}$ indiano que investigou a depressão em 174 indivíduos com câncer submetidos à quimioterapia identificou que 55,7\% apresentaram depressão, avaliados pela escala Brief Edinburgh Depression Scale (BEDS). Os que receberam quimioterapia por mais de 6 meses estavam mais propensos a ter depressão do que aqueles que tinham menos tempo de tratamento. O estudo, portanto, revelou que a depressão é substancialmente alta entre pacientes com câncer submetidos à quimioterapia ${ }^{111}$.

Um estudo ${ }^{112}$ de coorte sul-coreano investigou a prevalência de transtornos mentais (entre eles a depressão e ansiedade) em mulheres antes e depois do diagnóstico de câncer de ovário. O grupo em que foi identificado algum transtorno mental antes do diagnóstico era composto por 274 indivíduos, enquanto que o grupo pós-diagnóstico era de 540 membros. A depressão foi o distúrbio mais comumente relatado no período pós-diagnóstico (37,9\%). Com relação ao tempo do diagnóstico e a prevalência de transtornos mentais observou-se um pico na frequência de depressão e ansiedade dois meses após o diagnóstico de câncer de ovário.

A depressão e ansiedade podem causar influência na capacidade de lidar com o ônus da doença, diminuir a aceitação do tratamento e prolongamento da internação ${ }^{113}$. A depressão e ansiedade causam impacto importante na qualidade de vida ${ }^{106}$.

Em um estudo ${ }^{114}$ realizado em 100 pacientes adultos diagnosticados com melanoma cutâneo na Turquia utilizando a escala HADS, um total de 32 participantes tiveram ansiedade diagnosticada pelo instrumento utilizado. Quanto à depressão, 35 foram diagnosticados com sintomas depressivos. 0 que se observou é que antes do diagnóstico do melanoma, a maioria dos pacientes fora avaliada como normal quanto ao estado de ansiedade e depressão. Foi encontrada correlação significativa entre os escores de 
ansiedade e depressão ( $p<0,001$ ). Também constatou-se que os pacientes com doença avançada eram significativamente mais ansiosos e depressivos do que aqueles com doença em estágio inicial ${ }^{114}$.

Um estudo ${ }^{115}$ realizado no norte do Irã com 157 indivíduos sobreviventes de câncer colorretal investigou a sintomatologia de depressão e ansiedade com o objetivo de avaliar a relação entre as dimensões do sofrimento psíquico e a qualidade de vida. $\mathrm{O}$ estudo encontrou frequência relativamente alta de casos de ansiedade e depressão nestes indivíduos e forte associação entre estes sintomas. Os instrumentos utilizados neste estudo foram a escala HADS e o questionário que avalia qualidade de vida, European Organization for Research and Treatment of Cancer Quality-of-Life Questionnaire C30 (EORTC QLQ C30). A depressão foi fortemente associada à redução da qualidade de vida, e mais do que a ansiedade.

Um estudo ${ }^{116}$ longitudinal sueco com 245 indivíduos avaliou as mudanças na ansiedade e depressão desde o diagnóstico de câncer e ao longo de seis meses, aplicando a escala HADS no $1^{-\frac{0}{}}, 3^{\circ}$ e $6^{-0}$ mês. Os autores observaram que um em cada cinco pacientes desenvolveu sintomas de ansiedade e depressão nos seis meses subsequentes, com piora da qualidade de vida.

Um estudo ${ }^{117}$ realizado na Coreia do Sul que comparou os efeitos da fadiga, ansiedade e depressão na qualidade de vida de 830 sobreviventes de câncer de pulmão, utilizando a escala HADS para avaliação de depressão e ansiedade, identificou prevalência de depressão limítrofe em 38,9\% e depressão grave em 13,7\%. Para ansiedade limítrofe a prevalência foi igual a $20,9 \%$ e ansiedade grave de 7,3\%. Na análise de regressão logística todos os fatores (fadiga, depressão e ansiedade) estavam correlacionados com piora da qualidade de vida. A ansiedade e a fadiga exerceram efeitos significativos sobre o funcionamento emocional e estado de saúde geral (que são subescalas da escala de qualidade de vida).

Com relação à qualidade de vida, um estudo ${ }^{118}$ coreano identificou 28,9\% de indivíduos com depressão avaliados pela escala CES-D e revelou ser a depressão o fator de maior influência na qualidade de vida de pacientes com câncer de pulmão avançado. 
Um estudo ${ }^{113}$ realizado na África do Sul com 201 mulheres com câncer de mama avaliou níveis de sofrimento psicológico e sintomas de depressão, por meio da escala para depressão CES-D, e detectou escores elevados para depressão em $36,6 \%$ e para sofrimento psicológico de 34,3\%, por meio da escala Hopkins Symptom Checklist (HSCL-25). Os preditores de sintomas depressivos foram: o estresse pela mudança corporal e baixo apoio social. Angústia e depressão foram estudados em separado, pois conceitualmente são diferentes. A angústia pode ser considerada uma resposta normal e esperada diante de situações difíceis como o câncer.

A melhora nos índices de depressão e ansiedade foram encontrados em estudos que avaliaram os indivíduos após um tempo do diagnóstico. Um estudo $^{119}$ espanhol observou melhoras na depressão e ansiedade avaliadas pela escala HADS, um ano após a cirurgia de câncer colorretal. A melhora esteve associadas aos fatores de maior apoio social, melhorias no funcionamento físico, cognitivo e social. Nenhum paciente funcionalmente independente foi associado a menores melhorias na ansiedade e depressão.

Um estudo ${ }^{120}$ americano que usou a escala HADS para avaliar depressão e ansiedade em pacientes sobreviventes de melanoma quase 10 anos após o diagnóstico observou que os resultados para estes dois constructos eram semelhantes aos do grupo controle, sendo que foram avaliados 724 casos e 660 controles.

Um estudo ${ }^{121}$ multicêntrico que investigou a prevalência de sofrimentos em pacientes que sobreviveram a um câncer de pulmão em 561 indivíduos, com tempo médio de quatro anos desde o diagnóstico, identificou prevalência de depressão em 19\% da amostra e também 19\% para ansiedade. Também observaram que havia maior chance de estarem em sofrimento os indivíduos que tinham descoberto o diagnóstico há menos tempo. Um aumento no tempo desde o diagnóstico de um ano diminuiu as chances de sofrimento em $10 \%$. As pessoas analisadas no estágio I no momento do diagnóstico tiveram uma chance significativamente maior (duas vezes maior) de estarem em sofrimento do que aquelas nos estágios II a IV. As pessoas que informaram como estando em tratamento eram mais de três vezes menos propensas a ficarem ansiosas ou deprimidas do que as que naquele momento não estavam em tratamento. 
A depressão e ansiedade muitas vezes não são percebidas ou detectadas pelos profissionais de saúde e isto pode causar danos psicológicos e consequências ao indivíduo em seu tratamento ${ }^{110}$. A atenção na área da saúde deve estar voltada para esta questão, uma vez que há um aumento do risco de morbidade psiquiátrica entre pacientes com câncer ${ }^{105,122}$. As necessidades emocionais não atendidas aumentam o sofrimento causado pela doença e têm implicações diretas no aumento do custo com cuidados em saúde ${ }^{123,124}$.

Para isso recomenda-se a utilização de medidas de avaliação de depressão e ansiedade em pacientes diagnosticados com câncer. A avaliação precoce do sofrimento causado pelo diagnóstico de câncer pode servir como um importante marcador de vulnerabilidade emocional destes pacientes e prevenir problemas que podem se tornar persistentes ${ }^{107}$.

\subsubsection{Dimensões psicológicas da vivência de adoecimento por câncer na gravidez}

O câncer na gravidez e seu tratamento são percebidos pelas mulheres como uma interrupção no curso natural do desenvolvimento feminino e podem levar a um sofrimento psicológico intenso ${ }^{24}$.

O sentimento de ter suas expectativas interrompidas foi relatado por três mulheres que participaram de um estudo ${ }^{22}$ qualitativo australiano que inicialmente se propôs a investigar a experiência de mulheres jovens com câncer de mama. No decorrer do estudo, três mulheres que estavam grávidas foram recrutadas para poder relatar sobre a experiência do adoecimento por câncer na gravidez. A percepção destas mulheres foi de um sentimento de injustiça pela interrupção de um processo importante em suas vidas, exigindo adaptações pelas quais não estavam preparadas. 
Nenhum estudo se propôs a avaliar depressão e ansiedade em gestantes com câncer. Foram encontrados oito estudos que trataram de aspectos psicológicos relacionados à vivência do câncer na gestação, sendo que dois utilizaram metodologias quantitativas e seis, qualitativas. Tais estudos encontram-se sumarizados na Tabela 1:

\section{Tabela 1 - Descrição dos estudos que investigaram as dimensões psicológicas da vivência de adoecimento por câncer na gravidez, de acordo com o ano, país, o que foi investigado, amostra e instrumentos utilizados}

\begin{tabular}{|c|c|c|c|c|c|}
\hline Estudos & Ano & Local & O que foi investigado & $\begin{array}{l}\text { Amos- } \\
\text { tra }\end{array}$ & $\begin{array}{l}\text { Instrumentos } \\
\text { utilizados }\end{array}$ \\
\hline $\begin{array}{l}\text { Vieira RJS, Gomes R, } \\
\text { Trajano AJB }\end{array}$ & 2005 & Brasil & $\begin{array}{l}\text { Representações sociais sobre a } \\
\text { relação entre o diagnóstico de } \\
\text { câncer e a gravidez }\end{array}$ & 03 & $\begin{array}{l}\text { Entrevista } \\
\text { semidirigida }\end{array}$ \\
\hline $\begin{array}{l}\text { Archette D, Fregonese } \\
\text { AA }\end{array}$ & 2009 & Brasil & $\begin{array}{l}\text { Repercussões emocionais de } \\
\text { mulheres que conviveram com a } \\
\text { situação de gestação e câncer } \\
\text { concomitantemente, buscando } \\
\text { identificar o modo de } \\
\text { enfrentamento das mesmas. }\end{array}$ & 06 & $\begin{array}{l}\text { Análise dos } \\
\text { protocolos de } \\
\text { atendimento } \\
\text { psicológico }\end{array}$ \\
\hline $\begin{array}{l}\text { Henry M, Huang LN, } \\
\text { Sproule BJ, Cardonick } \\
\text { EH }\end{array}$ & 2012 & Canadá & $\begin{array}{l}\text { Sofrimento psicológico em } \\
\text { mulheres após um câncer } \\
\text { diagnosticado durante a gravidez }\end{array}$ & 74 & $\mathrm{IES}^{\mathrm{a}}$ e $\left.B S\right|^{\mathrm{b}}$ \\
\hline $\begin{array}{l}\text { Ives A, Musiello } \\
\text { T, Saunders C. }\end{array}$ & 2012 & Austrália & $\begin{array}{l}\text { Experiências das mulheres } \\
\text { quando diagnosticadas com } \\
\text { câncer de mama durante ou logo } \\
\text { após a gravidez }\end{array}$ & 15 & $\begin{array}{l}\text { Entrevista } \\
\text { semidirigida }\end{array}$ \\
\hline $\begin{array}{l}\text { Capelozza MLSS, } \\
\text { Peçanha DLM, Mattar } \\
\text { R, Sun SY }\end{array}$ & 2014 & Brasil & $\begin{array}{l}\text { Dinâmica emocional das } \\
\text { pacientes com diagnóstico } \\
\text { simultâneo de câncer e gravidez. }\end{array}$ & 11 & $\begin{array}{l}\text { Entrevista } \\
\text { semidirigida }\end{array}$ \\
\hline Rees S, Young A. & 2016 & Austrália & $\begin{array}{l}\text { Experiências de mulher } \\
\text { diagnosticadas com câncer } \\
\text { durante a gravidez }\end{array}$ & 03 & $\begin{array}{l}\text { Entrevista } \\
\text { semidirigida } \\
\text { young women }\end{array}$ \\
\hline $\begin{array}{l}\text { Vandenbroucke T, Han } \\
\text { SN, Van Calsteren } \\
\text { K, Wilderjans TF, Van } \\
\text { den Bergh BRH, Claes } \\
\text { L, Amant F. }\end{array}$ & 2017 & $\begin{array}{l}\text { Bélgica } \\
\text { e } \\
\text { Holanda }\end{array}$ & $\begin{array}{l}\text { Risco para angústia e níveis de } \\
\text { sofrimento psicológico com base } \\
\text { no seu perfil de enfrentamento } \\
\text { cognitivo de situações difíceis }\end{array}$ & 61 & $C E R Q^{c}$ e $C P Q^{d}$ \\
\hline $\begin{array}{l}\text { Hammarberg } \\
\text { K, Sullivan E, Javid } \\
\text { N, Duncombe } \\
\text { G, Halliday L, Boyle } \\
\text { F, Saunders C, Ives } \\
\text { A, Dickinson JE, Fisher } \\
\text { J. }\end{array}$ & 2018 & Austrália & $\begin{array}{l}\text { Experiências de mulheres } \\
\text { diagnosticadas com câncer de } \\
\text { mama na gestação relacionadas } \\
\text { aos cuidados recebidos por parte } \\
\text { da equipe de saúde }\end{array}$ & 17 & $\begin{array}{l}\text { Entrevista } \\
\text { semidirigida }\end{array}$ \\
\hline \multicolumn{6}{|c|}{$\begin{array}{l}\text { FONTE: Elaborada pela autora } \\
\text { NOTAS: }{ }^{a} \text { Impact of Event Scale (IES) }\end{array}$} \\
\hline
\end{tabular}


Um único estudo ${ }^{17}$ avaliou estas duas condições psicológicas como parte de uma avaliação mais ampla que pretendia investigar níveis de sofrimento psicológico em mulheres grávidas com câncer.

Neste estudo, Henry $M$ et al. ${ }^{17}$ analisaram 74 mulheres por meio de questionários autoadministrados: Impact of Event Scale (IES) e do questionário Brief Symptom Inventory-18 (BSI-18). A IES mede o sofrimento psicológico após um evento estressante por meio de três subescalas: pensamentos intrusivos, evitação e hiperatividade. A BSI-18 mede os níveis de sofrimento em três subescalas: ansiedade, depressão e somatização. As mulheres eram elegíveis para se inscrever, voluntariamente, se o câncer fosse diagnosticado entre o último período menstrual e o parto, aborto espontâneo ou interrupção da gestação. Os resultados demonstraram que, em ambas as escalas, as mulheres apresentaram altos níveis de sofrimento evidenciado, principalmente, por pensamentos intrusivos (no resultado da escala IES) e por ansiedade e somatizações (na escala BSI-18). Ao se fazer um recorte com relação à depressão e ansiedade neste estudo, é possível evidenciar níveis significativos de ansiedade e não de depressão.

A definição de angústia utilizada pelos autores ${ }^{17}$ foi de acordo com o National Comprehensive Cancer Network (NCCN), como uma experiência emocional desagradável, multifatorial, de natureza psicológica (cognitiva, comportamental, emocional), social ou espiritual que pode interferir na capacidade de lidar eficazmente com o câncer e seu tratamento. Este sentimento de angústia pode variar de sentimentos de vulnerabilidade, tristeza e medo até chegar a sentimentos que podem se tornar incapacitantes, como depressão, ansiedade, pânico e isolamento social.

Em outro estudo ${ }^{18}$ quantitativo, Vandenbroucke et al. ${ }^{18}$ se propuseram a avaliar o risco de angústia e altos níveis de sofrimento associados ao perfil de enfrentamento cognitivo de gestantes diante de situações difíceis. Para isso avaliaram 63 mulheres e seus companheiros de países da Bélgica e Holanda. Para esta investigação utilizaram os questionários Cognitive Emotion Regulation Questionnaire (CERQ) e o Cancer and Pregnancy Questionnaire (CPQ). Os autores identificaram três estratégias de enfrentamento do câncer associado à gravidez: a primeira denominada de Positive coping, que seria 
uma maneira mais adaptativa de lidar com a crise de maneira positiva $(N=59$, 48,3\%); uma estratégia de enfretamento baseada na ruminação de pensamentos, com intenção de se reorganizar diante da situação difícil a ser enfrentada, chamada de Internalizing ( $\mathrm{N}=40,32,8 \%$ ); e uma terceira maneira de enfretamento denominada de Blaming self/order ( $\mathrm{N}=23,18,9 \%$ ), cuja maneira de combater a situação de crise seria culpar a si mesmo ou outras pessoas.

As mulheres e seus parceiros que utilizam principalmente estratégias de ruminação de pensamentos apresentaram níveis significativamente maiores de preocupações do que aqueles que utilizam estratégias de enfrentamento positivas ou aqueles que culpam a si ou a outros pelo que aconteceu. Isto se refere principalmente com relação às preocupações com a saúde da criança ( $p$ $=039)$, com a doença e o tratamento $(p<0,001)$ e com a gravidez e o parto $(p=$ $0,009)^{18}$.

Nos estudos ${ }^{19-23}$ qualitativos diversos fatores emocionais foram relatados. Com relação à ansiedade, Ives et al. $^{22}$ descrevem relatos autorreferidos de ansiedade relacionada ao tratamento do câncer e o conflito entre receber o melhor tratamento para si e o receio de que este tivesse algum impacto na saúde do feto. Ao mesmo tempo que se sentiam mais seguras em proteger o feto de possíveis interferências em sua saúde devido ao tratamento recebido, sentiam-se ansiosas em pensar que deveriam também se cuidar para poder cuidar do filho após o nascimento. Também relataram ansiedade relacionada ao parto e com relação à amamentação, uma vez que a população deste estudo foram acometidas por câncer de mama.

Sobre a preocupação com o tratamento, foram relatados em três estudos $^{20-22}$ australianos a preocupação do impacto deste na saúde do feto, na amamentação posterior e na fertilidade futura.

A forma como a equipe estabelece a comunicação de informações sobre a doença e seu tratamento também foi relatada por muitas mulheres como causadoras de sofrimento psicológico, principalmente quando médicos de especialidades diferentes apresentavam conflitos e diferenças em suas informações. Com relação ao aspecto da comunicação, houve relatos positivos, ao referirem profissionais que davam atenção e espaço para suas perguntas e 
preocupações. Um fator relevante na comunicação foi 0 momento do diagnóstico, relatado por algumas mulheres como um choque e que algumas variáveis são fundamentais neste momento, como o tempo dispendido para a informação, a oportunidade de fazerem perguntas e informações consistentes provenientes da equipe ${ }^{20}$.

O sentimento de encorajamento para enfrentar a doença e seu tratamento advindo do sentimento de realização experimentado pela gravidez foi evidenciado em três estudos brasileiros, realizados em $2005^{23}, 2009^{8}$ e $2014^{19}$. Os estudos demonstram que o sofrimento causado pelo adoecimento pode ser amenizado pela vivência da gravidez, uma vez que a mesma foi interpretada por elas por meio de sentimentos de esperança, otimismo e crença na possibilidade de pensar no futuro de seus filhos.

Além disso, terem engravidado estando doentes de câncer deu a elas um sentimento de estarem saudáveis, uma vez que a ideia de gravidez está associada à saúde ${ }^{19}$.

Vieira et al. ${ }^{23}$ identificaram discursos de que engravidar após um câncer foi visto como um milagre, e que seria um evento capaz de transformar suas vidas.

Capelozza et al. ${ }^{19}$ em um estudo qualitativo que se propôs a investigar a dinâmica emocional das pacientes com diagnóstico simultâneo de câncer e gravidez, entrevistaram seis gestantes com câncer e cinco gestantes sem nenhuma intercorrência na gravidez identificaram que os sentimentos de bemestar manifestados pela gravidez amenizaram os sentimentos negativos advindos da doença e seu tratamento. Enquanto a gravidez aparecia como algo concreto para as mulheres, a doença evidenciava-se como algo intangível e, além disso, a gravidez remetia à ideia de vida enquanto que o câncer, à ideia de morte.

Os mesmos autores ${ }^{8,19,23}$ também observaram que as gestantes que descobriram o câncer na gravidez vivenciaram os sentimentos de ambivalência de maneira mais acentuada, devido ao medo da morte associado ao diagnóstico de câncer. Ao contrário, nas mulheres que já estavam tratando um câncer e descobriram a gravidez posteriormente, foram observados comportamentos e relatos de enfrentamento, em uma tentativa de superação 
da doença, uma vez que a gravidez trouxe-lhes força e ânimo para lutar contra a doença.

Quando comparadas as vivências das grávidas com câncer e as grávidas sem enfermidade, a questão do tempo foi detectado como uma diferença importante. Enquanto as mulheres sem câncer podiam fazer planos a longo prazo, as grávidas com câncer programavam-se para o alcance de metas a curto prazo ${ }^{19}$.

Porém, todos os sentimentos descritos nestes estudos denotam sentimentos de ambivalência entre a esperança e o medo da morte ${ }^{8,19,23}$.

Archette et al. $^{8}$, que por meio de um estudo retrospectivo qualitativo analisaram protocolos de atendimento psicológico, evidenciaram que com a evolução da doença os sentimentos de confiança com relação ao tratamento acabaram por diminuir. Porém, para as mulheres deste estudo, observou-se que a gestação passou a ser vivenciada como uma possibilidade de se sentirem vivas em contraponto ao diagnóstico de câncer que as fazia pensar na questão da finitude. Estas duas relações foram observadas como ambivalentes, uma vez que havia uma descrença na possibilidade de tratamento, enquanto que a vivência da gravidez trazia mais esperança.

Com relação ao feto, Capelozza et al. ${ }^{19}$ evidenciaram preocupação em protegê-los da ação dos medicamentos quimioterápicos e apresentaram medo de não conseguirem cuidar dos seus filhos após o nascimento e também com relação aos filhos mais velhos. Devido a isso, as gestantes parecem ter encontrado nos filhos a motivação para cuidar de si e querer viver. O filho representava um elemento compensador das adversidades enfrentadas em decorrência da doença.

Questões relacionadas às decisões médicas, como a não-amamentação ou a antecipação do parto para início do tratamento também podem levar a mulher a sentimentos de impotência e culpa que acabam por potencializar a experiência de sofrimento psicológico ${ }^{22}$.

O apoio recebido por parte de familiares e amigos foi um item relatado em alguns estudos ${ }^{19,23}$, que apontam que, apesar do sofrimento se estender à família, o apoio da mesma pode corroborar para o enfrentamento da situação e de auxílio na adesão ao tratamento. Hammarberg et al. ${ }^{20}$ demonstraram em 
seu estudo que quando as mulheres receberam o apoio vindo de outras mulheres que passaram pela vivência do câncer e sobreviveram, este apoio foi relatado como útil e reconfortante.

Os estudos são unânimes em afirmar a necessidade de intervenções psicológicas às mulheres que vivenciam o câncer na gestação e todas as suas consequências psicológicas.

\subsection{Autoestima}

O conceito de autoestima tem uma linha tênue entre sua utilização no senso comum e sua investigação científica ${ }^{125}$. A necessidade de um enfoque científico para este conceito se dá pela complexidade que ele representa para a personalidade do indivíduo e por estar associado à saúde mental ${ }^{29}$.

Autoestima é a apreciação que o indivíduo faz de si mesmo. É manifestada por pensamentos, sentimentos ou atitudes que podem ser positivos ou negativos dependendo do valor que o indivíduo se dá na avaliação que faz de $\mathrm{s}^{27-30}$. É, portanto, um juízo pessoal de valor que expressa uma atitude de aprovação ou repulsa consigo mesmo ${ }^{126}$.

A formação da autoimagem faz parte do desenvolvimento infantil. Freud $^{127}$ denominou de narcisismo primário a fase em que o bebê é tomado como um objeto de amor por seus pais. Este processo é crucial na vida da criança, pois somente desta maneira ele poderá se formar como pessoa. Os pais direcionam 0 afeto para 0 bebê e projetam nele possibilidades de realização de seus próprios desejos não cumpridos. O bebê e sua mãe se completam dentro de uma ilusão de ideal. Neste momento, e somente neste momento, esta simbiose é saudável para o bebê, uma vez que ele ainda não tem capacidade para lidar sozinho com as dificuldades da vida.

Este fenômeno psicológico faz parte do desenvolvimento infantil normal. As perturbações deste modelo de desenvolvimento levarão a perturbações psicopatológicas. A criança precisa ser investida narcisicamente pelos pais para que possa constituir-se como pessoa ${ }^{128}$. 
Lacan $^{129}$ denominou Estádio do Espelho a fase compreendida entre os 6 e os 18 meses da criança em que há a capacidade de reconhecer-se numa imagem no espelho. O psicanalista ${ }^{129}$ utiliza esta metáfora como forma de explicar a possibilidade de reconhecimento de si mesmo e do outro como diferenciados. A conquista da imagem especular é fundamental para pensar todas as outras aquisições do ser humano em uma interação com o mundo. Esta aquisição não depende apenas do desenvolvimento maturacional da criança, mas sim da presença de um outro na relação para que a criança possa constituir sua personalidade.

Por meio de um processo simbólico, a criança vai adquirir a capacidade de formar uma imagem de si mesma. Esta imagem advém de um relacionamento com outras pessoas que constituem as suas relações afetivas. Somente a partir destes fenômenos de interação é que a criança vai poder constituir uma imagem de si e ver-se como uma unidade e não mais como um todo fragmentado, como é experimentado pelo bebê ${ }^{130}$.

Estes processos psíquicos estão relacionados com o que se chama na psicanálise de constituição do sujeito, enquanto um ser psíquico e não apenas biológico. Todo este movimento de investimento afetivo seria a origem da formação do eu, o que possibilita a construção da imagem de si mesmo e o valor atribuído a ela. Este modelo seria o embrião da formação da autoimagem e consequentemente da autoestima ${ }^{130}$.

A formação da autoimagem é necessária para a construção da autoestima. Estes dois conceitos são complementares e interdependentes, porém têm sentidos diferentes. Enquanto a autoimagem está relacionada com a percepção que o indivíduo tem de si mesmo, a autoestima está relacionada com a valorização de si mesmo ${ }^{131}$.

Com o crescimento a criança vai internalizando o sentimento de proteção segurando 0 oferecido pelas figuras parentais e adquirindo capacidade de responder por si própria. Estas repostas vão sendo continuamente reforçadas pela opinião das pessoas e pelos momentos da vida e sucessivamente colocadas em avaliação ${ }^{130}$.

Esta matriz de formação do sujeito pode viver alterações das mais variadas, dependendo da disponibilidade dos pais ou cuidadores para 
expressarem ou investirem no bebê de maneira a facilitar experiências positivas ou negativas na relação afetiva. Com o tempo, isto vai determinando patologias ou recursos positivos psíquicos de enfrentamento do mundo. A imagem de si, portanto, é sempre baseada nas relações com o mundo e da capacidade do indivíduo de fazer o teste de realidade ${ }^{130}$.

Para Freud ${ }^{127}$, a autoestima tem origem no narcisismo infantil. Com o desenvolvimento do indivíduo, a autoestima vai estar relacionada com a satisfação da libido objetal, ou seja, estará direcionada à suas relações com os outros. Ou seja, quando não são amados, reduziriam-se os sentimentos de autoestima, enquanto que o sentimento de ser amado aumenta a autoestima.

Autoimagem e autoestima são, portanto, conceitos interligados e interdependentes $^{132}$. Enquanto a autoimagem se refere à maneira como a pessoa se percebe a partir do que o outro lhe proporcionou em termos de condições para isso, a autoestima diz respeito ao sentimento que o indivíduo tem de sua autoimagem e o valor atribuído a ela ${ }^{133}$.

A autoestima está constantemente sendo colocada à prova diante das situações adversas da vida. O sentimento de competência pessoal é fundamental para superar tais adversidades ${ }^{134}$. É, por conseguinte, um importante indicador de saúde mental, uma vez que pode interferir nas condições de enfretamento das situações adversas, em diferentes aspectos da vida e na interação do sujeito com o mundo ${ }^{135,136}$.

Autoestima é um processo dinâmico ao longo do desenvolvimento humano e pode se alterar diante de situações de crise ou a partir de experiências ruins ${ }^{32}$.

A partir da sua constituição psíquica, o indivíduo vai responder às situações de ameaça da vida de maneiras diferentes e a adaptação ou enfrentamento das situações dependerá da maneira como ele acredita que pode vencer ou não os desafios, ou seja, da qualidade da sua autoestima e nível de confiança em si mesmo ${ }^{27}$.

Autoestima pode ser considerada alta, média ou baixa. A autoestima elevada vai propiciar à pessoa que, a partir do afeto positivo que tem para consigo, ela possa acreditar na sua competência para resolver os problemas e desafios. Já uma autoestima rebaixada fará com que o indivíduo responda às 
situações adversas de maneira mais insegura, sem buscar ajuda de outras pessoas $^{27,31}$, sem acreditar em suas capacidades de resolver e adaptar-se aos problemas.

Avaliar a autoestima em situações adversas ou de crises é fundamental para verificar as possibilidades de enfrentamento das adversidades e verificar a saúde mental dos indivíduos ${ }^{132}$.

\subsubsection{Autoestima e gestação}

A gestação é um dos períodos de crise na vida da mulher e a manutenção da autoestima pode corroborar de maneira positiva na adaptação às mudanças advindas deste processo ${ }^{137}$.

Uma autoestima elevada pode ser considerada como um recurso de proteção para o desenvolvimento do vínculo com o bebê e prevenção da depressão materna ou pós-parto ${ }^{138}$.

São inúmeros os fatores que podem comprometer a autoestima das gestantes. Diversos estudos identificaram que a idade mais jovem, a baixa escolaridade $^{26,137,139-141}$, menor renda ${ }^{137,140-142}$, e a falta de ocupação ${ }^{137,139,141,142}$ podem interferir significativamente na autoestima, rebaixando-a e gerando sentimento de insegurança e de incapacidade.

Os fatores relacionados a gestações anteriores, como a multiparidade $^{139,141}$ ou intercorrências ${ }^{142}$, ou ainda fatores atuais como: gestação não desejada ${ }^{139,140}$, não planejada ${ }^{26,140,141}$ ou o desejo de interromper a gestação ${ }^{137,140,141}$, também podem levar a uma redução da autoestima.

Dias et al. ${ }^{141}$ referem que quando a mulher percebe ou teme a gravidez como um risco para si própria ou para o feto, ou nos casos de gestantes que ficam hospitalizadas, haveria uma redução da autoestima. Para os autores a falta de uma crença religiosa também teria impacto na autoestima, pois diminui a segurança e determinação na resolução de problemas.

As alterações na imagem corporal geram impactos muitas vezes negativos à mulher no período gestacional. Santos et al. ${ }^{139}$ destacam o ganho de peso na gravidez como uma condição que provocaria a baixa autoestima. 
Também representam fatores de risco para a diminuição da autoestima a falta de companheiro ou separação do mesmo ${ }^{26,137,139-141}$, a falta de suporte familiar $^{137}$, ou história de violência ${ }^{142}$.

Gestantes tabagistas ou que usaram drogas na gestação $0^{137,139,141}$ e etilistas ${ }^{137,139}$ também apresentaram baixa autoestima em estudos anteriores.

Silva et al. ${ }^{137}$ investigaram a relação entre transtornos mentais comuns em gestantes e sua relação com a autoestima em 1267 mulheres no Brasil. Neste estudo identificaram alta prevalência de distúrbios mentais e significativa associação com baixa autoestima. Ou seja, as mulheres com menor autoestima apresentaram maior probabilidade de transtornos mentais manifestados por sintomas depressivos não psicóticos, ansiedade e queixas somáticas que afetam o desempenho das atividades diárias ${ }^{137}$.

Um estudo ${ }^{143}$ longitudinal com 84.711 mulheres norueguesas conseguiu dados importantes sobre a autoestima em gestantes. A autoestima das mulheres diminuiu durante a gravidez, tendo uma elevação após 6 meses do parto. Esse padrão de respostas na Escala de Autoestima de Rosemberg fornece informações de possíveis variáveis associadas à redução da autoestima, como por exemplo, as mudanças físicas e na imagem corporal, preocupações sobre o desenvolvimento do bebê e sobre o parto.

Por outro lado, a gestação pode, para algumas mulheres, representar uma oportunidade de enfrentar desafios, o que pode levar a um sentimento de assertividade e capacidade, levando a um fortalecimento de sua autoestima ${ }^{144,145}$.

Jesse et al. ${ }^{146}$ afirmam que a autoestima pode ser um recurso positivo de enfrentamento diante das situações de estresse e sintomas depressivos na gestação.

Diante de todos estes fatores, considera-se a importância de avaliar a autoestima em gestantes como forma de melhorar a atenção materno-infantil ${ }^{26}$, preservar a formação do vínculo com o filho e fortalecer as mulheres no enfrentamento de situações adversas, protegendo-as de possíveis transtornos mentais ou sofrimento psicológico. 
A investigação da autoestima na gestação é muito importante, uma vez que alterações na avaliação que a gestante faz de si mesma pode interferir na construção do vínculo com o filho após o nascimento ${ }^{42-44}$.

\subsubsection{Autoestima e câncer}

O diagnóstico de câncer pode afetar negativamente a autoestima dos indivíduos, uma vez que coloca o indivíduo diante de diversas situações como: alterações na rotina diária, mudanças corporais, perdas importantes, estigma da doença e o próprio tratamento ${ }^{33}$.

Doenças que têm repercussões importantes na alteração da imagem corporal vão afetar negativamente a autoestima ${ }^{133}$. Um tratamento como a quimioterapia também pode ser fator decisivo para piora da autoestima, devido a todas as dificuldades que a pessoa tem que administrar ${ }^{33}$. 
Os estudos que avaliaram a autoestima em indivíduos com câncer apresentam resultados diversos e estão apresentados na Tabela 2. Todos são estudos quantitativos e utilizaram para a investigação a Escala de Autoestima de Rosemberg, que é a mesma utilizada em nosso estudo.

Tabela 2 - Descrição dos estudos que investigaram a associação de autoestima e adoecimento por câncer, de acordo com o ano, país, o que foi investigado, e amostra

\begin{tabular}{|c|c|c|c|c|}
\hline Estudos & Ano & $\begin{array}{c}\text { Local do } \\
\text { estudo }\end{array}$ & 0 que investigaram & Amostra \\
\hline Tonsing KN, Ow R & 2018 & Singapura & $\begin{array}{l}\text { Autoestima, qualidade de vida, } \\
\text { expectativas futuras e preocupações } \\
\text { relacionadas à saúde } \\
\text { adolescentes em } \\
\text { sobreviventes de câncer. }\end{array}$ & 68 \\
\hline $\begin{array}{l}\text { Mohd-Sidik S, Akhtari- } \\
\text { Zavare M, Periasamy } \\
\text { U, Rampal L, Fadhilah }\end{array}$ & 2018 & Malásia & $\begin{array}{l}\text { Autoestima e afeto psicológico } \\
\text { (ansiedade, depressão) de pacientes } \\
\text { com câncer. }\end{array}$ & 2120 \\
\hline Cieślak K, Wojciech G. & 2018 & Polônia & $\begin{array}{l}\text { Nível de aceitação das condições } \\
\text { incapacitantes do câncer e os níveis } \\
\text { de autoestima em mulheres após o } \\
\text { tratamento do câncer de mama. }\end{array}$ & 37 \\
\hline $\begin{array}{l}\text { Ferreira EC, Barbosa } \\
\text { MH, Sonobe HM, } \\
\text { Barichello E }\end{array}$ & 2017 & Brasil & $\begin{array}{l}\text { Autoestima e a qualidade de vida } \\
\text { relacionada à saúde de pacientes } \\
\text { estomizados por câncer colorretal. }\end{array}$ & 36 \\
\hline $\begin{array}{l}\text { Carvalho Leite MA, } \\
\text { Alves Nogueira D, de } \\
\text { Souza Terra F }\end{array}$ & 2015 & Brasil & $\begin{array}{l}\text { Autoestima em pacientes oncológicos } \\
\text { submetidos a quimioterapia. }\end{array}$ & 156 \\
\hline $\begin{array}{l}\text { Ortiz E, Méndez L, } \\
\text { Camargo J, Chavarro } \\
\text { S, Toro G, Vernaza M. }\end{array}$ & 2014 & Colômbia & 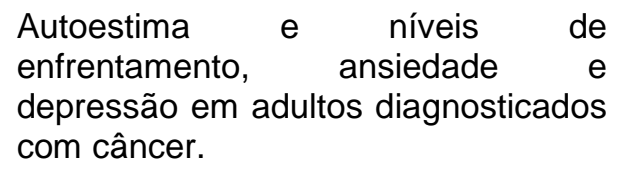 & 17 \\
\hline $\begin{array}{l}\text { Marques Jucá } \\
\text { Fernandes M, Cândido } \\
\text { Alves P, Lavinas } \\
\text { Santos MC, Moreira } \\
\text { Mota E, Carvalho }\end{array}$ & 2013 & Brasil & $\begin{array}{l}\text { Autoestima em mulheres } \\
\text { mastectomizadas. }\end{array}$ & 14 \\
\hline Gomes NS, Silva SR & 2013 & Brasil & $\begin{array}{l}\text { Autoestima de mulheres submetidas à } \\
\text { cirurgia oncológica mamária há pelo } \\
\text { menos um ano. }\end{array}$ & 37 \\
\hline $\begin{array}{l}\text { Oliveira MCM, Oliveira } \\
\text { TC, Schnaider TB. }\end{array}$ & 2012 & Brasil & $\begin{array}{l}\text { Autoestima, espiritualidade e } \\
\text { depressão em adultos portadores de } \\
\text { neoplasia colorretal. }\end{array}$ & 20 \\
\hline $\begin{array}{l}\text { Carvalho MP, Oliveira } \\
\text { Filho RS, Gomes HC, } \\
\text { Veiga DF, Juliano Y, } \\
\text { Ferreira LM. }\end{array}$ & 2007 & Brasil & $\begin{array}{l}\text { Autoestima de adultos com } \\
\text { carcinomas de pele, na cabeça e } \\
\text { pescoço. }\end{array}$ & 100 \\
\hline $\begin{array}{l}\text { Sebastián J, Manos D, } \\
\text { Bueno M J, Mateos N. }\end{array}$ & 2007 & Espanha & $\begin{array}{l}\text { Autoestima em mulheres que } \\
\text { realizaram cirurgia para câncer de } \\
\text { mama. }\end{array}$ & 175 \\
\hline
\end{tabular}


Carvalho et al. $^{147}$, em um estudo brasileiro analítico transversal, avaliaram a autoestima de 156 indivíduos com câncer de pele na face e pescoço e evidenciaram que os pacientes portadores deste tipo de carcinoma apresentaram menor autoestima do que os indivíduos do grupo controle sem câncer. Além disso, observou-se que a faixa etária de pacientes com idade inferior a 65 anos com a doença apresentaram mais efeitos negativos da doença sobre a autoestima.

Outro estudo brasileiro ${ }^{148}$ que avaliou a autoestima, espiritualidade e depressão em 20 indivíduos com neoplasia colorretal e submetidos a tratamento cirúrgico demonstrou que $95 \%$ da amostra apresentaram autoestima rebaixada. Nenhum dos pacientes havia recebido qualquer tipo de intervenção psicoterápica devido à vivência do câncer, e os autores enfatizam a importância do mesmo, o que poderia aumentar a autoestima dos portadores de doença malignas.

Mohd-Sidik et al. ${ }^{149}$ em um estudo realizado na Malásia em 2018 que teve como objetivo investigar o resultado de uma intervenção de orientação com relação à quimioterapia e a autoestima, evidenciaram resultados de baixa autoestima no início da pesquisa em toda a amostra, que envolveu 1060 pacientes com câncer no grupo que participou de uma intervenção e 1060 pacientes com câncer no grupo controle que não participou da intervenção. Os índices iniciais de autoestima estavam rebaixados, mas após a realização da intervenção os índices aumentaram. O grupo de intervenção teve melhora estatisticamente significativa na auto-estima $(p=0,000)$ ao longo do tempo.

Em contrapartida, alguns estudos demonstram resultados de autoestima elevada em indivíduos que tiveram câncer.

O que se observou em alguns estudos é que o tempo do diagnóstico ou do tratamento realizado acaba por impactar na melhora da autoestima. Cieślak et al. ${ }^{150}$ investigaram a autoestima de 37 mulheres após mastectomia e o nível de aceitação das condições incapacitantes impostas pela doença e tratamento. Observaram que quanto maior o nível de aceitação das suas limitações, maior é o nível de autoestima. Também foi encontrada uma forte correlação entre depressão e baixa autoestima. Quanto mais depressão vivenciada por um indivíduo, menor é o nível de autoestima ou menor a depressão vivenciada por 
eles, maior é a autoestima. Alguns achados positivos em um estudo ${ }^{151}$ brasileiro poderiam explicar os resultados elevados para a autoestima, como o fato da maioria das mulheres apresentarem uma ocupação profissional, o apego à religiosidade, estarem participando de um grupo de apoio psicológico e o tempo decorrido da mastectomia. Para os autores, existe um estágio inicial de crise logo após o diagnóstico e com o tempo haveria uma possibilidade de adaptação.

Gomes et al. ${ }^{31}$ avaliaram a auto estima de 37 mulheres submetidas a cirurgia oncológica mamária há pelo menos um ano. Os autores justificam os resultados pela idade das pacientes, afirmando que a autoestima tende a aumentar com o envelhecimento e também pelo tempo decorrido do procedimento cirúrgico. Os resultados também demonstram que as taxas de autoestima elevadas estão associadas à presença do companheiro, e o fato de algumas terem feito a reconstrução mamária. Dentre as que retornaram ao trabalho, 72,73\% possuíam autoestima elevada, enquanto que as que não retornaram possuíam resultados médios para autoestima (50\%).

Leite et al. ${ }^{33}$ também obtiveram resultados altos para autoestima na avaliação de 156 pacientes oncológicos submetidos a tratamento quimioterápico. Neste trabalho, os autores não discutem quais os prováveis fatores que levaram ao aumento da autoestima, mas sim a importância de se ter níveis mais elevados deste constructo para facilitar o enfrentamento da doença e de todas as suas consequências. Salientam a importância dos profissionais de saúde estarem atentos a esta característica e não somente ao quadro clínico do sujeito.

Outro fator que pode ser destacado como influenciador dos resultados para a autoestima preservada seriam as estratégias de enfretamento utilizadas pelo indivíduo. Em um estudo que avaliou a relação entre as estratégias de enfrentamento do câncer e os níveis de depressão, ansiedade e autoestima com 17 pessoas portadoras da doença, identificou autoestima preservada e relacionou com as estratégias mais comuns de enfrentamento, que são: religião, reavaliação positiva, solução de problemas e busca de apoio profissional $^{152}$. Tais estratégias facilitariam a manutenção da autoestima. 


\subsection{Vínculo materno-fetal}

A gestação em si é considerada como um fenômeno biológico enquanto que a constituição da maternidade se dá por meio de um fenômeno psicológico ${ }^{153}$.

A mulher desde cedo, ainda nas brincadeiras infantis, está envolvida pelo imperativo da maternidade. Mesmo que, nas sociedades contemporâneas a mulher tenha assumido outras funções e tem a possibilidade de escolher outras formas de realizações pessoais que não a maternidade, a culpa é uma expressão emocional do não cumprimento desta ordem social e cultural ${ }^{154}$.

Além da dimensão cultural e social, o projeto da maternidade tem aporte na história individual ${ }^{155}$. A descendência dá ao adulto a possibilidade de legitimar a fantasia de imortalidade e permite recuperar a sensação de completude vivenciada nas primeiras relações com seus cuidadores parentais. Esta é uma vivência psicológica, da ordem do inconsciente, descrita por Freud ${ }^{127}$ como narcísica.

Um filho existe no imaginário dos pais mesmo antes de sua concepção. Com a gravidez, os pais passam a imaginar o feto e atribuem a ele características baseadas no repertório de experiências, modelos adquiridos nas suas relações afetivas, no que desejam para ele e no que não puderam realizar e esperam que ele possa cumprir ${ }^{156,157}$.

A projeção de atributos ao feto permite personificar sua imagem uma vez que ele não pode ser visto nem tocado. Inaugura-se neste campo uma relação, ainda que rudimentar. Trata-se de uma relação constituída a partir da concepção e será influenciada pela representação simbólica do futuro bebê e da mulher como futura mãe $e^{157-159}$.

O conceito de vínculo materno-fetal tem sido utilizado para descrever a intensidade das emoções, percepções e comportamentos relacionados ao feto adquiridos pelos pais durante a gestação ${ }^{160}$. Pode ser considerado como uma forma básica e primeira de relação humana ${ }^{35}$.

A vinculação no período gestacional pode ser considerada um preditor $^{36,37,161}$ da qualidade do vínculo dos pais com o bebê após o nascimento e também dos relacionamentos posteriores da criança com outras pessoas ${ }^{36}$. 
É na possibilidade de vincular-se que a criança vai adquirir a capacidade para desenvolver outros relacionamentos durante o seu desenvolvimento ${ }^{36,37}$.

Desta forma, o tipo de vínculo desenvolvido nas primeiras relações se estende para a primeira infância e pode ainda constituir o alicerce do estilo de apego individual na idade adulta $^{36,162,163}$, para o desenvolvimento da personalidade e possíveis psicopatologias ${ }^{164}$.

Segundo Bowlby ${ }^{162}$, há uma necessidade humana inata para formar laços afetivos desde o nascimento até a velhice. Esta forma de vinculação vai se modificando conforme a fase de desenvolvimento. Esta teoria foi chamada pelo autor de Teoria do Apego, ou Teoria da Vinculação. Na infância, a criança constrói uma representação mental de vínculo a partir da relação que estabelece com seus pais.

Este modelo de vinculação vai influenciar todos os relacionamentos posteriores. A qualidade da interação dos pais com a criança leva ao desenvolvimento de um senso de segurança e confiança que serão determinantes na relação com outras pessoas ${ }^{163}$.

$O$ processo de vinculação materno-fetal para Bowlby ${ }^{162}$ tem um constructo de ordem biológica que visa à preservação da espécie por meio de comportamentos de nutrir e proteger ${ }^{165,166}$, e outro de ordem emocional ${ }^{163}$ que envolve a disponibilidade da mãe para que a vinculação aconteça.

Cranley ${ }^{167}$, ao analisar a relação de mães e bebês após o nascimento em 1981 definiu a possibilidade de avaliar a qualidade do vínculo a partir do grau em que as mulheres têm comportamentos de apego e interação com o bebê, ou não.

Portanto, o processo de vinculação pode ser satisfatório ou não. A qualidade da relação entre gestante e feto pode ser observada pelos comportamentos que expressam cuidado e comprometimento, ou mesmo por meio das expectativas e sentimentos da gestante com relação ao feto ${ }^{168}$.

$O$ bebê é indefeso e absolutamente incapaz de sobreviver por si só. $O$ desenvolvimento da criança não segue o mesmo determinismo biológico de outros mamíferos. Ele nasce refém de todas as suas necessidades biológicas e dependente de um outro que cuide, muito tempo além que de filhotes de outras espécies. A satisfação das necessidades biológicas do ser humano tem que 
ser provida por um cuidador para que este sobreviva. Com o tempo e crescimento, a criança vai se desenvolvendo de maneira mais independente em sua relação com o ambiente. Porém, este primeiro vínculo com a mãe não abrange apenas a satisfação das necessidades físicas e vitais, mas também a satisfação de necessidades afetivas traduzidas sob a forma de afeto, linguagem e compreensão da linguagem corporal do bebê para atender as suas necessidades ${ }^{127}$.

A reciprocidade dos pais em responder às necessidades da criança e a qualidade da interação que estabelecem com a mesma, permitem o desenvolvimento de um senso de segurança, bem-estar e confiança que servem de base para as etapas do desenvolvimento emocional e cognitivo posterior $^{163,169}$.

Em estudos ${ }^{37,170}$ realizados evidenciou-se associação significativa entre a avaliação de apego materno-fetal e maior nível de instrução da mãe, menor número de filhos e o apoio social dado à gestante por familiares e companheiro $^{171}$. Também se evidenciou que o apego materno-fetal aumenta ao longo do período gestacional.

À medida que o feto se desenvolve, suas capacidades sensoriais aumentam, respondendo a uma maior variedade de estímulos ${ }^{172}$. Pesquisas têm salientado que o feto responde aos estímulos recebidos no período prénatal, como por exemplo, à luz ${ }^{173}$ e ao som ${ }^{174}$. A gestante pode perceber o desenvolvimento das capacidades sensoriais do feto por meio dos movimentos fetais e isto também influencia na capacidade de interação da mulher com o feto $^{175}$.

Os fatores que influenciam na vinculação pré-natal de maneira negativa são descritos na literatura como o aumento da paridade ${ }^{167}$, a preocupação com a imagem corporal, autoestima rebaixada ${ }^{170,171}$, abuso de álcool e drogas ${ }^{37}$, gestação de risco ${ }^{102}$, e elevados níveis de ansiedade e depressão ${ }^{15,176}$.

Alhusen et al. ${ }^{177}$ demonstraram que mulheres que apresentam estilos de relação materno-fetal mais seguros, seus filhos mostraram melhor desenvolvimento precoce em comparação com as mulheres com estilos de apego mais inseguros. 
O vínculo com as figuras parentais ou outro cuidador que exerça esta função naquele momento é condição importante para que as crianças se tornem adultos saudáveis e com interações positivas no mundo em que vivem $^{178}$.

É fundamental investigar os níveis de apego materno-fetal existentes entre a mãe e o feto uma vez que representam implicações notáveis na aquisição das novas funções ligadas à maternidade, e também no desenvolvimento posterior da criança. Reconhecer quais os fatores que influenciam no apego dos pais com o feto permite o planejamento de intervenções com objetivos de prevenir distúrbios visando ao bem-estar psicológico no pré-natal e melhor desenvolvimento físico e psicológico do recém-nascido ${ }^{179}$.

A gravidez de alto risco pode ser um fator que influencia o vínculo da gestante com o feto ${ }^{179}$ devido às incertezas relacionadas ao filho e à sua saúde, preocupações com o parto e nascimento, a hospitalização e distanciamento da família ${ }^{180}$. Os sentimentos advindos desta condição de frustração, fracasso, incapacidade de ter uma gestação saudável, medo de colocar em risco sua vida e a do bebê, de não conseguir concluir a gravidez em segurança e falta de controle sobre o seu próprio corpo podem interferir na vinculação materno-fetal ${ }^{181}$.

A angústia durante a gravidez pode afetar o relacionamento da mulher com o feto, afetando o seu desenvolvimento e a constituição da identidade da mulher no papel de mãe, pois as emoções negativas podem causar impacto intenso no estabelecimento do vínculo da gestante com o feto e prejudicar a formação da identidade materna ${ }^{182}$.

A literatura estabelece com clareza a associação entre depressão e ansiedade no período gestacional e os efeitos negativos sobre a qualidade do vínculo mãe-bebê estabelecidos ${ }^{39-41}$.

Mesmo os sintomas depressivos maternos de menor intensidade estão associados a uma menor qualidade na relação entre ambos ${ }^{183,184}$.

Diante de um quadro depressivo, a disponibilidade emocional da mãe encontra-se diminuída para atender de maneira eficaz às necessidades do filho, de maneira a fornecer os cuidados essenciais que vão amparar o 
desenvolvimento físico e psicológico da criança ${ }^{185,186}$. As mães emocionalmente indisponíveis para o recém-nascido podem ocasionar privação psicossocial e gerar condições de desenvolvimento adversas ${ }^{176,187}$. Consequentemente levam a uma menor responsividade por parte da criança para os cuidados maternos ${ }^{188}$ e diminuição do interesse da mesma pela comunicação e aprendizagem ${ }^{189}$. Da mesma forma, a mães ansiosas também apresentam menor sensibilidade para identificar as necessidades do filho ${ }^{99}$.

Os pensamentos negativos advindos dos sintomas depressivos alteram o foco atencional da mãe e também interferem reduzindo a capacidade para responder às necessidades do bebê e do ambiente ${ }^{190}$.

Pode-se dizer que há uma díade mãe-bebê deprimida, que apresenta menor intensidade de comunicações vocais e visuais ${ }^{34}$.

A interferência da depressão materna nos futuros cuidados com o bebê mantém a criança numa condição muito vulnerável ${ }^{191}$, uma vez que eles são sensíveis às influências ambientais e extremamente dependentes do cuidado de um adulto ${ }^{192}$.

Os efeitos adversos da depressão na relação mãe-filho e no desenvolvimento Infantil precoce abrangem fatores $\operatorname{cognitivos}^{193,194}$, comportamentais $^{193}$ e sociais ${ }^{194}$.

O exercício da maternidade em mulheres deprimidas pode apresentar-se por meio de comportamentos hostis ou de indiferença e diminuição dos comportamentos positivos $^{195}$. Quando o afeto é positivo, os cuidados, a fala, os comportamentos da mãe para com o bebê têm um efeito benéfico ao desenvolvimento cognitivo e linguístico dele ${ }^{196,197}$. Porém, se a maternidade é exercida de maneira hostil, estão associados padrões de atividade cerebral infantil ligadas a emoções ansiosas que podem persistir ao longo do tempo ${ }^{198}$.

As mães deprimidas classificam seus bebês como mais difíceis ${ }^{199,200}$, e têm mais dificuldades para interpretar a comunicação dos seus bebês ${ }^{184}$.

Com relação aos sintomas de ansiedade, é importante distinguir a ansiedade específica relacionada ao bem-estar do bebê, da tendência geral a responder de forma ansiosa a situações do dia a dia. A ansiedade específica direcionada à preocupação com o bebê tende a fortalecer o apego maternofetal. No entanto, a ansiedade mais generalizada tende a prejudicar o vínculo ${ }^{15}$. 
É importante o rastreamento da depressão na gravidez como forma de prevenir possíveis situações danosas futuras. A maioria dos programas preventivos atingem 0 período pós-parto, e não existem publicações disponíveis para descrever as intervenções específicas para a relação mãebebê antes do parto ${ }^{14,16}$.

Também os sintomas de depressão ou ansiedade resultantes desta condição podem interferir no desenvolvimento do vínculo materno-fetal. Hart e McMahon ${ }^{15}$ avaliaram o impacto da depressão e da ansiedade no apego da gestante com o feto e perceberam que as mulheres que tiveram baixa qualidade de ligação fetal relataram níveis significativamente mais elevados de ansiedade e depressão.

A ansiedade foi 0 fator mais influente como prejudicial no desenvolvimento do vínculo materno-fetal em gestantes de alto risco ${ }^{102}$.

Há um risco de psicopatologias no bebê ou no desenvolvimento da criança quando estão presentes transtornos mentais na mãe ${ }^{192}$. A presença de depressão materna na gestação está associada com implicações no desenvolvimento físico e mental do bebê, assim como na vinculação com o mesmo ${ }^{201}$.

Alguns estudos ${ }^{185,202,203}$ têm relatado associações significativas entre depressão materna gestacional e doenças obstétricas, fetais e neonatais ${ }^{204}$. Recém-nascidos expostos à depressão materna no período pré-natal têm maior risco de nascimentos prematuros e baixo peso ao nascer ${ }^{202,205,206}$.

Alguns estudos ${ }^{207,208}$ identificaram alterações cognitivas nos filhos de mães com depressão pré-natal. Uma revisão sistemática da literatura sobre os estudos que examinam o impacto da depressão pré-natal no desenvolvimento da criança indicou forte associação entre depressão durante a gravidez e um risco elevado de comportamento antissocial nos filhos ${ }^{87,209}$. 


\section{MÉTODO}

Trata-se de estudo prospectivo transversal.

\subsection{Casuística}

A amostra foi do tipo não probabilística por conveniência e coletada no período de junho de 2012 a junho de 2015; foi realizado o estudo que avaliou 63 gestantes com diagnóstico de câncer, atendidas no Ambulatório de Tumores na Gestação da Divisão de Clínica Obstétrica do Hospital das Clínicas da Faculdade de Medicina da USP (HC-FMUSP) e 72 gestantes sem diagnóstico de câncer, atendidas no Ambulatório de Pré-Natal de baixo risco do mesmo serviço.

\subsection{Local do Estudo}

O estudo foi realizado no HC-FMUSP, na Divisão de Clínica Obstétrica. As gestantes com câncer pertenciam ao Ambulatório de Tumores na Gestação, que realiza o pré-natal de mulheres com diagnóstico de qualquer tipo de tumor encaminhadas de outros serviços. O seguimento pré-natal das gestantes que recebem o diagnóstico de câncer é realizado por equipe multidisciplinar, composto por médicos (obstetra, oncologista clínico, radiologista e mastologista), equipe de enfermagem, psicólogo, nutricionista, fisioterapeuta e assistente social.

\subsection{Critérios de inclusão}

- Maiores de 18 anos;

- Feto vivo;

- Ausência de diagnóstico de má-formação fetal; 
- Estar realizando pré-natal no Ambulatório de Tumores na Gestação da Divisão de Clínica Obstétrica e ter recebido diagnóstico de câncer;

- Estar realizando pré-natal no ambulatório da Divisão de Clínica Obstétrica no setor de baixo risco;

- As gestantes foram pareadas por idade gestacional.

\subsection{Critérios de exclusão}

Não terminar de responder aos instrumentos deste estudo.

\subsection{Instrumentos}

- Roteiro sociodemográfico (Anexo A).

Foi solicitado que as gestantes respondessem sobre idade, escolaridade, estado civil, tempo de relacionamento com parceiro atual, ocupação, renda per capita, número de gestações, número de filhos vivos, complicações nas gestações anteriores, abortamento espontâneo, abortamento provocado, crença de fé e religião.

- Entrevista semidirigida (Anexo B)

A entrevista semidirigida contém dez questões. Quatro questões foram destinadas às participantes com e sem diagnóstico de câncer na gestação e investigam como foi a descoberta da gestação, a realização do pré-natal, sobre o relacionamento com o feto e significado atribuído à gravidez. As outras seis questões foram dirigidas apenas para as gestantes com câncer e indagaram sobre a reação frente à descoberta da doença, vivência do tratamento do câncer, adaptação ao adoecimento, crenças sobre o relacionamento com o feto, a vivência do câncer com a gestação e o significado atribuído ao câncer. A entrevista semidirigida inclui intervenções do entrevistador para facilitar quando 0 
entrevistado não sabe como começar ou continuar e preencher lacunas de informações, ou mesmo contradições, ambivalências ou verbalizações confusas $^{210}$.

- Escala de apego materno-fetal - MFAS (Anexo C)

A Escala de apego materno-fetal (MFAS) é um instrumento multidimensional. Contém 24 subitens com cinco possibilidades de resposta cada, que variam de 5 (Quase sempre) a 1 (Nunca), tendo o item 22 pontuação invertida. É capaz de medir a extensão do comportamento que a mulher desenvolve durante a gravidez na preparação para o nascimento dos bebês. Adaptada e validada para o Brasil por Feijó ${ }^{211}$, seu escore varia de 24 a 120 pontos e o ponto de corte é: baixo apego (24-47 pontos), médio apego (48-97 pontos) e alto apego (98-120 pontos).

- Escala 'Hospital Anxiety and Depression' - HAD (Anexo D):

Avalia a depressão sem incluir sintomas vegetativos, manifestos. Além disso, a HAD é uma escala validada para a população brasileira e foi desenvolvida para ser aplicada a pacientes de serviços não psiquiátricos de um hospital geral ${ }^{212}$. Tem a vantagem de ser um instrumento de fácil aplicação, contendo 14 questões de múltipla escolha que foram lidas e preenchidas pela pesquisadora imediatamente após as entrevistas, evitando as restrições usualmente existentes às pacientes analfabetas ou com pouca escolaridade. Cada um dos seus itens pode ser pontuado de zero a três, compondo uma pontuação máxima de 21 pontos para cada escala. O ponto de corte para depressão é: sem depressão (0-8 pontos), com depressão ( $\geq 9)$. O ponto de corte para ansiedade é: sem ansiedade (0-8 pontos), com ansiedade ( $\geq 9)$.

- Prenatal Psychosocial Profile - PPP - Subescala de Autoestima (Anexo E) 
A subescala de Autoestima compõe, juntamente com mais 3 outras subescalas, o Prenatal Psychosocial Profile (PPP). Este instrumento avalia o perfil psicossocial de gestantes, sendo composto por 44 itens, e as três outras subescalas que o compõe são: estresse, apoio social do companheiro e apoio social recebido de outras pessoas. Foi validada para 0 Brasil por Weissheimer ${ }^{213}$. A subescala de autoestima é composta por 11 frases, as respostas são divididas em quatro grupos de pontuação de 1 a 4; os escores podem variar de 11 a 44 . Os pontos de corte são: baixa autoestima (> que 22), média autoestima (22-26), elevada autoestima (< que 26).

\subsection{Procedimentos}

A partir da aprovação do estudo pelo Comitê de Ética da Instituição, Comissão de Ética para Análise de Projetos de Pesquisa (CAPPesq) $n^{\circ}$ 279.127 (Anexo F), foram incluídas no estudo gestantes com diagnóstico de câncer atendidas no Ambulatório de Tumores na gestação da Clínica Obstétrica do HC-FMUSP e gestantes sem diagnóstico de câncer provenientes do Ambulatório de Pré-natal de Baixo Risco, do mesmo serviço. As gestantes foram abordadas pela pesquisadora enquanto aguardavam por consulta na sala de espera do ambulatório. Foram apresentados os objetivos e procedimentos da pesquisa por meio da leitura do Termo de Consentimento Livre e Esclarecido e aquelas que concordaram em participar assinaram o referido termo. A partir de então, foram colhidos dados sociodemográficos. Posteriormente, foi aplicada a escala HAD que avalia sintomatologia de depressão e ansiedade; a escala MFAS que avalia o apego materno-fetal e a subescala que avalia autoestima do PPP. Por fim, foi realizada uma entrevista semidirigida com as gestantes com diagnóstico de câncer e sem diagnóstico de câncer que abordaram questões referentes à descoberta da gestação, realização do pré-natal, relacionamento com o feto e significado da gravidez. $\mathrm{Na}$ mesma entrevista, algumas questões foram direcionadas apenas às pacientes com diagnóstico de câncer, tais como: a reação frente à descoberta da doença, vivência do tratamento do câncer, adaptação ao adoecimento, 
crenças sobre o relacionamento com o feto, a vivência do câncer com a gestação e o significado atribuído ao câncer. Posteriormente as entrevistas foram transcritas para a realização da análise temática. O tempo despendido na aplicação do protocolo foi de aproximadamente 40 minutos.

Não foram entrevistadas as gestantes que estavam na sua primeira consulta, uma vez que, em alguns casos, as gestantes que iniciam o pré-natal no Ambulatório de Tumores na gestação da Clínica Obstétrica do HCFMUSP, vêm encaminhadas de outros serviços e ainda estão em processo de confirmação do diagnóstico.

\subsection{Análise dos dados}

Trata-se de estudo quantitativo e qualitativo.

As variáveis quantitativas são resumidas através de: média, mediana, desvio-padrão, valores mínimo e máximo. As variáveis qualitativas são apresentadas por frequências absolutas (n) e porcentagens (\%).

Para a comparação de dois grupos em relação a variáveis quantitativas, foi utilizado o teste não paramétrico de Mann-Whitney e para comparação de mais de dois grupos foi considerado o teste não paramétrico de Kruskal-Wallis. Em situações que o teste de Kruskal-Wallis apresentou resultado significativo, ou seja, com indícios de que pelo menos um grupo é diferente dos demais em relação à variável quantitativa em questão, o teste de Dunn para comparações 2 a 2 foi considerado com a devida correção dos valores $p$ (valor $p$ ajustado) ao considerar múltiplas comparações. Com o intuito de avaliar a associação entre duas variáveis qualitativas foi considerado o teste qui-quadrado de Pearson ou o teste exato de Fisher, quando apropriado.

Com o intuito de avaliar se os grupos de depressão e câncer são consistentemente significativos na presença de variáveis potencialmente confundidoras, modelos de regressão lineares foram ajustados.

O nível de significância adotado é de $5 \%$, ou seja, resultados com valores $p(p)$ menores que 0,05 são considerados significativos. A análise dos dados foi realizada no software IBM SPSS versão 20. 
Para análise qualitativa foi utilizada a Técnica de Análise Temática ou de Conteúdo, que tem como objetivo descrever, interpretar e compreender os dados. Bardin define essa técnica como "um conjunto de técnicas de análise da comunicação visando a obter, por procedimentos sistemáticos e objetivos, da descrição do conteúdo das mensagens, indicadores (quantitativos ou não) que permitam a inferência de conhecimentos relativos às condições de produção / recepção destas mensagens"214.

As três fases para a análise de conteúdo são: pré-análise, exploração do material, tratamento dos resultados por meio da inferência e interpretação ${ }^{214}$.

A pré-análise permite, por meio de uma leitura flutuante, estabelecer um primeiro contato com o material, conhecer o texto e se deixar invadir por impressões e ideias acerca do material. Após a pré-análise deve-se fazer o recorte do texto em unidades comparáveis de categorização para que seja possível realizar a análise temática. A categorização é um processo que classifica os elementos que constituem o texto por similaridades definidas previamente na pré-análise. As categorias são, portanto, registros que utilizam um título genérico agrupados de acordo com características comuns dos elementos $^{214}$.

Os dados descritivos sobre os discursos das gestantes com diagnóstico de câncer e sem diagnóstico de câncer sobre: a descoberta da gestação, a realização do pré-natal, sobre o relacionamento com o feto e significado da gravidez, foram divididos em categorias e encontram-se apresentados na Tabela 3.

No que diz respeito ao questionamento acerca da descoberta da gestação, os discursos foram divididos em seis categorias. A categoria denominada de "Ambivalência" identifica sentimentos ambivalentes, como por exemplo, o relato de ter gostado de saber da gravidez, mas ao mesmo tempo ter se preocupado muito por causa do câncer ou do tratamento do câncer, ou nas gestantes sem diagnóstico de câncer a ambivalência devido ao fato de não ter planejado a gravidez. Na categoria denominada de "Sinais Típicos", as respostas encontravam-se relacionadas à descoberta da gravidez por meio de sinais considerados típicos de gestação, como por exemplo, atrasos na menstruação, dores e enjoos. A categoria denominada de "Enfoque positivo" 
relacionou respostas sobre sentimentos tais como: felicidade, expectativa boa e surpresa agradável. A categoria "Rotina/Tratamento" descreve relatos sobre a descoberta da gestação em situações que as gestantes não estavam esperando a gravidez e descobriram por causa de exames de rotina ou por causa do tratamento do câncer ou outra condição médica. A categoria denominada "Planejaram" identifica relatos de mulheres que estavam planejando a gravidez e haviam parado com os métodos utilizados para contracepção e referiram já esperar um resultado positivo para a gravidez. A categoria "Enfoque negativo" destaca alguns relatos em que as mulheres referem não terem ficado felizes com a gravidez por não estarem esperando, relatando sentimentos de choque e preocupação.

Ao serem indagadas sobre a vivência do pré-natal, as mulheres apresentaram discursos que compuseram três categorias. Na primeira, denominada "Enfoque positivo", foram incluídas respostas que identificaram o pré-natal com percepções satisfatórias, tais como: serem bem atendidas e apresentarem confiança nos médicos. Na categoria "Não opinou", as mulheres relataram ter realizado poucas consultas, e portanto não se sentiam à vontade para emitir uma opinião sobre o pré-natal. No que diz respeito à categoria "Enfoque negativo", as mulheres elencaram fatores negativos às consultas prénatais, como algo confuso, dificuldade de acumular várias consultas na mesma semana, a distância da residência e do hospital.

Sobre o relacionamento com o feto, os discursos foram divididos em seis categorias. "Conversa" refere-se a uma descrição da forma de interação com o feto por meio de conversa. Na segunda categoria, "Bom relacionamento" foram relacionadas percepções sobre um bom relacionamento com o feto, mas sem especificar de que maneira ocorre a interação e sem citar nenhum sentimento com relação a isso. $\mathrm{Na}$ terceira categoria denominada "Medo" foram identificados sentimentos de medo de que o tratamento pudesse ter consequências negativas para o feto, de perder o bebê, ou medo pela gravidez inesperada. Na categoria "Alegria" foram referidos sentimentos de felicidade ou alegria em relação ao feto e à gravidez. "Milagre" foi a categoria denominada para os discursos em que as mulheres mencionaram que a gravidez foi um milagre, que foi o feto que deu força para continuar com o tratamento, ou que 
era a razão de suas vidas. Por fim, na categoria "Não se relaciona", foram elencadas respostas em que as gestantes afirmaram não se relacionar de maneira alguma com o bebê, tais como: esquecer que está grávida, dar pouca ou nenhuma atenção ao bebê.

Ao serem questionadas sobre o significado de gravidez, as respostas das gestantes foram distribuídas em três categorias. Denominou-se "Enfoque positivo" para as respostas relacionadas com significados positivos atribuídos à gravidez, tais como: vida, felicidade, realização, bênção de Deus, momento especial. Em "Responsabilidade" foram agregadas respostas que referem à responsabilidade da gravidez no sentido de ter que cuidar de outra pessoa, na construção de uma família e a preocupação com a criação do filho. Identificouse uma terceira categoria com respostas que afirmam "Não saber explicar" o significado de gravidez para elas.

A apresentação da categorização das respostas obtidas por meio de entrevistas semidirigidas com gestantes com diagnóstico de câncer e sem o diagnóstico estão apresentadas na Tabela 3.

Tabela 3 - Apresentação da categorização das respostas obtidas na entrevista semidirigida, para análise qualitativa: gestantes com diagnóstico de câncer e sem diagnóstico de câncer

\begin{tabular}{|c|c|}
\hline \multicolumn{2}{|c|}{ Gestantes com diagnóstico de câncer e sem diagnóstico de câncer } \\
\hline Temas & Categorias \\
\hline Descoberta da gestação & $\begin{array}{ll}\text { - } & \text { Ambivalência } \\
\text { - } & \text { Sinais típicos } \\
\text { - } & \text { Enfoque positivo } \\
\text { - } & \text { Rotina/Tratamento } \\
\text { - } & \text { Planejaram } \\
\text { - } & \text { Enfoque negativo }\end{array}$ \\
\hline Vivência pré-natal & $\begin{array}{ll}\text { - } & \text { Enfoque positivo } \\
\text { - } & \text { Não opinou } \\
\text { - Enfoque negativo }\end{array}$ \\
\hline Relacionamento com o feto & $\begin{array}{ll}\text { - } & \text { Conversa } \\
\text { - } & \text { Bom relacionamento } \\
\text { - } & \text { Alegria } \\
\text { - } & \text { Milagre } \\
\text { - } & \text { Não se relaciona }\end{array}$ \\
\hline Significado da gravidez & $\begin{array}{ll}\text { - } & \text { Enfoque positivo } \\
\text { - } & \text { Responsabilidade } \\
\text { - } & \text { Não sabe explicar }\end{array}$ \\
\hline
\end{tabular}

FONTE: Elaborada pela autora 
As mulheres que tiveram a vivência do câncer concomitantemente com a gestação discorreram sobre a reação frente à descoberta da doença, vivência do tratamento do câncer, adaptação ao adoecimento, crenças sobre o relacionamento com o feto, a vivência do câncer com a gestação e o significado atribuído ao câncer.

Sobre a descoberta da doença, as respostas foram distribuídas em quatro categorias. $\mathrm{Na}$ categoria denominada "Choque" foram incluídos discursos que referiram sentimentos de choque, angústia, algo vivenciado de forma pavorosa ou de maneira inesperada. "Autopercepção" foi o nome dado à categoria que envolveu relatos sobre a descoberta da doença pelo autoexame das mamas ou outra autopercepção que levou a uma investigação médica posterior. Em "Rotina/tratamento" estão descritos alguns relatos onde a descoberta do câncer se deu por meio de exames de rotina ou durante algum tratamento. Na categoria "Otimismo", estão elencadas falas que evidenciaram sentimentos de otimismo, fé, coragem e força.

Sobre como está sendo a vivência do tratamento do câncer, a categoria "Enfoque negativo" agrupou respostas que referiram dificuldade de conciliar a gestação com o tratamento pelo número elevado de consultas, cansaço e sofrimento no tratamento. "Não está em tratamento" é uma categoria que identificou as respostas das participantes que não se encontravam em tratamento durante a entrevista, ou porque ainda não haviam iniciado ou porque já haviam terminado. A categoria nomeada "Enfoque positivo" relacionou respostas cuja percepção do tratamento foi boa, superando expectativas ruins antes dele começar, segurança nos profissionais e aprendizado. Na categoria "Normal" foram identificados relatos em que não têm conotação postiva e nem negativa sobre o tratamento.

Os discursos relacionados à percepção das mulheres sobre a adaptação ao adoecimento foram divididos em cinco categorias, denominadas a partir dos sentimentos descritos, como: "Aceitação", com discursos voltados para a aceitação da doença e foco no tratamento e pensamento positivo; "Não aceitação" em que descrevem a não aceitação da doença e sobre o sofrimento que advém dela; "Negação", com discursos voltados para tentativa de não pensar no assunto, não pensar na doença, evitação. Como "Medo" foram 
identificados sentimentos de preocupação e medo do que possa acontecer por causa da doença e também medo com relação ao bebê. Como "Revolta" foram identificadas representações de raiva.

Sobre as crenças sobre o relacionamento com o feto em mulheres que vivenciam o câncer concomitantemente com a gravidez, as respostas foram divididas em quatro categorias. A primeira denominada "Sentido à vida" agrupou discursos de que o relacionamento com o feto poderia ajudá-las a dar um sentido à vida e forças para enfrentar a doença. A categoria "Preocupação" evidencia preocupações com o bebê, como a possibilidade dele nascer com algum problema ou sobre a dúvida se elas poderiam cuidar de forma eficiente do bebê. Algumas mulheres consideram que nada muda no relacionamento com o feto, sendo dado o nome de "Nada muda" para categoria a ele atribuída. Algumas mulheres referiram acreditar que estando doentes sentem um carinho maior pelo filho por não saberem quanto tempo irão viver, categoria esta denominada "Carinho".

Os dados referentes aos discursos sobre como está sendo a vivência do câncer na gestação foram elencados em quatro categorias. Na primeira, "Enfoque negativo", estão descritos relatos desta vivência como: uma situação difícil, preocupações com o bebê, medo delas não poderem cuidar do bebê e os relatos sobre o sofrimento causado pela doença. A segunda categoria, denominada "Enfoque positivo", retratou os relatos que referem à força que a gravidez dá no enfrentamento da doença. Na categoria "Dualidade" estão descritos os sentimentos contraditórios relacionados a esta vivência. A categoria "Normal" demonstra informações sobre a percepção de que está tudo bem na vivência do câncer na gestação.

Os discursos apresentados pelas participantes sobre o significado atribuído ao câncer foram divididos em quatro categorias, sendo que a primeira, denominada "Morte/sofrimento", relacionou ideias de morte e sofrimento causados pela doença. A categoria "Cura/tratamento" identificou aspectos ligados à esperança na cura e possibilidades de tratamento. A terceira categoria, denominada "Superação", elencou conteúdos de associação do câncer com a possibilidade de superação e aprendizado. A quarta categoria, 
denominada "Causa", trouxe relatos que abordaram a comprrensão das mulheres sobre as possíveis causas emocionais do câncer.

As categorias obtidas a partir do discurso somente das gestantes com diagnóstico de câncer estão apresentadas na Tabela 4.

Tabela 4 - Apresentação da categorização das repostas obtidas por meio de entrevista semidirigida para análise qualitativa: somente gestantes com diagnóstico de câncer

\begin{tabular}{|c|c|}
\hline \multicolumn{2}{|c|}{ Gestantes com diagnóstico de câncer } \\
\hline Temas & Categorias \\
\hline Como foi a descoberta da doença & $\begin{array}{ll}\text { - } & \text { Choque } \\
\text { : } & \text { Autopercepção } \\
\text { - } & \text { Rotina/tratamento } \\
& \text { Otimismo }\end{array}$ \\
\hline Vivência do tratamento do câncer & $\begin{array}{ll}\text { - } & \text { Enfoque negativo } \\
\text { - } & \text { Eño está em tratamento } \\
& \text { Normal }\end{array}$ \\
\hline Adaptação ao adoecimento & $\begin{array}{ll}\text { - } & \text { Aceitação } \\
\text { - } & \text { Não aceitação } \\
\text { - } & \text { Negação } \\
\text { - } & \text { Medo } \\
\text { - } & \text { Revolta }\end{array}$ \\
\hline $\begin{array}{l}\text { Crenças sobre o relacionamento } \\
\text { com o feto }\end{array}$ & $\begin{array}{ll}\text { - } & \text { Sentido à vida } \\
\text { - } & \text { Nada muda } \\
\text { - } & \text { Carinho }\end{array}$ \\
\hline Vivência do câncer na gestação & $\begin{array}{ll}\text { - } & \text { Enfoque negativo } \\
\text { : } & \text { Enfoque positivo } \\
\text { : } & \text { Normalidade } \\
& \text { Normal }\end{array}$ \\
\hline Significado atribuído ao câncer & $\begin{array}{ll}\text { - } & \text { Morte/sofrimento } \\
\text { - } & \text { Cura/tratamento } \\
\text { - } & \text { Causa }\end{array}$ \\
\hline
\end{tabular}

FONTE: Elaborada pela autora 


\section{RESULTADOS}

\subsection{Análise quantitativa}

Dentro do período estudado foram realizados o pré-natalde 77 gestantes portadoras de câncer e gestação. Destas, foram entrevistadas 63, deste modo, esta amostra representa $81,8 \%$ destas gestantes.

A associação entre os dados sociodemográficos e diagnóstico de câncer encontra-se apresentada na Tabela 5. Foi encontrada diferença significativa entre os grupos presença de diagnóstico de câncer e ausência do diagnóstico de câncer no que diz respeito à média da renda per capita ( $p>0,001)$.

Tabela 5 - Associação entre a presença e ausência de diagnóstico de câncer com variáveis sociodemográficas

\begin{tabular}{|c|c|c|c|}
\hline \multicolumn{4}{|c|}{ Diagnóstico de câncer } \\
\hline Variáveis & $\begin{array}{l}\text { Presença } \\
n=63\end{array}$ & $\begin{array}{l}\text { Ausência } \\
\mathrm{n}=72\end{array}$ & $\mathbf{p}$ \\
\hline \multicolumn{4}{|l|}{ Idade } \\
\hline $\begin{array}{l}\text { Média ( } \pm \text { DP) } \\
\text { Mediana (Min-Máx) }\end{array}$ & $\begin{array}{l}30,79(6,32) \\
31,00(18-43)\end{array}$ & $\begin{array}{l}29,51(6,15) \\
29,00(18-47)\end{array}$ & $0,236^{a}$ \\
\hline \multicolumn{4}{|l|}{ Renda per capita } \\
\hline $\begin{array}{l}\text { Média ( } \pm \mathrm{DP}) \\
\text { Mediana (Min-Máx) }\end{array}$ & $\begin{array}{l}667,99(563,54) \\
600,00(0-3500)\end{array}$ & $\begin{array}{l}1163,69(868,98) \\
1000,00(0-4000)\end{array}$ & $<0,001^{a}$ \\
\hline \multicolumn{4}{|c|}{$\begin{array}{l}\text { Idade gestacional em } \\
\text { semanas }\end{array}$} \\
\hline $\begin{array}{l}\text { Média ( } \pm \mathrm{DP}) \\
\text { Mediana (Min-Máx) }\end{array}$ & $\begin{array}{l}23,25(8,89) \\
24,00(7-40)\end{array}$ & $\begin{array}{l}25,19(10,04) \\
26,50(5-40)\end{array}$ & $0,239^{a}$ \\
\hline
\end{tabular}


$\mathrm{Na}$ associação dos dados sociodemográficos com os grupos de gestantes com presença ou ausência de diagnóstico de câncer constatou-se diferença significativa entre escolaridade $(p=0,001)$; paridade $(p<0,001)$ e trabalho remunerado $(p=0,015)$, conforme os dados apresentados na Tabela 6 .

Tabela 6 - Associação entre a presença e ausência de diagnóstico de câncer com escolaridade, paridade, crença de fé, trabalho remunerado e abortamentos anteriores

\begin{tabular}{|c|c|c|c|}
\hline \multicolumn{4}{|c|}{ Diagnóstico de câncer } \\
\hline Variáveis & $\begin{array}{c}\text { Presença } \\
n(\%) \\
n=63\end{array}$ & $\begin{array}{c}\text { Ausência } \\
n(\%) \\
n=72\end{array}$ & $\mathbf{p}$ \\
\hline \multicolumn{4}{|l|}{ Escolaridade } \\
\hline Fundamental & $17(27)$ & $8(11,1)$ & \multirow{3}{*}{$0,001^{a}$} \\
\hline Médio & $33(52,4)$ & $29(40,3)$ & \\
\hline Superior & $13(20,6)$ & $35(48,6)$ & \\
\hline \multicolumn{4}{|l|}{ Paridade } \\
\hline Nulípara & $12(19)$ & $36(50)$ & \multirow{2}{*}{$<0,001^{b}$} \\
\hline Não nulípara & $51(81)$ & $36(50)$ & \\
\hline Crença de Fé & $59(93,7)$ & $67(93,1)$ & \\
\hline & & & $0,999^{\mathrm{a}}$ \\
\hline \multicolumn{3}{|l|}{ Religião } & \\
\hline Católica & $23(36,5)$ & $27(37,5)$ & \multirow{4}{*}{$0,926^{a}$} \\
\hline Espírita e outras & $6(9,5)$ & $9(12,5)$ & \\
\hline Evangélica & $29(46)$ & $30(41,7)$ & \\
\hline Não tem & $5(7,9)$ & $6(8,3)$ & \\
\hline Presença do companheiro & $59(93,7)$ & $68(94,4)$ & $0,999^{a}$ \\
\hline Trabalho remunerado & $39(62,9)$ & $58(81,7)$ & $0,015^{\mathrm{a}}$ \\
\hline Abortamentos espontâneos & $14(22,2)$ & $15(20,8)$ & $0,845^{\mathrm{b}}$ \\
\hline Abortamentos provocados & $3(4,8)$ & $1(1,4)$ & $0,339^{\mathrm{a}}$ \\
\hline
\end{tabular}


Nas mulheres do grupo de presença de diagnóstico de câncer foi investigado: o tipo de câncer, e se o diagnóstico foi recebido antes ou após a gravidez. Constatou-se que $44 \%$ das mulheres apresentavam diagnóstico de câncer de mama; $57,1 \%$ receberam o diagnóstico de câncer antes da gestação conforme os dados apresentados na Tabela 7.

Tabela 7 - Distribuição dos casos de acordo com o tipo de câncer e o momento do diagnóstico

\begin{tabular}{lcc}
\hline & $\mathbf{n}$ & n=63 \\
\hline Diagnóstico de câncer & 28 & 44,4 \\
Mama & 7 & 11,0 \\
Colo uterino & 4 & 6,3 \\
Intestino & 4 & 6,3 \\
Tireoide & 3 & 4,8 \\
Ósseo & 3 & 4,8 \\
Cerebral & 3 & 4,8 \\
Fígado & 3 & 4,8 \\
Pulmão & 3 & 4,8 \\
Ovário & 1 & 1,6 \\
Paragânglios & 1 & 1,6 \\
Palato & 1 & 1,6 \\
Pâncreas & 1 & 1,6 \\
Melanoma & 1 & 1,6 \\
Rim & & \\
Diagnóstico de Câncer e da Gestação & 36 & 57,1 \\
Recebeu primeiro o diagnóstico de câncer & 27 & 42,9 \\
Recebeu primeiro o diagnóstico da gravidez & &
\end{tabular}


A distribuição dos dados de acordo com o ponto de corte para sintomatologia de depressão e presença de câncer encontra-se apresentada na Tabela 8. Foi encontrada associação significativa entre depressão e presença ou ausência de diagnóstico de câncer $(p=0,041)$.

Tabela 8 - Associação entre presença ou ausência de diagnóstico de câncer e presença ou ausência de depressão

\begin{tabular}{|c|c|c|c|}
\hline Depressão & $\begin{array}{c}\text { Presença de } \\
\text { Câncer } \\
n(\%) \\
n=63 \\
\end{array}$ & $\begin{array}{c}\text { Ausência de } \\
\text { Câncer } \\
\text { n(\%) } \\
\text { n=72 }\end{array}$ & p \\
\hline $\begin{array}{l}\text { Presença de depressão } \\
\text { Ausência de depressão }\end{array}$ & $\begin{array}{l}21(33,3) \\
42(66,7)\end{array}$ & $\begin{array}{l}13(18,1) \\
59(81,9)\end{array}$ & $0,041^{a}$ \\
\hline
\end{tabular}

FONTE: Elaborada pela autora

NOTA: ${ }^{a} Q u i-q u a d r a d o$

Os escores da avaliação de ansiedade, autoestima e apego maternofetal e a associação com a presença ou ausência de câncer encontram-se apresentados na Tabela 9.

$\mathrm{Na}$ associação entre presença de câncer e escala de ansiedade observou-se que a mediana do grupo com diagnóstico de câncer apresentou maiores escores de ansiedade $(p=0,039)$. Na avaliação com a escala de autoestima observou-se mediana de escore maior no grupo de gestantes sem diagnóstico de câncer quando comparado ao grupo de gestantes com diagnóstico de câncer ( $p<0,001)$. Ambos os resultados apresentam diferença significativa. Não foi constatada diferença significativa entre os grupos e a escala de apego materno-fetal $(p=0,800)$.

Tabela 9 - Associação entre presença ou ausência de diagnóstico de câncer com ansiedade, autoestima e apego materno-fetal

\begin{tabular}{|c|c|c|c|}
\hline Variáveis & $\begin{array}{c}\text { Presença de } \\
\text { Câncer } \\
n=63\end{array}$ & $\begin{array}{l}\text { Ausência de } \\
\text { Câncer } \\
n=72\end{array}$ & $\mathbf{p}$ \\
\hline \multicolumn{4}{|l|}{ Ansiedade } \\
\hline $\begin{array}{l}\text { Média ( } \pm \text { DP) } \\
\text { Mediana (Min-Máx) }\end{array}$ & $\begin{array}{c}8,06(4,42) \\
7,00(1-21)\end{array}$ & $\begin{array}{c}6,54(4,20) \\
5,00(0-18)\end{array}$ & $0,039^{b}$ \\
\hline \multicolumn{4}{|l|}{ Autoestima } \\
\hline $\begin{array}{l}\text { Média ( } \pm \mathrm{DP}) \\
\text { Mediana (Min-Máx) }\end{array}$ & $\begin{array}{l}24,50(3,07) \\
25(12-30)\end{array}$ & $\begin{array}{c}26,42(2,60) \\
26,50(21-34)\end{array}$ & $<0,001^{b}$ \\
\hline \multicolumn{4}{|l|}{ Apego materno-fetal } \\
\hline $\begin{array}{l}\text { Média }( \pm D P) \\
\text { Mediana (Min-Máx) }\end{array}$ & $\begin{array}{l}87,95(13,32) \\
87(52-120)\end{array}$ & $\begin{array}{c}88,69(9,87) \\
88,50(64-116)\end{array}$ & $0,800^{b}$ \\
\hline
\end{tabular}


A combinação entre 0 diagnóstico de câncer e o diagnóstico de depressão dá origem a quatro grupos, a saber: gestantes com diagnóstico de câncer e com depressão $(C+D)$, gestantes com diagnóstico de câncer e sem depressão (C-D), gestantes sem diagnóstico de câncer e com depressão (SC+D) e gestantes sem diagnóstico de câncer e sem depressão (SC-D).

A associação entre os dados sociodemográficos e a combinação de diagnóstico de câncer e depressão encontram-se apresentadas na Tabela 10. Constatou-se diferença significativa entre os grupos analisados e renda per capita $(p<0,001)$.

Tabela 10 - Associação dos dados de acordo com média, desvio padrão, mediana, mínimo e máximo da idade; idade gestacional; renda per capita e a combinação de diagnóstico de câncer e depressão

\begin{tabular}{|c|c|c|c|c|c|}
\hline Variáveis & $\begin{array}{c}\text { Câncer e } \\
\text { com } \\
\text { depressão } \\
(C+D) \\
n=21\end{array}$ & $\begin{array}{c}\text { Câncer e } \\
\text { sem } \\
\text { depressão } \\
\text { (C-D) } \\
\mathrm{n}=42\end{array}$ & $\begin{array}{c}\text { Sem câncer } \\
\text { e com } \\
\text { depressão } \\
(S C+D) \\
n=13\end{array}$ & $\begin{array}{c}\text { Sem câncer } \\
\text { e sem } \\
\text { depressão } \\
\text { (SC-D) } \\
n=59\end{array}$ & $\mathbf{p}$ \\
\hline \multicolumn{6}{|l|}{ Idade } \\
\hline $\begin{array}{l}\text { Média } \\
( \pm D P) \\
\text { Mediana } \\
\text { (Min-Máx) }\end{array}$ & $\begin{array}{c}30,85 \\
(5,49) \\
31,00 \\
(22-40)\end{array}$ & $\begin{array}{c}30,7619 \\
(6,76) \\
30,50 \\
(18-43)\end{array}$ & $\begin{array}{c}27,84 \\
(5,17) \\
27,00 \\
(19-36)\end{array}$ & $\begin{array}{c}29,88 \\
(6,32) \\
29,00 \\
(18-47)\end{array}$ & $0,474^{a}$ \\
\hline \multicolumn{6}{|l|}{$\begin{array}{l}\text { Idade } \\
\text { gestacional }\end{array}$} \\
\hline $\begin{array}{l}\text { Média } \\
( \pm D P) \\
\text { Mediana } \\
\text { (Min-Máx) }\end{array}$ & $\begin{array}{l}21,85 \\
(7,41) \\
24,00 \\
(8-33)\end{array}$ & $\begin{array}{l}23,95 \\
(9,54) \\
24,00 \\
(7-40)\end{array}$ & $\begin{array}{c}24,92 \\
(10,69) \\
27,00 \\
(07-38)\end{array}$ & $\begin{array}{l}25,25 \\
(9,98) \\
26,00 \\
(5-40)\end{array}$ & $0,463^{a}$ \\
\hline \multicolumn{6}{|l|}{$\begin{array}{l}\text { Renda per } \\
\text { capita }\end{array}$} \\
\hline $\begin{array}{l}\text { Média } \\
( \pm D P) \\
\text { Mediana } \\
\text { (Min-Máx) }\end{array}$ & $\begin{array}{c}513,66 \\
(303,26) \\
450,00 \\
(0-1000)\end{array}$ & $\begin{array}{c}743,27 \\
(644,17) \\
633,33 \\
(0-3500)\end{array}$ & $\begin{array}{c}948,26 \\
(1200,44) \\
525,00 \\
(0-4000)\end{array}$ & $\begin{array}{c}1208,25 \\
(790,07) \\
1033,33 \\
(0-4000)\end{array}$ & $<0,001$ \\
\hline
\end{tabular}

FONTE: Elaborada pela autora NOTA: ${ }^{\mathrm{T} T e s t e}$ de Kruskal-Wallis 
A associação entre a combinação de diagnóstico de câncer e depressão e a pontuação nas escalas de ansiedade, autoestima e apego materno-fetal encontram-se apresentadas na Tabela 11. Constatou-se associação significativa entre a combinação de diagnóstico de câncer e depressão e a pontuação nas escalas de ansiedade $(p<0,001)$ e autoestima $(p=0,001)$.

Há indícios de que pelo menos um grupo apresenta distribuição estatisticamente diferente dos demais nas escalas de ansiedade $(p=<0,001)$ e na escala de autoestima $(p=0,001)$.

Tabela 11 - Associação dos dados de acordo com média, mediana, desvio padrão, mediana, mínimo e máximo da pontuação obtida nas escalas de ansiedade, autoestima e apego materno-fetal e a combinação de diagnóstico de câncer e depressão

\begin{tabular}{|c|c|c|c|c|c|}
\hline Escalas & $\begin{array}{c}\text { Câncer e } \\
\text { com } \\
\text { depressão } \\
\text { (C+D) } \\
n=21\end{array}$ & $\begin{array}{c}\text { Câncer e } \\
\text { sem } \\
\text { depressão } \\
\text { (C-D) } \\
\text { n=42 }\end{array}$ & $\begin{array}{c}\text { Sem } \\
\text { câncer e } \\
\text { com } \\
\text { depressão } \\
\text { (SC+D) } \\
n=13\end{array}$ & $\begin{array}{c}\text { Sem } \\
\text { câncer e } \\
\text { sem } \\
\text { depressão } \\
(S C-D) \\
n=59\end{array}$ & $\mathbf{p}$ \\
\hline \multicolumn{6}{|l|}{ Ansiedade } \\
\hline $\begin{array}{l}\text { Média } \\
( \pm D P) \\
\text { Mediana } \\
\text { (Min-Máx) }\end{array}$ & $\begin{array}{c}12,19 \\
(3,88) \\
11,00 \\
(3-21)\end{array}$ & $\begin{array}{c}6,00 \\
(3,01) \\
6,00 \\
(1-13)\end{array}$ & $\begin{array}{l}11,38 \\
(3,28) \\
11,00 \\
(5-18)\end{array}$ & $\begin{array}{c}5,47 \\
(3,59) \\
5,00 \\
(0-17)\end{array}$ & $<0,001^{2}$ \\
\hline \multicolumn{6}{|c|}{ Autoestima } \\
\hline $\begin{array}{l}\text { Média } \\
( \pm D P) \\
\text { Mediana } \\
\text { (Min-Máx) }\end{array}$ & $\begin{array}{c}23,76 \\
(3,4487) \\
25,00 \\
(12-27)\end{array}$ & $\begin{array}{c}24,80 \\
(2,83) \\
25,00 \\
(18-30)\end{array}$ & $\begin{array}{l}25,92 \\
(3,50) \\
25,00 \\
(22-34)\end{array}$ & $\begin{array}{l}26,52 \\
(2,38) \\
27,00 \\
(21-33)\end{array}$ & $0,001^{a}$ \\
\hline \multicolumn{6}{|c|}{$\begin{array}{l}\text { Apego } \\
\text { materno-fetal }\end{array}$} \\
\hline $\begin{array}{l}\text { Média } \\
( \pm D P)\end{array}$ & $\begin{array}{c}81,62 \\
(13,04)\end{array}$ & $\begin{array}{c}91,11 \\
(12,43)\end{array}$ & $\begin{array}{l}87,07 \\
(10,14)\end{array}$ & $\begin{array}{l}89,03 \\
(9,86)\end{array}$ & \multirow[t]{2}{*}{$0,077^{a}$} \\
\hline $\begin{array}{l}\text { Mediana } \\
\text { (Min-Máx) }\end{array}$ & $\begin{array}{c}84,00 \\
(52-105)\end{array}$ & $\begin{array}{c}91,00 \\
(68-120)\end{array}$ & $\begin{array}{c}85,00 \\
(66-104)\end{array}$ & $\begin{array}{l}90,00 \\
(64-116)\end{array}$ & \\
\hline
\end{tabular}

FONTE: Elaborada pela autora NOTA: ${ }^{a}$ Teste de Kruskal-Wallis 
Após a análise apresentada na Tabela 11 foram realizadas comparações 2 a 2 dos quatro grupos (resultando em seis comparações) quanto aos escores de ansiedade e autoestima.

Nas comparações 2 a 2 dos quatro grupos para a escala de ansiedade, constatou-se que a mediana de escore do grupo $\mathrm{C}+\mathrm{D}$ é significativamente maior do que a mediana apresentada pelo grupo $C-D(p$ ajustado $>0,001)$ e pelo grupo SC-D ( $p$ ajustado <0,001). O grupo SC+D também apresenta diferença estatística significante quando comparado ao grupo com C-D, sendo que a mediana do primeiro é maior do que a mediana do segundo ( $p$ ajustado $=0,001$ ). $O$ grupo $S C+D$ apresenta diferença significativa quando comparado ao grupo SC-D ( $p$ ajustado $<0,001$ ).

Não foi encontrada diferença estatística nas comparações entre os seguintes grupos: C-D e SC-D ( $p$ ajustado=0,999) e $C+D$ e $S C+D$ ( $p$ ajustado $=0,999$ ). A representação gráfica da comparação dos escores da escala de ansiedade entre os grupos citados encontra-se apresentada na Figura 1:

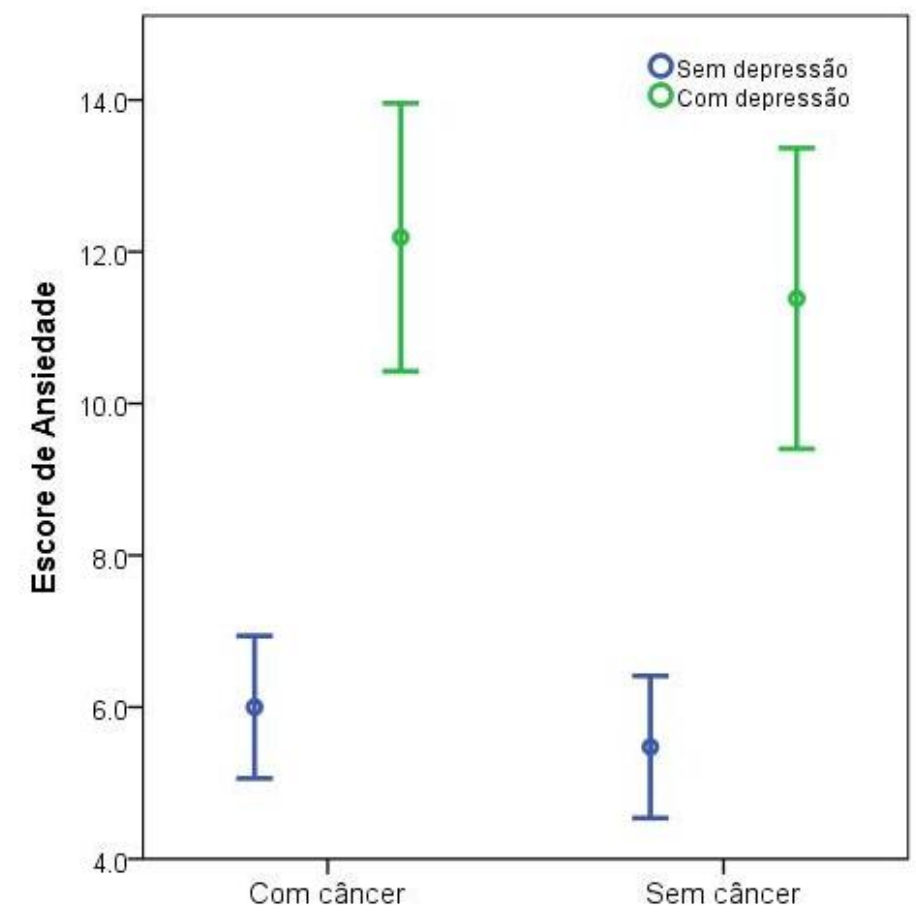

Figura 1 - Gráfico das medianas (símbolo) e respectivos intervalos com 95\% de confiança para mediana (barras) dos escores da escala de ansiedade para a combinação de diagnóstico de câncer e depressão. 
Nas comparações 2 a 2 dos quatro grupos para a escala de autoestima não foi encontrada diferença significativa entre a mediana de escore do grupo $C+D$ com os grupos $C-D$ ( $p$ ajustado $=0,999$ ) e $S C+D$ ( $p$ ajustado $=0,999$ ).

Quando analisada a mediana dos grupos C+D com SC-D constatou-se diferença estatística significativa ( $p$ ajustado $=0,003$ ).

Verificou-se diferença significativa entre a mediana dos escores dos grupos C-D quando comparado à mediana dos escores do grupo SC-D ( $p$ ajustado $=0,017)$.

O grupo C-D não apresenta resultado significativo quando comparado ao grupo $\mathrm{SC}+\mathrm{D}$ ( $p$ ajustado=0,999).

Quando comparado a mediana dos grupos SC+D ao grupo SC-D não foi encontrada diferença significativa ( $p$ ajustado $=0,829$ ).

A representação gráfica da comparação dos escores da escala de autoestima entre os grupos citados encontra-se apresentada na Figura 2:

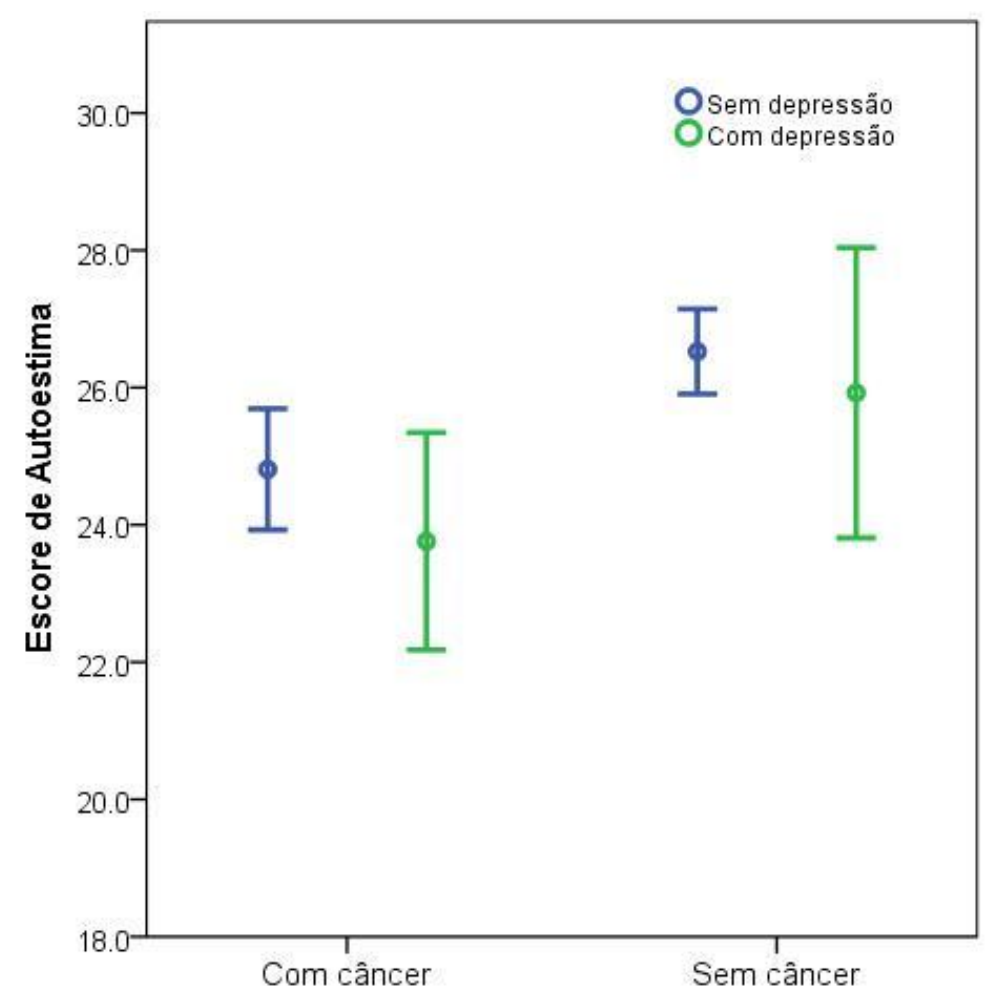

Figura 2 - Gráfico das medianas (símbolo) e respectivos intervalos com 95\% de confiança para mediana (barras) dos escores da escala de autoestima para a combinação de diagnóstico de câncer e depressão. 
A Figura 3 apresenta a representação gráfica das medianas dos escores de apego dos grupos $\mathrm{C}+\mathrm{D}, \mathrm{C}-\mathrm{D}, \mathrm{SC}+\mathrm{D}$ e SC-D, com seus respectivos intervalos de confiança, tendo em vista que não foram realizadas comparações 2 a 2 entre os grupos, pois não houve diferença significativa entre eles.

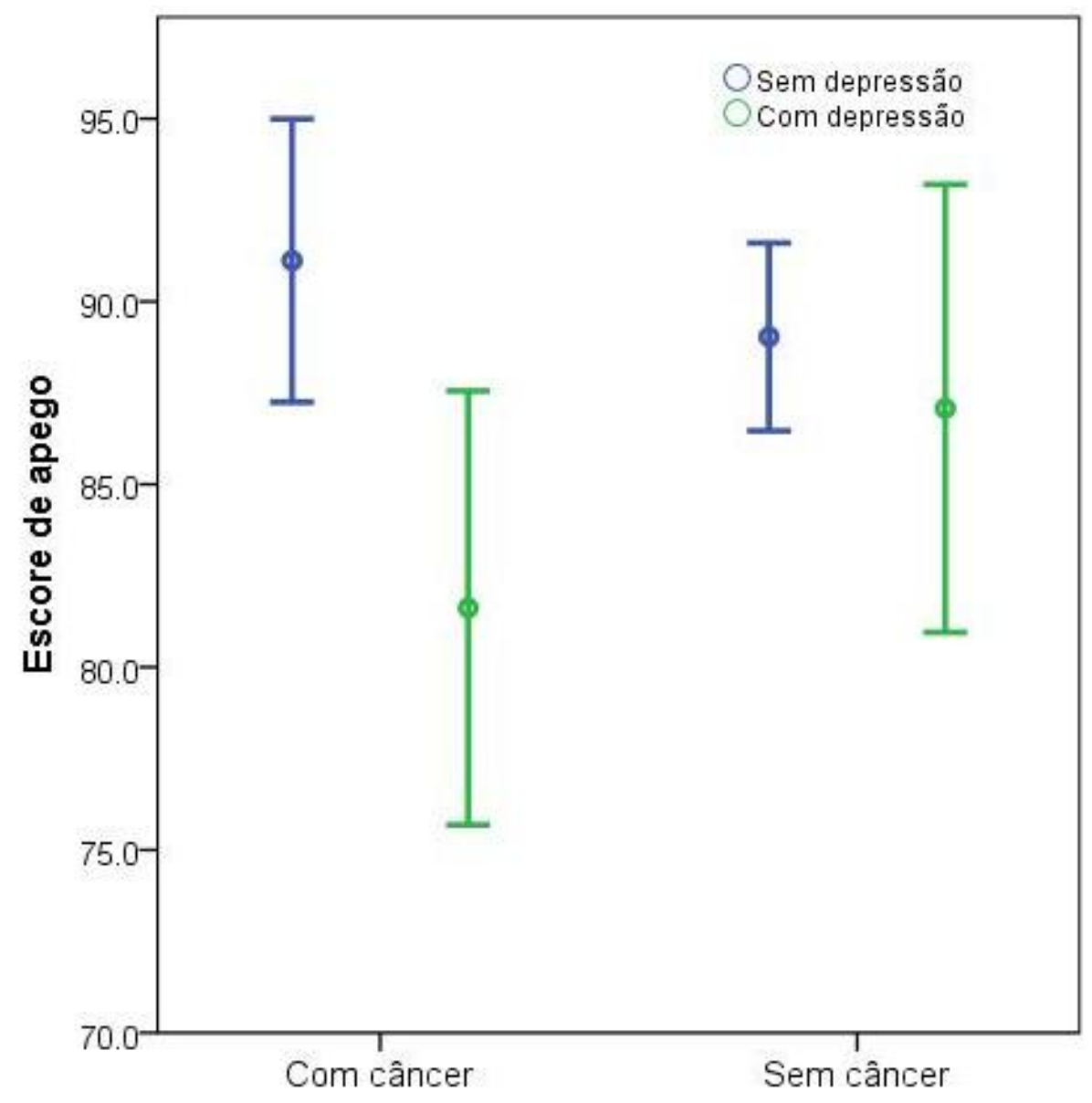

Figura 3 - Gráfico das medianas (símbolo) e respectivos intervalos com 95\% de confiança para mediana (barras) dos escores da escala de apego materno-fetal para a combinação de diagnóstico de câncer e depressão. 
Foram ajustados modelos de regressão linear múltipla para ansiedade, autoestima e apego materno-fetal com intuito de verificar se a significância de depressão e/ou câncer se mantém consistente mesmo considerando as variáveis de confusão.

Desta forma, as variáveis explicativas do modelo são: ocupação, escolaridade, renda per capita, presença ou não do diagnóstico de câncer, nulípara e depressão.

Em relação à ansiedade, somente a depressão se mantém significativa ( $p$ ajustado<0,001) e no que diz respeito à autoestima, identificou-se que apenas a presença de câncer se mantém significativa ( $p$ ajustado=0,012).

Quanto ao apego, a depressão se apresenta significativa ( $p$ ajustado=0,005). Os dados estão apresentados na Tabela 12.

Tabela 12 - Valores $p$ dos modelos de regressão linear para ansiedade, autoestima e apego

\begin{tabular}{lcccccc}
\hline & Ansiedade & $\mathbf{p}$ & Autoestima & $\mathbf{p}$ & Apego & $\mathbf{p}$ \\
\hline $\begin{array}{l}\text { Ocupação } \\
\text { Escolaridade }\end{array}$ & $-0,68(0,76)$ & 0,367 & $-0,31(0,570)$ & 0,596 & $1,54(2,47)$ & 0,532 \\
$\begin{array}{l}\text { Fundamental } \\
\text { Médio }\end{array}$ & $-0,47(1,03)$ & 0,896 & $-1,51(0,777)$ & & & \\
$\begin{array}{l}\text { Renda per } \\
\text { capita }\end{array}$ & $-0,27(0,76)$ & $0,896,093$ & $-0,19(0,576)$ & $-2,75(2,36)$ & 0,294 \\
$\begin{array}{l}\text { Diagnóstico } \\
\text { de câncer }\end{array}$ & $0,00(0,00)$ & 0,513 & $0,00(0,00)$ & 0,669 & $-0,00(0,00)$ & 0,121 \\
$\begin{array}{l}\text { Nulípara } \\
\text { Depressão }\end{array}$ & $0,36(0,65)$ & 0,242 & $-1,22(0,49)$ & 0,012 & $-0,78(2,11)$ & 0,714 \\
\hline
\end{tabular}

FONTE: Elaborada pela autora

NOTA: Coeficiente (Erro padrão)

\subsection{Resultados qualitativos}

Nesta seção os resultados qualitativos são divididos em categorias, o que possibilita a apresentação das respectivas frequências com que eles foram relatados. Encontra-se fracionada em duas partes. A primeira demonstra os resultados das entrevistas semidirigidas às gestantes com e sem diagnóstico de câncer. A segunda parte apresenta os resultados das questões que foram propostas apenas para o grupo de mulheres que já tinham diagnóstico de 
câncer, por se tratar de particularidades vivenciadas a partir daquele diagnóstico.

\subsubsection{Entrevistas realizadas com as gestantes com diagnóstico de câncer e sem diagnóstico de câncer}

Os discursos apresentados a seguir versam sobre os seguintes temas: descoberta da gestação, vivência do pré-natal, relacionamento com o feto e significado de gravidez.

\subsubsection{Descoberta da gestação}

Quando questionadas sobre a descoberta da gestação, observaram-se sentimentos ambivalentes em 36,5\% das gestantes com câncer e 29,2\% das gestantes sem a doença. Estes resultados encontram-se descritos na Tabela 13.

Tabela 13 - Distribuição dos dados de acordo com presença ou ausência de diagnóstico de câncer na gestação e a percepção sobre a descoberta da gestação

\begin{tabular}{lcc}
\hline & \multicolumn{2}{c}{ Diagnóstico de câncer } \\
\hline Variáveis & $\begin{array}{c}\text { Presença } \\
\mathbf{n}(\%)\end{array}$ & $\begin{array}{c}\text { Ausência } \\
\mathbf{n}(\%)\end{array}$ \\
Descoberta da gestação & $\mathbf{n = 6 3}$ & $\mathbf{n = 7 2}$ \\
Ambivalência & & \\
Sinais típicos & $23(36,5)$ & $21(29,2)$ \\
Enfoque positivo & $18(28,6)$ & $25(34,7)$ \\
Rotina/Tratamento & $10(15,9)$ & $10(13,9)$ \\
Planejaram & $9(14,2)$ & $5(6,9)$ \\
Enfoque negativo & $2(3,2)$ & $9(12,5)$ \\
\hline
\end{tabular}

FONTE: Elaborada pela autora

A respeito do questionamento sobre a descoberta da gestação, algumas mulheres responderam sobre os sentimentos envolvidos e outras sobre como efetivamente descobriram que estavam grávidas. As respostas que referiram sentimentos foram alocadas nas categorias: Ambivalência, Enfoque positivo e Enfoque negativo. Os temas sobre como descobriram a gestação foram 
agrupados nas categorias: Sinais típicos da gravidez, Rotina/tratamento e Planejaram.

Nas gestantes com diagnóstico de câncer os discursos que representam a categoria "Ambivalência" são:

Minha descoberta foi...não foi nem feliz e nem alegre, que eu não sabia qual era o problema que vinha. Eu fiquei feliz e ao mesmo tempo fiquei triste né, por saber que, que a neném tinha tomado radiação, essas coisas, não sabia como ela, como ela vem. É, era uma gravidez muito esperada, mas, eu me preocupei com o neném. (protocolo 42, 41 anos, câncer de mama)

Ah...no começo eu fiquei meio abatida né, mas depois eu relevei porque falei: Ah, já que veio vamos...aí eu vim pra cá, os médicos me recebeu muito bem e tal...eu não queria fazer quimioterapia devido o bebê e tudo, mas daí os médicos já falou que assim, eu fiquei com medo de ter malformação do bebê, mas aí foi normal e eu fui tirando um pouco de preocupação. Eu fiquei abatida por causa do meu tratamento, eu estava tão focada no meu tratamento que eu não esperava uma gravidez, mas assim, quando eu soube da gravidez, bom...eu fiquei super feliz, mas fiquei um pouco preocupada também. (p.53, 38 anos, câncer de mama).

Segue um relato que representa a categoria "Ambivalência" entre as gestantes sem o diagnóstico de câncer:

Eu descobri eu estava de quatro mês de gestação, e pra mim foi um susto. E não esperava, não estava planejando a gravidez, e no começo eu não aceitava né, mas depois eu fui aceitando. O tempo foi passando, e hoje eu estou feliz que eu vou ser mãe. (p.74, 33 anos)

A seguir alguns relatos que demonstram como as gestantes com câncer descobriram a gestação por meio de "Sinais típicos":

A minha menstruação estava atrasada 10 dias. Como estava atrasada e eu estava sentindo muito mal, fiz o exame da farmácia e daí deu positivo. Eu fiquei na dúvida, fiz outro teste, deu positivo de novo. Aí fiz o ultrassom, e no ultrassom já mostrou que eu estava com 2 meses. (p.7, 21 anos, câncer de ovário)

Nessa troca de remédio que eu fiquei grávida. Comecei a me sentir estranha, enjoar, e falei: vou ver se desce, todo dia 26 desce; se não 
descer, vou fazer um exame de farmácia. Aí fiz, e descobri que estava grávida. (p.21, 27 anos, câncer de intestino)

Ah, eu estava comendo bastante! Notei que eu estava comendo uma quantidade muito maior do que eu costumo geralmente e sempre sentindo fome. Aí a minha irmã foi lá e comprou o teste, eu fiz e deu positivo. (p.47, 24 anos, câncer de mama)

Nas gestantes sem diagnóstico de câncer, esta categoria está demonstrada no exemplo a seguir:

Foi de repente, porque minha menstruação atrasou uns vinte dias e eu comecei achar estranho; meu esposo também achou estranho e pediu pra eu fazer um teste. Aí eu fiz um de urina e deu positivo, mas ainda assim eu não acreditei, fui no posto de saúde e fiz mais um e deu positivo. (p.61, 32 anos)

Os relatos das gestantes com diagnóstico de câncer descrevem a categoria "Enfoque positivo" conforme evidenciado a seguir:

Ah, pra mim foi interessante porque até que eu gostei de receber a notícia, porque como eu já tinha conversado com a médica, se depois do tratamento eu poderia ter mais um filho, ela falou que a possibilidade é rara, né. Que é difícil, então, apesar de tudo que eu estou passando, eu fiquei muito feliz. (p.23, 36 anos, câncer de mama)

Foi muito bom porque eu estava tentando há cinco anos. Foi um milagre na minha vida. (p.126, 32 anos, câncer de intestino)

E, nas gestantes sem câncer, segue um relato que elucida o mesmo tema:

Foi maravilhosa a experiência porque eu e meu marido estávamos planejando ter outro filho e quando soube que estava grávida foi aquela festa. Meu filho também ficou super feliz porque queria ter uma irmãzinha, então foi tudo muito feliz. (p.107, 29 anos)

Os relatos a seguir descrevem a categoria "Rotina/tratamento" nas gestantes com diagnóstico de câncer: 
Num exame de rotina. Eu fui fazer um papa e o médico já falou que eu estava grávida. Quando descobriu, pediu o exame e já deu positivo. De rotina, uma consulta de rotina. (p.4, 28 anos, câncer de mama)

Tem dois meses que eu descobri. Eu fui fazer um ultrassom, minha barriga começou a crescer, eu não estava menstruando, mas a médica falou que é normal, né. Por causa do problema de saúde. Daí eu fiz um ultrassom e deu que era, que eu estava grávida. De cinco meses. (p.22, 26 anos, câncer de pulmão)

Nas gestantes sem diagnóstico de câncer, a categoria "Rotina/tratamento" está demonstrada nos seguintes discursos:

Foi do nada, eu descobri que estava grávida porque tive infecção urinária e fiz o exame e descobri que estava grávida. Deu positivo. (p.72, 25 anos)

A categoria "Planejaram" está evidenciada nos relatos das gestantes com diagnóstico de câncer, a seguir:

É, eu pensei que estava grávida logo depois de uma semana, assim que a gente teve relação sem preservativo, que eu fiz as contas, vi que era um dia que provavelmente poderia engravidar. Daí eu fiz o teste para confirmar. E foi assim que eu descobri. (p.11, 24 anos, câncer de fígado)

Eu parei de tomar o remédio e alguns dias depois, eu fiz um teste de farmácia que deu positivo. Aí, fui no posto e foi diagnosticado gravidez. Aí comecei a fazer o pré-natal. (p.21, 27 anos, câncer de intestino)

Nas gestantes sem diagnóstico de câncer, o tema está evidenciado nas falas a seguir:

Eu acho que eu descobri no mesmo dia que ele foi feito digamos. Primeiro porque era comemoração de aniversário de casamento! (Risadas!) Depois que eu pensei mais ou menos na tabelinha e tudo, imaginei que fosse o dia. (p.115, 33 anos)

O discurso que retrata a categoria "Enfoque negativo", em uma gestante com diagnóstico de câncer: 
Ah, eu fiquei muita tensa, e não fiquei feliz. Eu fiquei muito preocupada e muito pra baixo mesmo. (p.122, 22 anos, câncer de pulmão)

Já os discursos que representam gestantes sem diagnóstico de câncer foram:

Ah foi um choque! Assim, eu desejava a gestação, mas não nesse momento, né, da minha vida. Então eu fiquei muito assustada. (p.95, 34 anos)

Foi inesperada, foi um choque, que eu jamais iria, como eu posso dizer, esperar isso, porque eu achava que não poderia engravidar, então foi um choque imenso. (p.124, 19 anos)

\subsubsection{Vivência do pré-natal}

Com relação à vivência do pré-natal, $71,4 \%$ das mulheres com diagnóstico de câncer e $86,1 \%$ sem este diagnóstico utilizaram enfoque positivo para descrevê-la. Os resultados estão apresentados na Tabela 14.

Tabela 14 - Distribuição dos dados de acordo com presença ou ausência de diagnóstico de câncer na gestação e a percepção sobre a vivência do pré-natal

\begin{tabular}{lcc}
\hline & \multicolumn{2}{c}{ Diagnóstico de câncer } \\
\hline & Presença & Ausência \\
Variáveis & $\mathbf{n}(\%)$ & $\mathbf{n}(\%)$ \\
Vivência do pré-natal & $\mathbf{n = 6 3}$ & $\mathbf{n = 7 2}$ \\
Enfoque positivo & & \\
Não opinou & $46(73,0)$ & $62(86,1)$ \\
Enfoque negativo & $12(19,1)$ & $8(11,1)$ \\
& $5(7,9)$ & $2(2,8)$ \\
\hline
\end{tabular}

FONTE: Elaborada pela autora

Nas gestantes com diagnóstico de câncer os discursos que representam a categoria "Enfoque positivo" foram:

Muito bom, muito bom! Excelente. Eu me sinto protegida aqui porque eu sei que estão cuidado muito bem, né? É maravilhoso! (p.27, 22 anos, câncer de pâncreas) 
Tá muito bom, todos os médicos tá em cima de mim, todos preocupado. E tão fazendo o máximo possível pra tá perto de mim e do bebê. Minha maior preocupação era ver como está o bebê. Mas eu fiz a ultrassom morfológica na primeira consulta; fiz, e fiquei mais tranquila porque tá tudo bem. Então, por enquanto tá tudo bom. (p.57, 22 anos, câncer ósseo)

Os relatos das gestantes sem diagnóstico de câncer que fazem alusão ao mesmo tema são:

Maravilhoso, ótimo, os médicos são muitos bons. Os médicos são excelentes, tiram todas as minhas dúvidas. (p.69, 24 anos de idade)

Tá tranquilo. Eu vou fazer exame agora para ver ela. Sempre me emociono quando vejo. (p.70, 36 anos de idade)

A seguir alguns relatos que exemplificam a categoria "Não opinou", nas gestantes com diagnóstico de câncer:

Comecei agora, então...não sei ainda. Já me falaram que vai ser muito bom, porque vou ter toda atenção que eu precisar, né? Vão me encaminhar, tudinho certinho. Não estou preocupada, não. (p.12, 30 anos, câncer de mama)

Da mesma forma, algumas gestantes sem diagnóstico de câncer não opinaram, conforme demonstrado a seguir:

Ah, é que no caso eu ainda não comecei, mas eu estou ansiosa pra começar. (p.95, 34 anos)

Os relatos das gestantes com diagnóstico de câncer que descrevem a categoria "Enfoque negativo" são:

Cansativo, né. Porque passa no mastologista, no obstetra, vários exames que tenho que fazer. É o plástico que tem que vir também. $E$ isso pra mim é muito cansativo. Hoje mesmo eu tenho duas consultas, tenho a consulta com a doutora, tenho o exame e vou ter o ultrassom só na parte da tarde. Então vou ter que ficar aqui esperando o dia inteiro. Semana passada vim três dias na semana. É cansativo. (p.8, 34 anos, câncer de mama) 
Nas gestantes sem diagnóstico de câncer, esta categoria está demonstrada no seguinte exemplo:

O pré-natal está sendo bastante cansativo porque eu moro longe. São muitas visitas. (p.118, 29 anos)

\subsubsection{Relacionamento com o feto}

De acordo com a percepção das mulheres sobre o relacionamento que estabelecem com o feto, 38,1\% das gestantes com câncer e 38,9\% das gestantes sem o diagnóstico de câncer relataram como forma de interação a conversa. Estes resultados estão apresentados na Tabela 15.

Tabela 15 - Distribuição dos dados de acordo com presença ou ausência de diagnóstico de câncer na gestação e a percepção sobre o relacionamento com o feto

\begin{tabular}{lcc}
\hline & \multicolumn{2}{c}{ Diagnóstico de câncer } \\
\hline Variáveis & $\begin{array}{c}\text { Presença } \\
\mathbf{n}(\%)\end{array}$ & $\begin{array}{c}\text { Ausência } \\
\mathbf{n}(\%)\end{array}$ \\
& $\mathbf{n}=63$ & $\mathbf{n}=72$ \\
Relacionamento com o feto & & \\
Conversa & $24(38,1)$ & $28(38,9)$ \\
Bom relacionamento & $17(27,0)$ & $21(29,2)$ \\
Medo & $10(15,9)$ & $3(4,2)$ \\
Alegria & $5(7,9)$ & $15(20,8)$ \\
Milagre & $5(7,9)$ & $1(1,4)$ \\
Não se relaciona & $2(3,2)$ & $4(5,5)$ \\
\hline
\end{tabular}

FONTE: Elaborada pela autora

Os discursos a seguir descrevem a categoria "Conversa", nas gestantes com diagnóstico de câncer:

Olha! Eu converso bastante com ela, viu. Meu esposo também, ela não pode ouvir a voz do pai que começa a chutar. (p.7, 21 anos, câncer de ovário)

Ah, eu converso bastante com ele, né. Ainda mais agora que eu descobri também que eu estou doente, né, eu converso bastante com ele, falo que vai dar tudo certo, né. Mas tá indo bem também. 
Ele parece que me responde também. Tudo bem. (p.16, 40 anos, câncer de mama)

Nas gestantes sem diagnóstico de câncer, os relatos que seguem representam a mesma temática:

Tenho conversado bastante com ele na barriga. Ele tem se mexido bastante à noite. Ele mexe, às vezes, ao ponto de incomodar. Então eu converso bastante, acaricio a barriga, tento ter uma relação legal com ele. (p.132, 32 anos)

De vez em quando assim, eu converso com ele, passo a mão na barriga, sinto que ele tá me ouvindo, meu esposo também é a mesma coisa. Meu esposo conversa até mais com ele do que eu, mas tá gostoso. (p.61, 32 anos)

A categoria "Bom relacionamento" pode ser demonstrada a seguir nas narrativas das gestantes com diagnóstico de câncer:

Ah, tudo bem. Tá ótimo a minha, a minha relação com ele. (p.28, 23 anos, câncer de colo de útero)

Eu nunca tive nenhum problema nas minhas gravidezes, eu aceitei muito bem os meus filhos e foram as gravidezes assim, bem tranquilas. Essa estou aceitando normal também, apesar de ser mais delicada, estou me relacionando bem. Logo eu trago meu bebê aqui pra você ver. (p.12, 30 anos, câncer de mama)

Segue relato que representa a mesma categoria entre as gestantes sem o diagnóstico de câncer:

Muito bem. Eu tento me relacionar bem com ele desde quando eu descobri. (p. 88, 22 anos)

As narrativas das gestantes com diagnóstico de câncer se referem à categoria "Medo", conforme listadas a seguir:

No começo foi como eu te falei. Eu tinha um pouco de medo, tipo assim, por que fui engravidar agora? Não dava pra esperar um pouco? Ou algo parecido assim. Porque eu achava que o bebê veio 
pra atrapalhar o tratamento, digamos assim. (p. 8, 34 anos, câncer de mama)

Porque antes era muita preocupação. Na verdade antes da cirurgia eu fiquei morrendo de medo, e depois que eu fiz a cirurgia. O médico falou pra mim, ou eu fazia a cirurgia, ou eu deixava avançar mais o câncer até ele nascer. Então foi muito preocupante. Mas depois da cirurgia eu comecei amar ele. (p. 27, 22 anos, câncer de pâncreas)

A mesma temática pode ser demonstrada por meio do discurso de uma gestante sem diagnóstico de câncer:

No começo assim, eu fiquei um pouco assustada porque eu queria ser mãe, mas eu não queria assim...como eu posso dizer...eu queria que fosse mais preparado assim, tivesse mais organizado. (p. 62, 28 anos)

Um pouco de medo. Tanto que todas as dúvidas que eu tenho, eu tenho um caderninho que eu anoto pra doutora. Questionei da última vez se era normal ele mexer muito, ela falou que era. Que como é a minha primeira gestação, então eu não conheço nada, não sei nada, né? (p. 104, 34 anos)

Seguem alguns relatos que exemplificam a categoria "Alegria", nas gestantes com diagnóstico de câncer.

Muito bem. Muito feliz. Agora eu estou morrendo de ansiedade pra começar a mexer, eu começar a ler pra ele, tocar, porque eu toco música clássica e tenho vontade de fazer isso pra ele, pra ele escutar e ficar um bebê calminho. (p. 57, 22 anos, câncer ósseo)

Muito bem. Uma alegria, né? Tá tudo ótimo! (p. 6, 25 anos, câncer ósseo)

O relato a seguir também abrange a mesma categoria nas gestantes sem diagnóstico de câncer.

Agora tá uma maravilha, muito bom, a gente sente mexer, uma sensação, no meu caso, tipo maravilhosa, sempre quis. (p. 60, 28 anos)

Ah, muito bem, assim, cada dia que passa é uma felicidade que toma conta assim, de mim, eu fico pensando nele todos os dias, 
imaginando o rostinho. Só falta ele nascer agora, a gente tá bem preparado pra recebê-lo. (p. 125, 34 anos)

A categoria "Milagre" pode ser demonstrada por meio das narrativas de gestantes com diagnóstico de câncer a seguir:

Os médicos também me falavam que a possibilidade da Vitória viver dentro da minha barriga, sendo operada, não era muito grande. Mas foi uma bênção, um milagre. Tá aí pra contar a história, continuidade de vida. (p. 13, 25 anos, câncer de fígado)

Estou amando ele a cada dia. É uma coisa nova. Parece que eu tenho alguém aqui comigo, que me dá força, eu me sinto mais forte, bem mais forte, com esse neném aqui. (p. 17, 30 anos, câncer de mama)

Nas gestantes sem diagnóstico de câncer, a mesma temática pode ser percebida pela seguinte fala:

Posso dizer assim: que ele não nasceu ainda, mas já tá sendo minha razão sabe?! Tá me dando mais disposição pra fazer um monte de coisas. E sei lá...agora é só ele e eu, eu e ele. (p. 100, 21 anos)

Os trechos a seguir, oriundos de respostas de gestantes com diagnóstico de câncer, referem-se à categoria "Não se relaciona":

Ah, devido a esses problemas que aconteceram, às vezes eu até esqueço que eu estou grávida, não me relaciono ainda com ele. ( $\mathrm{p}$. 33, 31 anos, câncer de mama)

Olha! Eu não costumo me relacionar com o meu bebê, eu acho que meu bebê...eu espero ele nascer pra me relacionar com ele. Eu não consigo ficar conversando com a barriga, essas coisas. (p. 127, 38 anos, câncer de mama)

Seguem alguns discursos de gestantes sem diagnóstico de câncer que demonstram o mesmo tema:

Ah, eu... a minha vida é muito corrida. Sempre tenho muita coisa pra fazer, é trabalho ou os afazeres de casa, as minhas outras 
filhas...então eu tento dar um pouco de atenção, mas como ele não está fisicamente presente, aqui necessitando de mais atenção, talvez eu não esteja dando atenção pra ele, não esteja me relacionando como deveria. (p. 130, 29 anos)

Porque é assim, como eu tenho outro menino, de dois anos e cinco meses, acaba me tomando muito tempo. Diferente dele porque quando eu estava grávida dele a atenção era mais na barriga, tinha essa coisa de conversar e agora é um tempo que eu não tenho. Por que ele exige muito de mim. Aí acaba que eu não tenho muito tempo em relação ao bebê. (p. 115, 33 anos)

\subsubsection{Significado de gravidez}

Ao serem questionadas sobre qual o significado de gravidez para elas, a maioria das respostas, em ambos os grupos, utilizaram enfoque positivo, conforme demonstrado na Tabela 16.

Tabela 16 - Distribuição dos dados de acordo com presença ou ausência de diagnóstico de câncer na gestação e o significado atribuído à gravidez

\begin{tabular}{lcc}
\hline & \multicolumn{2}{c}{ Diagnóstico de câncer } \\
\hline \multirow{2}{*}{ Variáveis } & $\begin{array}{c}\text { Presença } \\
\mathbf{n}(\%)\end{array}$ & $\begin{array}{c}\text { Ausência } \\
\mathbf{n}(\%) \\
\end{array}$ \\
Significado de gravidez & $\mathbf{n = 6 3}$ & $\mathbf{n = 7 2}$ \\
Enfoque positivo & $50(79,3)$ & $53(73,6)$ \\
Responsabilidade & $12(19,1)$ & $18(25,0)$ \\
Não sabe explicar & $1(1,6)$ & $1(1,4)$ \\
\hline
\end{tabular}

FONTE: Elaborada pela autora

As narrativas das gestantes com diagnóstico de câncer fazem referência à categoria "Enfoque positivo" nos seguintes casos:

Ah, é um ser que tá dentro da gente, né. Essa gravidez pra mim tá mudando muito minha vida, porque acho que Deus já me deu essa gravidez pra ocupar a minha mente em relação à doença, o resultado que eu ia receber da doença. Então acho que a gravidez veio pra ocupar a minha mente. Então pra mim está sendo muito bom. (p. 16, 40 anos, câncer de mama)

É uma coisa muito especial, não sei dizer o que é; gravidez, né? Porque é um momento único, a gente é mãe, é muito especial. Uma 
coisa muito especial, divina. Acho que é uma coisa divina. Só Deus mesmo pra, né, nascer um ser dentro da gente, né, formar, né? Divino. Uma bênção de Deus. (p. 25, 35 anos, câncer de mama)

Eu acho que é como se tivesse me completado como mulher. Ser uma mulher e poder ter um filho pra mim já me completa assim. Depois que eu tiver meu bebê, posso dizer que eu sou uma mulher completa. (p. 11, 24 anos, câncer de fígado)

O mesmo tema pode ser demonstrado nas falas de gestantes sem diagnóstico de câncer:

Uma mudança de vida, mudança pra melhor. Readaptação e redescobrimento, é isso que significa pra mim. Uma realização! ( $p$. 101,38 anos)

É a continuidade da vida, né? Tem um significado muito amplo, né? Pra mim a gravidez é a etapa da vinda de outro ser humano; então, o que eu posso falar mesmo é esperar a vinda dele, é a continuidade da vida. (p. 95, 34 anos)

A categoria "Responsabilidade" pode ser demonstrada nas narrativas das gestantes com diagnóstico de câncer, a seguir:

Responsabilidade. Bastante responsabilidade, e uma certa preocupação. Eu acredito que é isso. Não mais do que isso. Acho que é a parte mais preocupante, é a responsabilidade, né. Porque independente de como venha seu filho, será responsabilidade pra sempre, né. É isso. (p. 21, 27 anos, câncer de intestino)

Que significa gravidez pra mim? Significa uma grande vida que tá chegando aí no mundo aí, que vai precisar de mim por algum tempo, entendeu. E peço a Deus todo dia pra me ajudar na minha saúde pra mim criar pelo menos eles, meus filhos, porque, é, como eu vou dizer pra você, eu não tenho assim muita esperança mais de vida sabe, pelo tanto de coisa que eu passei na minha vida, pra mim já bastou, entendeu? (p. 13, 25 anos, câncer de fígado)

Da mesma forma, este tema pode ser percebido em uma fala de gestante sem diagnóstico de câncer.

Uma responsabilidade, você pensar em uma pessoa indefesa que depende de você! (p. 110, 25 anos) 
Os relatos de gestantes com diagnóstico de câncer, a seguir, descrevem a categoria "Não sabe explicar":

Não sei, nesse momento agora eu não sei. [demora] Desculpa. Sei lá, não sei explicar. (p. 33, 31 anos, câncer de mama)

Com relação ao mesmo, uma fala de uma gestante sem diagnóstico de câncer exemplifica este tema:

Nem sei... como é a minha primeira gravidez ainda não sei dizer bem como é que é. Isso aí eu não sei. (p. 106, 25 anos)

\subsubsection{Entrevistas realizadas com as gestantes com diagnóstico de câncer}

Os discursos apresentados a seguir versam sobre os temas: a descoberta da doença, vivência do tratamento do câncer, adaptação ao adoecimento, crenças sobre o relacionamento com o feto, a vivência do câncer com a gestação e o significado atribuído ao câncer.

\subsubsection{Descoberta do câncer}

Com relação ao questionamento sobre a descoberta do câncer, 39,7\% das mulheres relataram sentimentos de choque, conforme Tabela 17.

\begin{tabular}{ccc} 
Tabela 17 - Distribuição dos dados de acordo com presença de \\
$\begin{array}{c}\text { diagnóstico de câncer na gestação e a percepção sobre a } \\
\text { descoberta do câncer }\end{array}$ \\
\hline Descoberta do câncer & $\mathbf{n = 6 3}$ & $\%$ \\
\hline Choque & 25 & 39,7 \\
Autopercepção & 21 & 33,4 \\
Rotina/tratamento & 13 & 20,6 \\
Otimismo & 4 & 6,3 \\
\hline
\end{tabular}

FONTE: Elaborada pela autora

A categoria "Choque" pode ser observada nos seguintes relatos: 
Foi um baque, na verdade, porque eu não imaginava, uma coisa que eu... surgiu do nada. Então o dia que ele me falou eu fiquei meio atordoada, eu estava sozinha, era perto do Natal. Saí consultório atordoada e eu tinha que buscar o meu marido. (p. 20, 39 anos, câncer de colo de útero)

Quando eu descobri, eu não imaginava, porque eu não tenho sintomas. Eu não imaginava passar por isso, e na hora que o médico me falou, assim, minha real situação, a verdade clara assim, me choquei bastante, na hora. Eu fiquei um pouco triste, fiquei depressiva, né? Mas de momento assim, foi um choque pra mim. Porque eu não imaginava. (p. 28, 23 anos, câncer de colo de útero)

Os discursos que representam a categoria "Autopercepção" foram:

Eu estou com um nódulo, é um caroço, apareceu um caroço, um carocinho no meu seio, eu mesma achei esse caroço. Aí eu falei com a doutora lá, que eu passei no posto, né; aí ela pediu pra mim passar com a mastologista. E foi quando a doutora foi e falou que eu fiz o ultrassom da mama, mamografia, aí eu descobri aqui que eu estava com câncer, deu maligno. (p. 16, 40 anos, câncer de mama)

Então...eu sempre me apalpei. Aí chegou um dia eu apertei o mamilo, e saiu uma secreção. Não era só sangue. Tinha uma aguinha misturada. Aí eu até achei que era da gestação passada. Aí falei "deve ter ficado algum leite e deve tá saindo", alguma coisa parecida com isso. Mas aí eu fui no ginecologista do posto, e eu falei com ele. Ele mandou fazer um ultrassom da mama, só que no ultrassom não deu nada. E continuou saindo essa secreção. Fiz uma mamografia. Foi aí que eu descobri. (p. 8, 34 anos, câncer de mama)

Os relatos a seguir descrevem a categoria "Rotina/Tratamento":

Foi por um acaso. Não foi, a gente não sabia, eu fui pra fazer um exame de rotina e fiz, aí ele foi me pedindo outros, outros e outros e aí deram o diagnóstico. (p. 35, 30anos, câncer de intestino)

Ah, então, como eu estava falando, eu fiz lá a biópsia, né, pra fazer esse tratamento que de 6 em 6 meses a médica tinha que fazer, aí numa dessas consultas ela resolveu pediu para fazer a biópsia por causa do nódulo e constatou que eu tava com câncer. Só isso, depois desse dia ela me pediu pra transferir pra cá, pras Clínicas, 
porque aqui eu ia ter acompanhamento no médico tanto da mama quanto do pré-natal. (p. 43, 26 anos, câncer de mama).

A categoria "Otimismo" está representada por meio das seguintes narrativas:

Foi bom porque eu descobri no começo. Porque eu queria ficar grávida, e no meu caso, na minha família, ninguém tem câncer, então eu nunca imaginei que eu ia ter câncer. E como minha família é grande, minha mãe teve nove filhos...família grande e ninguém teve esse caso, só eu. Então, não fiquei assustada, como todo mundo pensava que eu ia ficar, entendeu? Pensei: vou tratar e pronto! (p. 42, 41 anos, câncer de mama)

Eu acho que foi a parte mais tranquila. Acho que porque eu já tinha passado na família, então, eu não entrei em pânico não. Sei que tem tratamento. (p. 56, 32 anos, câncer de mama)

\subsubsection{Vivência do tratamento do câncer}

Os resultados apresentados na Tabela 18 se referem às categorias definidas a partir do questionamento sobre como percebem o seu tratamento para o câncer, e onde $38,1 \%$ das mulheres utilizaram enfoque negativo neste contexto.

Tabela 18 - Distribuição dos dados de acordo com presença de diagnóstico de câncer na gestação e a percepção sobre a vivência do tratamento

\begin{tabular}{ccc}
\hline $\begin{array}{c}\text { Vivência do tratamento } \\
\text { do câncer }\end{array}$ & $\mathbf{n = 6 3}$ & $\%$ \\
\hline Enfoque negativo & 25 & 39,7 \\
Não está em tratamento & 21 & 33,3 \\
Enfoque positivo & 11 & 17,5 \\
Normal & 6 & 9,5 \\
\hline
\end{tabular}

FONTE: Elaborada pela autora

No que se refere à categoria "Enfoque negativo", foram incluídos relatos sobre a vivência do tratamento por meio de diferentes aspectos. A seguir estão apresentados alguns sobre a dificuldade de enfrentar o tratamento pelo cansaço: 
Tá sendo difícil, porque conciliar a gestação com o tratamento tá sendo um pouco difícil. Tenho que praticamente morar aqui. Tá sendo um pouco difícil pra mim. Eu tenho que repetir toda semana todos os exames que é para saber se está crescendo, se tá diminuindo, como é que tá. (p. 2, 40 anos, câncer de mama)

Outros relatos que evidenciam o cansaço relacionado ao tratamento:

Faço tudo. Venho todas as vezes. É cansativo, mas eu venho em todas as consultas, faço tudo direitinho. (p. 8, 34 anos, câncer de mama)

Também há relatos que tratam dos aspectos negativos relacionados ao sofrimento que o tratamento causa:

A única coisa que eu sofri mesmo foi com a cirurgia, que eu tive um corte muito grande, porque estava muito grande. Eles cortaram minha barriga de assim, levei 30 pontos. Foi bem dolorido a cirurgia. (p. 7, 21 anos, câncer de ovário)

Ah...está um pouco difícil, mas...a quimioterapia, os efeitos...mas dá para superar, dá para levar. (p. 52, 29 anos, câncer de mama)

Mais aspectos se referem às dúvidas que ele suscita:

Isso é que tá mais me prejudicando, me sentindo mal, porque eu não tenho resposta. E pra mim tá crescendo mais e mais. Não sei como eu vou ficar depois do tratamento. (p. 17, 30 anos, câncer de mama)

Difícil, difícil, porque nada resolve. O tratamento estou fazendo, mas não tem certeza, nenhum tem certeza. (p. 29, 18 anos, câncer no cérebro)

$\mathrm{Na}$ categoria "Enfoque positivo" estão relacionados temas que se referem à possibilidade de enfrentamento, pelo aprendizado e pela excelência dos profissionais e do serviço aos quais são submetidas. Alguns relatos evidenciam esta categoria, conforme os seguintes exemplos:

Por enquanto graças a Deus só estou encontrando pessoas boas, profissionais bons, né, que tranquiliza a gente. E você sabe que tá em boas mãos. Isso tá me apoiando bastante, né, dando força 
também. Porque a gente sabe que está nos melhores hospitais, tem solução. Isso tá sendo bom. (p. 25, 35 anos, câncer de mama)

Então...mas depois que eles me falaram que estava tudo bem, que a cirurgia foi um sucesso, aí foi onde eu falei assim: gente, eu tenho que abrir o olho e se eu passei por tudo isso foi porque tinha que ter passado, pra ver se aprendia alguma coisa, pra, tanto de coisa que deixei porque Deus queria que eu ficasse curada, porque na época que eu descobri que eu estava doente. Tem sido um aprendizado. (p. 36, 24 anos, câncer de pulmão)

A categoria "Normal" pode ser exemplificada nas falas a seguir:

Ah, tá normal por enquanto. Por enquanto eu não vi resultado nenhum. (p. 10, 25 anos, câncer de colo de útero)

Normal. É...tem uns altos e baixos, mas normal. Eu até agora não tenho sentido nada, nenhuma reação, assim; normal. (p. 12, 30 anos, câncer de mama)

\subsubsection{Adaptação ao adoecimento}

Com relação à adaptação ao adoecimento observamos que 63,5\% tiveram algum tipo de relato que remetia à aceitação, conforme demonstrado na Tabela 19.

Tabela 19 - Distribuição dos dados de acordo com presença de diagnóstico de câncer na gestação e a percepção sobre a adaptação ao adoecimento

\begin{tabular}{ccc}
\hline Adaptação ao adoecimento & $\mathbf{n = 6 3}$ & $\%$ \\
\hline Aceitação & 40 & 63,5 \\
Não aceitação & 10 & 15,9 \\
Negação & 7 & 11,1 \\
Medo & 4 & 6,3 \\
Revolta & 2 & 3,2 \\
\hline
\end{tabular}

FONTE: Elaborada pela autora

No que diz respeito à categoria "Aceitação" foram incluídos todos os discursos que versavam sobre aceitar a doença de alguma forma; no entanto, nesta mesma categoria apareceram discursos de diferentes formas de aceitação: adaptação, apoio recebido, pelo desafio, pela fé, foco no bebê, pela 
esperança de cura. A seguir apresentamos os discursos que ilustram a aceitação por meio da adaptação à doença:

Agora eu já estou mais adaptada. Estou aceitando bastante, embora é, seja, seja difícil. Eu sei que eu preciso me tratar pra me curar, e é isso que eu estou fazendo. Eu aceitei. Embora não, eu não esperasse, não imaginasse, mas enfim, apareceu. Então mesmo sendo difícil, mesmo às vezes eu parando, chorando e me sentindo mais triste, eu aceitei. (p. 20, 39 anos, câncer de colo de útero)

Segue um exemplo sobre a aceitação relacionada ao apoio recebido de familiares:

Ah! No início foi difícil, agora eu já acostumei e estou conseguindo. Está tranquilo, porque eu estou tendo apoio do meu marido. A gente está procurando, correndo atrás, vai dar tudo certo. (p. 2, 40 anos, câncer de mama)

Foi muito ruim, porque eu nunca esperava. Foi de repente, em um mês apareceu a doença em mim do nada, porque até então eu nem sabia que tinha isso. E de repente minha barriga cresceu em menos de um mês, e aí eu fui fazer o exame e descobri que era câncer, então...eu fiquei...nossa eu fiquei muito triste! Foi muito ruim, mas eu tive o apoio total da minha família, do meu marido, de todo mundo, então...foi fácil de superar, né? É, porque estava todo mundo me apoiando. Então foi mais fácil. (p. 7, 21 anos, câncer de ovário)

O fato de encarar a doença como um desafio:

Sei lá...um desafio, uma prova, não sei. (p. 52, 29 anos, câncer de mama)

A fé em Deus:

Não, antes eu chorava muito, né?! Toda vez que eu fazia algum exame e aprecia alguma coisa eu já chorava. Agora não. Eu tenho fé em Deus. Também, muito, tenho bastante. (p. 4, 28 anos, câncer de mama)

Agora eu vou falar pra senhora, é, a minha relação entre esse problema aí, é só; me apego muito com Deus, eu peço muito pra Deus cuidar de mim, entendeu. Pra não deixar nenhum desse problema acabar com a minha vida, pra mim continuar criando os 
meus filhos, e quando eu cumprir minha missão poder me levar. Estou pronta pra ir embora. (p. 13, 25 anos, câncer de fígado)

O foco no bebê ou nos outros filhos para ter forças de enfrentar a doença:

Eu estava com medo antes. Eu prefiro me tratar, tirar o peito e ficar bem porque eu tenho outros filhos, então eu tenho que ficar bem por causa deles também. Não, eu penso assim, ainda bem que aconteceu comigo e não é com meus filhos. (p. 8, 34 anos, câncer de mama)

Ah, no começo eu não aceitei. Mas agora só penso no bebê. (p. 35, 30 anos, câncer de intestino)

E, a esperança na cura:

Agora estou aceitando bem, e estou fazendo o máximo pra me curar logo. Isso. (p. 15, 25 anos, câncer de tireóide)

Eu preciso estar bem. Eu...eu busco força. Estou fazendo tudo que tem que ser feito, porque eu creio na cura. (p. 34, 38 anos, câncer de mama)

A categoria "Não aceitação da doença" pode ser evidenciada pelo relato a seguir:

Ah, a gente não aceita, né? Igual eu sou, eu me acho nova, mas é uma coisa pra mim, mas tá, tem que seguir em frente, só isso. ( $\mathrm{p}$. 32, 25 anos, câncer de mama)

Ah, é muito ruim. Parece que toda hora aparece na televisão casos de pessoas que morrem de câncer, filme de gente morrendo de câncer. E câncer não tem cura, e câncer isso, câncer aquilo. Parece que você só ouve a parte ruim da história. Não sei se é um pouco psicológico; pode ser, né? Você começa a sentir dor nas outras partes do corpo, e aí você já acha que tá relacionado a isso. (p. 33, anos, 31 câncer de mama)

A seguir alguns relatos que demonstram a categoria "Negação": 
Tento não lembrar dela, tento ver como uma doença qualquer, não como uma coisa que pode te matar. Uma coisa qualquer, pra não entrar em depressão. Porque se a gente for ficar pensando, né, tô com câncer, vou passar por isso, por aquilo, né. Eu tento não pensar nela. (p. 25, 35 anos, câncer de mama)

Não penso muito nela na verdade. Quero muito que avance o tratamento, mas eu não penso; quanto antes, a ideia de me ver livre dela. Mas eu não, não, não penso muito. (p. 30, anos, 36 câncer de mama)

O "Medo" é uma categoria que pode ser observada nas narrativas que se seguem:

Com a doença...no começo a gente fica muito pensativa, né. A gente não sabe como vai ser o tratamento, como a gente vai ficar, o que vai acontecer. Então a gente fica muito, assim, muito medo, na mente da gente. Muito medo. (p. 50, anos, 35 câncer de mama)

Então doutora. Eu sinto assim, muito, muito medo. Porque assim...eu lembro muito da minha irmã que teve câncer. Ela sofreu demais. É...ela quando foi descoberto ela estava com 25 anos. Os médicos não acreditavam, né; falavam que não podia ser. Então eu fico pensando demais, sabe... E não quero passar as coisas que ela passou. Sinto muito medo. (p. 9, 30 anos, câncer de mama)

Alguns discursos que exemplificam a categoria "Revolta" estão relacionados a seguir:

Ah, eu fico meia revoltada. Fico, porque você sempre tem aquela esperança, né, que pronto, acabou assim, vai ser a última vez. Quando você menos espera, não adianta nada, quase nada. Então fico brava. Meio nervosa. Nervosa mesmo, fico estressada. Aí eu me estranho com todo mundo, não quero atenção de ninguém. Fico quieta no meu canto. Aí eu fico quietinha, não consigo conversar, não consigo fazer nada. Fico quieta no meu canto, não gosto que ninguém fale comigo também. (p. 29, 18 anos, câncer no cérebro)

Em casa, é, algumas pessoas que não sabem, não ficam sabendo, porque eu também não gosto de ficar falando. Conhecidos, assim. Agora, aqui no hospital eu converso, é melhor. Mas lá, já na rua, assim, eu não gosto de falar. Porque tem gente até que, tem umas pessoas que encontrei esses dias que, comecei a sair de casa esses dias; "nossa, fiquei sabendo que você tá com câncer". Parecia, do jeito que eles falaram, que eu ia morrer. Parecia que eu ia morrer, 
sabe? Fico muito revoltada com isso. Então eu não, pra mim eu não gosto de compartilhar muito, pra falar. (p. 27, 22 anos, câncer de pâncreas)

\subsubsection{Crenças sobre o relacionamento com o feto}

Com relação às crenças sobre o relacionamento com o feto pelo fato de estarem vivenciando a gravidez com o adoecimento pelo câncer, 38,1\% relataram que este relacionamento Ihes dá um sentido à vida, conforme Tabela 20.

Tabela 20 - Distribuição dos dados de acordo com presença de diagnóstico de câncer na gestação e as crenças sobre o relacionamento com o feto

\begin{tabular}{ccc}
\hline Crenças sobre o & $\mathbf{n = 6 3}$ & $\%$ \\
relacionamento com o feto & 24 & 38,1 \\
Sentido à vida & 18 & 28,6 \\
Preocupação & 17 & 27,0 \\
Nada muda & 4 & 6,3 \\
Carinho &
\end{tabular}

FONTE: Elaborada pela autora

Com relação à categoria "Sentido à vida", as mulheres referiram que a maneira de se relacionar com o feto é diferente pelas seguintes condições: mais força para lutar, dão mais valor à vida, a relação com o feto torna-se especial, a percepção de que a gravidez veio para salvá-las e que esquecem a parte ruim da doença porque pensam mais no bebê, conforme os relatos a seguir:

Sim. Porque eu acho que o bebê, assim, dá mais força de você lutar, de você querer vencer a doença, pra você cuidar dele, entendeu? De cuidar, que ele precisa da gente pra tudo, né? Mas daí é uma satisfação. Eu acho que altera sim, pra melhor. É uma vitória. (p. 25, 35 anos, câncer de mama)

Eu acho que a mulher que tem câncer junto com a gravidez, eu acho que dá até mais força. Acho que eu tenho até mais força do que se eu tivesse o câncer sem o bebê. Não, tá sendo mais iluminada, mais abençoada. (p. 51, 31 anos, câncer de palato) 
Às vezes eu tenho a sensação de que o bebê veio justamente pra, entre aspas, pra me salvar né, pra gente descobrir tudo isso e, porque eu acredito realmente na cura. Eu acho que o bebê veio até, sei lá, talvez veio pra me ajudar também, com tudo isso aí. É um milagre! (p. 20, 39 anos, câncer de colo de útero)

Acredito que sim. Porque é uma nova vida. Você, praticamente, tá quase morrendo...porque essa doença é bem difícil. Aí de repente você tá dando uma vida pra alguém! (p. 22, 26 anos, câncer de pulmão)

Exemplos da categoria "Preocupação" vêm na sequência:

Sim. É mais preocupação, né, de se vai vir bem a criança. Essa preocupação a gente sempre tem com a gravidez, mas pelo fato de você, no meu caso que eu tive que passar por duas cirurgias, acho que foi mais difícil. É, você tem muito mais preocupação. Você não pensa no bebê? Vai vir parecido com o pai, vai vir parecido com a mãe. Não. Hoje você pensa assim, meu filho tem que vir saudável, será que ele vem saudável ou vai vir com algum problema neurológico, ou será que ele vem com algum problema de físico. Essa é minha preocupação hoje. (p. 8, 34 anos, câncer de mama)

Você acha que ele pode nascer também com deformações, com...no meu caso que a doença podia causar, porque é problema hormonal, né, poderia causar deformações na criança. E eu ficava com muito medo, e eu falei assim: gente, mas eu não vou poder tirar essa criança, e se ela nascer deformada? Minha cabeça virou um tormento nessa época, porque eu fiquei imaginando horrores. Pensei que não ia aguentar nem chegar até o final. Mas é muito difícil uma pessoa que tem câncer ficar grávida. (p. 36, 24 anos, câncer de pulmão)

Eu sei que eu não vou poder amamentar, mas eu sei que tem leite que você pode dar. Fico preocupada com isso. (p. 17, 30 anos, câncer de mama)

A categoria "Nada muda" pode ser demonstrada nas narrativas das gestantes que seguem:

Eu acho que não. Eu não me relaciono com o bebê de forma diferente. E...eu converso normal, como nas minhas outras gravidez; eu acho que não. Eu acho que é a mesma coisa. (p. 9, 30 anos, câncer de mama) 
Eu me relaciono com o meu bebê praticamente normal. Normal, praticamente eu me relaciono, mas eu acredito sim que existe. ( $p$. 24, 40 anos, câncer de mama)

"Carinho" foi a denominação da categoria exemplificada nas frases a seguir:

Eu acho que sim. É, está sendo diferente. Pela minha gestação de antes, né? Eu agora, eu converso mais, falo pra ele assim, que se eu não sobreviver, né, se eu durar muito pouco, quem vai cuidar vai ser a tia dele. Então assim, eu converso muito mais com ele do que com os meus primeiros. Conversava, mas nem muito assim. Eu acho que eu estou me relacionando mais com esse daqui. (p. 16, 40 anos, câncer de mama)

Sim, né, não vou falar que não. É, eu acho que sim porque você trata com mais carinho. Você passa a ver a vida com outro sentido também. Passa a cuidar mais ainda do seu filho. Se já cuida bem, passa a cuidar melhor ainda, né, dá mais valor também. (p. 28, 23 anos, câncer de colo de útero)

Sim, sou mais apegada, agradeço muito o bebê, acredito que sim. Eu pelo menos sou. Sim. (p. 35, 30 anos, câncer de intestino)

\subsubsection{Vivência do câncer na gestação}

A Tabela 21 apresenta os resultados relacionados ao questionamento sobre a vivência do câncer na gestação, sendo que $47,6 \%$ das gestantes referiram algum aspecto negativo em seu discurso e $22,2 \%$ aspectos positivos.

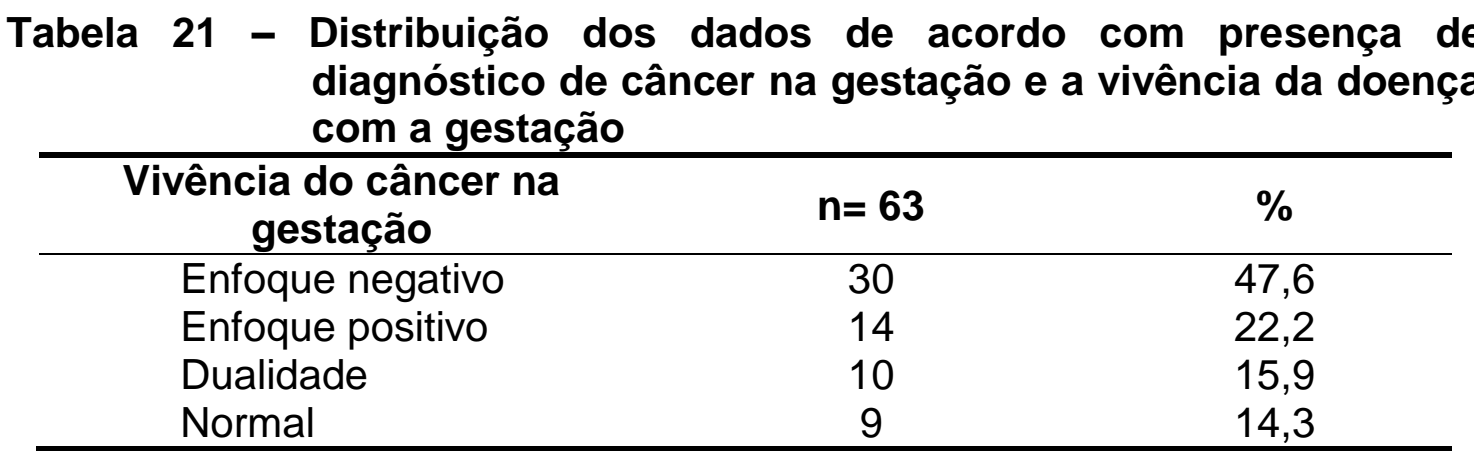

FONTE: Elaborada pela autora 
Os relatos das gestantes com diagnóstico de câncer que descrevem a categoria "Enfoque negativo" foram:

Tenho medo de acontecer alguma coisa quando ele nascer. Toda mãe pensa, e se acontecer alguma coisa comigo, ele vai ficar com quem? (p. 27, 22 anos, câncer de pâncreas)

Tem dia que eu não quero tomar o remédio, mas aí eu fico com medo de não tomar e o cérebro do bebê dar problema. É complicado. É preciso eu tomar, mas eu fico pensando: "e se eu salvar a minha pele e acabar prejudicando ele?" Eu não quero que aconteça nada de ruim com ele. Eu já tenho passado muita coisa difícil, não queria passar por isso, queria respirar um pouquinho tranquila. (p. 31, 37 anos, câncer de tireoide)

A categoria "Enfoque positivo" está evidenciada nestes relatos:

Bem, como eu falei, penso mais na gestação do que no câncer. Principalmente quando eu começo a pensar, né, começa a mexer, aí já começo a esquecer a doença, só penso nele mesmo. Só no neném mesmo. Cuidar dele, né; fico imaginando, sonho com ele, com o rostinho dele, é isso. (p. 25, 35 anos, câncer de mama)

Como eu falei, a gravidez veio pra me dar força, e é ela que tem me dado. Eu sei que...que é possível! Estou me sentindo muito bem, é como se ele, ele fosse uma bênção, entendeu? (p. 34, 38 anos, câncer de mama)

É, eu acho que agora tá num momento, tá, caminha separado, eu acho que caminha separado. Então também por isso é interessante o que eu penso, assim, interessante eu me cuidar pra poder combater a doença e seguir com a gravidez mais forte. (p. 30, 36 anos, câncer de mama)

A categoria "Dualidade" está representada nos seguintes discursos:

Contraditórios, né? Um fala da morte, outro fala da vida. Eu acho contraditório, mas não dou espaço, na verdade. Acredito que não vai aparecer, estou muito tranquila; e se aparecer, que a gente vai resolver da melhor forma possível. (p. 41, 29 anos, câncer de mama)

Eu acho que é ao mesmo tempo uma alegria e ao mesmo tempo uma tristeza, né? (p. 6, 25 anos, câncer ósseo) 
Ah, de um lado tá bom, mas de um outro você vê que vai ser difícil, né? Eu não sei se faz bem pro bebê, tem cirurgia também. Fico ao mesmo tempo $50 \%$ tranquila e $50 \%$ preocupada, às vezes. Às vezes tem hora que eu estou bem, tranquila. Aí daí tem hora que eu já fico meio preocupada, paro pra pensar, daí fico um pouco preocupada. (p. 29, 18 anos, câncer no cérebro)

Segue relato que demonstra a categoria "Normal":

Normal, eu acho. Eu acho que está super normal, parece que pra mim...às vezes até esqueço que eu tenho câncer. As coisas que eu faço, eu fiz na gravidez anterior, estou fazendo ainda, normal. Pra mim tá sendo normal, não tá sendo muito diferente. (p. 37, 43 anos, câncer de mama)

\subsubsection{Significado atribuído ao câncer}

Os significados atribuídos à palavra câncer versaram sobre representações de morte e sofrimento em 41,2\%, das gestantes entrevistadas, conforme evidenciado na Tabela 22.

Tabela 22 - Distribuição dos dados de acordo com presença de diagnóstico de câncer na gestação e o significado atribuído ao câncer

\begin{tabular}{ccc}
\hline $\begin{array}{l}\text { Significado atribuído ao } \\
\text { câncer }\end{array}$ & $\mathbf{n = 6 3}$ & $\%$ \\
\hline Morte/sofrimento & 26 & 41,2 \\
Cura/tratamento & 25 & 39,7 \\
Superação & 10 & 15,9 \\
Causa & 2 & 3,2 \\
\hline
\end{tabular}

FONTE: Elaborada pela autora

A seguir estão relacionadas algumas frases que identificam a categoria "Morte/sofrimento":

Olha, eu não sei, significa a morte, o fim da vida porque, é, não é fácil...é uma doença, ah, é uma doença, uma coisa muito difícil de se encarar; e não é fácil. Câncer pra mim é morrer, porque é lutar, é batalhar, é uma coisa horrível; é uma coisa horrível. É isso a classificação pra mim. (p. 12, 30 anos, câncer de mama) 
Ah, câncer pra mim é uma coisa muito ruim, que ela mutila as pessoas, ela acaba com as pessoas aos poucos, né? Vai, que a pessoa vai se definhando. Pra mim é isso, é uma coisa ruim que vai acabando com a pessoa aos poucos. (p. 23, 36 anos, câncer de mama)

O que significa câncer. Significa tudo que tem de ruim pra acontecer, no ser humano. Eu acho que, mesmo que você se cure, te marca muito, que vai te marcar pro resto da vida. Que acontece pra te derrubar mesmo! Pra querer quebrar você todinha e você não ter nem meios que se levantar. Mais força daquele que tem força pra levantar. (p. 36, 24 anos, câncer de pulmão)

Essa doença é uma desgraça. É um sofrimento, não tem o que falar, é um...é uma doença que, sei lá, acaba com todo mundo, uma coisa que você não espera, né, e vem de repente, assim, é um baque. ( $\mathrm{p}$. 7, 21 anos, câncer de ovário)

As declarações que seguem representam a categoria "Cura/tratamento":

Hoje; hoje é cura. Antigamente não, mas hoje eu acredito que hoje pode curar, tudo no começo. Eu acredito na cura. (p. 6, 25 anos, câncer ósseo)

Bom, antes, se fosse antes a gente pensava: morte! Hoje não. Um tratamento, uma fase da vida que tem que passar, difícil, né, mas vai ter que passar por isso. (p. 25, 35 anos, câncer de mama)

Uma doença destrutiva, te mata aos poucos, mas que devido à tecnologia, os estudos, a gente consegue, os médicos conseguem recuperar a gente. Uma doença a ser tratada. (p. 35, 30 anos, câncer de intestino)

A categoria "Superação" pode ser demonstrada por meio das seguintes narrativas:

Antes de eu, dessa, desse meu problema, significava muito, mas depois do que eu passei, e eu vi: graças a Deus, foi fácil de lidar com isso e superar tudo isso. Eu consegui superar isso. (p. 26, 24 anos, câncer de fígado)

Uma lição de vida. (p. 42, 41 anos, câncer de mama)

Ah, ele é uma doença terrível, mas eu acho que ao mesmo tempo que é uma doença terrível, a gente pode aprender muita coisa. É um aprendizado. A gente aprende a olhar com a força que pessoas 
normais sem nenhuma doença nunca olharia. (p. 57, 22 anos, câncer ósseo)

Os discursos que seguem identificam a categoria denominada "Causa":

Eu acho que quando você tá muito triste assim...como se suas células ficassem assim da mesma forma. Então, quando você fica entristecido, aí, as suas células ficam da mesma forma e não vivem bem; e aí quando chega nessa fase, é como se tivesse doente permanentemente. Aí você não volta mais assim. Eu acho que é o mais difícil, assim, pra todo mundo que escuta essa palavra. Você tem esse diagnóstico. Mas se você se entristece de tudo, é como se não voltasse a célula nunca mais. Você e o seu corpo. Eu acho que o câncer, a doença em si, se comporta da mesma forma. (p. 21, 27 anos, câncer de intestino)

Coisas mal resolvidas. (p. 41, 29 anos, câncer de mama) 


\section{DISCUSSÃO}

Neste trabalho foram avaliadas sintomatologia de depressão e ansiedade, autoestima e vínculo materno fetal em gestantes com câncer. As duas condições em separado, a gestação e o adoecimento por câncer, representam situações de maior vulnerabilidade a transtornos emocionais. A vivência das duas situações simultaneamente representa um risco potencial para o sofrimento psicológico e esta ocorrência precisa ser investigada servindo de indicador para o planejamento de ações na assistência pré-natal. Além disso, câncer e depressão são considerados importantes problemas de saúde pública.

São poucos os estudos sobre o impacto emocional causado pela experiência do câncer na gravide $z^{17,215}$, o que torna relevante o estudo desta temática.

Com relação aos dados sociodemográficos, constatou-se diferença significativa entre os resultados de renda per capita, trabalho remunerado, escolaridade e paridade.

A renda per capita foi menor no grupo de gestantes com câncer. A doença associada à gestação pode ser um impeditivo para o trabalho remunerado, estando as gestantes com câncer mais sujeitas a uma série de consultas médicas e realização de exames, dificultando o ingresso ou a permanência no trabalho formal, comprometendo sua renda.

Isto se confirma nos resultados da combinação realizada entre diagnóstico de câncer e diagnóstico de depressão onde a renda per capita mostrou associação significativa com o diagnóstico de câncer e não com depressão.

Na comparação entre os grupos, as gestantes sem câncer apresentaram maior nível de escolaridade. Acredita-se que esta diferença esteja relacionada a características da amostra do grupo controle que foi composto por mulheres que realizam o pré-natal em um hospital de nível terciário, porém pertencem a um ambulatório de gestantes sem intercorrências clínicas, composto, em sua maioria, por funcionárias da própria instituição. 
Cabe ressaltar que os grupos foram pareados pela idade gestacional e não pela escolaridade, uma vez que esta diferença foi prevista no início do estudo e considerado que, para este trabalho, a escolaridade diferente não traria prejuízo significativo na associação dos dados entre os grupos.

Da mesma forma, com relação à paridade, as gestantes sem câncer eram em maior número nulíparas. Esta diferença também pode ser atribuída às características do grupo controle. Cabe ressaltar que o fato de terem outros filhos e estarem grávidas com câncer pode representar preocupações adicionais.

Ives et al. ${ }^{21}$, por meio de entrevistas qualitativas com 15 mulheres que receberam o diagnóstico de câncer de mama na gestação e que, na maioria, tinham outros filhos, apresenta relatos de receios relacionados ao desejo de sobreviverem e verem seus filhos crescerem.

A maioria das gestantes com câncer engravidou depois de ter conhecimento do diagnóstico de câncer. Esta condição pode incitar uma reflexão sobre a questão da maternidade após um diagnóstico de câncer. $O$ fato das mulheres engravidarem após o diagnóstico de câncer pode auxiliá-las a enfrentar as adversidades do tratamento e da doença, pelo fato da gravidez fomentar uma ideia de esperança, força e vida.

Isto se confirma na literatura, em um estudo ${ }^{19}$ qualitativo em que os autores utilizaram entrevistas semiestruturadas com seis gestantes com câncer. Os relatos das mulheres que engravidaram estando com câncer estavam relacionados a ideias de saúde, juventude, felicidade e sensação de poder por conseguirem engravidar apesar da doença.

Em outro estudo ${ }^{23}$ qualitativo que também utilizou entrevistas semiestruturadas, desenvolvido com três gestantes com diagnóstico de câncer, observou-se relatos sobre a gravidez após o câncer com uma conotação de milagre, dádiva, possibilidade de cura e como acontecimento capaz de transformar suas vidas.

O câncer de mama foi o mais frequente na população estudada. Também é o mais frequente nas mulheres no país do estudo correspondendo à estimativa de 60 mil casos no biênio 2018-2019 216 . Associado à gravidez pode representar uma perda importante, pelo risco da impossibilidade da 
amamentação, levantando fantasias de não estar cumprindo o seu papel de mãe de forma eficiente, conforme pode ser contatado na análise qualitativa realizada neste estudo.

Apesar do câncer de mama estar mais diretamente relacionado ao simbolismo do feminino e consequentemente da gestação, o diagnóstico de câncer em si, independentemente da sua localização, remete ao conflito existencial que diz respeito à vida e a morte, impactando diretamente o psiquismo destas mulheres.

Com relação à avaliação de depressão, constatou-se diferença significativa entre os dois grupos, onde as gestantes com câncer tiveram maior prevalência de depressão do que gestantes sem diagnóstico de câncer.

A literatura apresenta dados sobre o aumento da prevalência de depressão na gestação ${ }^{77,93}$, na gestação de alto risco ${ }^{9}$ e no adoecimento por câncer ${ }^{107}$.

Porém, com relação à presença de depressão em gestantes com câncer foi encontrado um único estudo ${ }^{17}$ que avaliou 74 gestantes utilizando a escala BSI-18, e este não evidenciou aumento da depressão nesta população, discordando dos dados do presente estudo. É possível que a diferença entre os estudos estejam relacionadas aos instrumentos utilizados e que o foco do estudo não foi avaliar depressão, mas sim o sofrimento psicológico em gestantes com câncer.

Os estudos ${ }^{18-23}$ encontrados na literatura abordam aspectos mais abrangentes do sofrimento psicológico, e com isso, pode-se dizer que alguns fatores levam ao aumento da depressão e a estes estão relacionadas consequências físicas e emocionais do tratamento ${ }^{217}$, o medo da morte ${ }^{19}$, do nascimento de um filho com malformação ${ }^{19}$.

A depressão no período gestacional é fator preocupante. Tal fato pode ser corroborado pela recomendação do American College of Obstetricians and Gynecologists $^{218}$ que destaca a necessidade da realização de um rastreamento para depressão durante a gravidez e reforçado pelo Royal College of Obstetricians and Gynecologists (RCOG) na indicação de que os profissionais de saúde devem indagar sobre o humor de uma gestante para identificar 
possíveis sinais de depressão durante a gravidez no primeiro encontro com os serviços de pré-natal ${ }^{219}$.

Isso leva a pensar que as consequências físicas e emocionais do tratamento remetem a um sentimento de falta de controle sobre o seu próprio destino, diante das limitações que ele acarreta na vida do indivíduo, gerando sentimentos de medo e insegurança ${ }^{217}$. As implicações emocionais frente às incertezas com relação à própria saúde e a saúde do feto são riscos emocionais potenciais principalmente relacionados ao conflito entre receber 0 melhor tratamento e não afetar a saúde do feto ${ }^{220}$.

Junta-se a isso: os medos da morte, do nascimento do filho com uma malformação, de deixar os outros filhos sozinhos, de não ter condições adequadas de cuidar deles, da dor e sofrimento ${ }^{19}$.

Estes devem ser considerados na assistência pré-natal das mulheres uma vez que as tornam mais vulneráveis ao aumento do sofrimento ampliando o risco para a depressão. Além dos fatores de risco, as consequências da depressão materna também devem ser consideradas.

Outro problema apontado no estudo desenvolvido por Lindegren et al. ${ }^{221}$ é que mulheres grávidas que estão deprimidas podem ser menos propensas a se envolver em práticas positivas de saúde, como comparecer às consultas de rotina no pré-natal, dormir o suficiente e aderir a práticas saudáveis.

Além disso, a depressão no período gestacional é considerada fator de risco para o desenvolvimento da depressão pós-parto. Esta preocupação tornase pertinente na medida em que os estudos apontam que a presença de depressão pós-parto leva a consequências negativas no desenvolvimento do recém-nascido, assim como problemas emocionais e comportamentais, dificuldades de apego e déficits $\operatorname{cog}$ itivos ${ }^{209}$.

Stern $^{222}$ destaca que diante de uma depressão materna, a mulher pode se tornar menos responsiva em relação ao seu bebê e menos sensível, portanto, às necessidades que ele apresenta. A relação com a mãe vai sendo aprendida pelo bebê por meio de eventos cotidianos como o olhar, o sorriso, o falar, cantar com o bebê, que estaria seriamente prejudicado diante da presença do diagnóstico de depressão, pois interações estariam permeadas 
por meio de microeventos não-responsivos: um sorriso que não retorna, uma fala que não se estabelece, ou um olhar que não perdura.

Apesar da importância de considerar a associação entre os efeitos da depressão materna no desenvolvimento infantil ${ }^{223}$, esta se encontra permeada por diversas variáveis confundidoras, dificultando o estabelecimento de uma relação direta entre eles. Herba et al. ${ }^{224}$ destacam que uma série de outros fatores ambientais e sociais podem estar vinculados, o que acaba por impedir uma associação direta de causa e efeito entre as variáveis já que são multifatoriais.

Em estudo de revisão de literatura Biaggi et al. ${ }^{225}$ apontaram que a depressão não tratada leva a uma repetição do ciclo de sofrimento psicológico impedindo o desenvolvimento em todas as áreas da vida.

Com relação aos sintomas de ansiedade, evidenciou-se diferença significativa entre os dois grupos estudados, sendo que as gestantes com câncer apresentaram níveis mais elevados de ansiedade. Quando a análise foi feita a partir dos grupos formados pela combinação de diagnóstico de câncer e de depressão, evidenciou-se que a ansiedade estava associada à depressão e não com o diagnóstico de câncer. Ou seja, as gestantes com diagnóstico de depressão apresentam níveis maiores de ansiedade do que as mulheres sem depressão, independentemente do diagnóstico de câncer.

Estes dados são confirmados na literatura que demonstra associação entre as duas sintomatologias ${ }^{226}$.

Na gestação é ainda mais difícil a detecção dos sintomas de ansiedade por causa da sobreposição dos sintomas de depressão e de gestação ${ }^{227}$.

Os sintomas de ansiedade podem passar despercebidos pelas equipes de saúde que cuidam das gestantes e até mesmo das próprias mulheres, que acabam não procurando ajuda para estes sintomas ${ }^{228}$.

A ansiedade e a depressão associadas podem elevar os níveis de sofrimento durante a gestação.

As gestantes com câncer apresentaram autoestima rebaixada em comparação às gestantes sem câncer, sendo que este resultado demonstrou significância estatística. Além disso, na comparação entre os grupos com diagnóstico de câncer e depressão, demonstrou que o rebaixamento da 
autoestima está relacionado à presença de câncer e não com outras variáveis. Independentemente das mulheres terem ou não depressão, aquelas que têm o diagnóstico de câncer têm escores menores para autoestima.

O adoecimento pelo câncer tem também um impacto direto na autoestima do indivíduo. Como a autoestima está relacionada à maneira como a pessoa se vê e se valoriza, com o adoecimento pelo câncer, o estigma que a doença carrega, a pessoa pode experimentar sentimentos de desvalorização de si mesmo pelo fato de estar doente.

Conforme demonstrado na literatura ${ }^{149}$, o diagnóstico de câncer afeta negativamente a autoestima devido a diversos fatores, como as mudanças na aparência física, os impedimentos à realização de atividades rotineiras, o estigma da doença, perda de emprego. O impacto emocional da doença afeta a imagem corporal, afetando por consequência a autoestima.

O adoecer leva a um sentimento de fracasso, de aumento da vulnerabilidade, de impossibilidade de cuidar de si e de impotência. É como se a pessoa ficasse identificada com a doença e com o que há de ruim nela. As perdas que o indivíduo experimenta com o câncer, limitações de atividades de vida diária, do trabalho e no relacionamento com as pessoas, é uma perda real que se expande para a uma instância que é psíquica ocupada pelas emoções. O que pode resultar em uma perda da estima por si mesmo.

Os sentimentos negativos, como raiva, medo, sensação de incapacidade de manter sua própria saúde, culpa, podem aparecer, aliados a uma dificuldade em administrá-los. Estes sentimentos passam a ser incorporados como uma representação de si mesmo como ruim, diminuindo a autoestima. Como se ela estivesse marcada pela doença.

Os temas recorrentes e que podem alterar a autoestima em gestantes com câncer são aqueles relacionados ao sentimento de fracasso por não poder ou por achar que não poderá cumprir de maneira eficaz com suas tarefas de mãe.

O aumento da depressão, ansiedade e rebaixamento da autoestima são importantes marcadores de saúde mental. Estas condições devem ser levadas em consideração na assistência pré-natal. 
Estar doente, de uma maneira geral, tem uma implicação psicológica importante. Tira a pessoa de uma condição de saúde e a obriga a se reposicionar frente à vida, em suas tarefas e nas perspectivas que visualizou para o futuro. $O$ indivíduo tem que lidar com situações que não eram esperadas e exigem um processo de adaptação.

Tanto a detecção como as intervenções devem estar associadas ao programa de pré-natal ${ }^{193,229}$ e devem incluir as equipes multiprofissionais. A equipe de saúde, quando instrumentalizada para perceber os marcadores de depressão e ansiedade, pode encaminhar para um profissional especializado neste tipo de intervenção.

Ações direcionadas à família e ao companheiro também são necessárias, uma vez que a literatura comprova a importância da família para o apoio $^{225}$.

Com relação ao vínculo materno-fetal não foram identificadas diferenças nos grupos estudados de gestantes com e sem diagnóstico de câncer.

De acordo com a literatura ${ }^{215,230}$, o diagnóstico de câncer na gestação pode comprometer o vínculo com o feto, mas isto não foi observado neste estudo. Este fator pode ser melhor compreendido a partir dos resultados qualitativos onde as mulheres descrevem que no relacionamento com o feto encontraram forças para lutar contra a doença.

Com relação à análise dos dados qualitativos, os resultados deste estudo permitiram compreender quais as ideias, percepções, sentimentos e preocupações das mulheres gestantes com câncer que poderão nortear os profissionais de saúde a pensar em intervenções para minimizar os riscos emocionais desta vivência.

Foram encontrados estudos qualitativos ${ }^{8,19-22}$ que alertaram para a importância de considerar os fatores emocionais envolvidos na vivência do câncer na gestação.

Os estudos que utilizam esta metodologia possibilitam a apreensão do significado atribuído a determinada experiência, facilitando a compreensão do fenômeno e a análise sobre sua aplicação na prática assistencial ${ }^{231}$. 
Com relação à descoberta da gestação, observaram-se relatos de ambivalência de sentimentos tanto pelas gestantes com câncer como pelas gestantes sem câncer.

Os discursos revelaram que nas gestantes com câncer um dos motivos mais frequentemente relatados para a ambivalência de sentimentos estava relacionado ao medo de que o tratamento trouxesse efeitos nocivos ao feto.

A descoberta da gravidez gera sentimentos contraditórios, como o desejo e a alegria em contrapartida a sentimentos de apreensão e dúvida, sendo comum a manifestação de sentimentos ambivalentes ${ }^{232}$.

Essas mesmas manifestações de medo da influência do tratamento na saúde do feto pode ser verificada em estudos ${ }^{19,21,22}$ qualitativos anteriores.

Ives et al. ${ }^{21}$ entrevistaram 15 gestantes com câncer, e nos discursos identificaram o conflito existente entre a preocupação com a saúde do bebê e a preocupação com sua própria saúde e bem-estar.

Rees et al. $^{22}$, na análise de três entrevistas identificaram que 0 diagnóstico de câncer perturbou suas expectativas e planos para a gravidez, relatando os medos dos efeitos do tratamento na saúde do feto.

Capelozza et al. ${ }^{19}$, em uma amostra de 11 gestantes com câncer que apesar do medo com relação à saúde do feto, a possibilidade da maternidade Ihes dava forças para lutar devido ao desejo de estarem saudáveis para cuidar do bebê após o nascimento.

As gestantes consideraram em seus relatos a contradição existente na experiência do câncer na gestação, demonstrando a capacidade de identificar as duas vertentes de um mesmo evento, não ficando restritas apenas à percepção aspectos positivos ou negativos.

Os relatos das gestantes sem diagnóstico de câncer estavam voltados para o inesperado da gravidez e o processo de aceitação da mesma. Como não tinham a vivência da doença associada, estavam relacionados à questão da maternidade em si. O que reforça a ideia de que os sentimentos ambivalentes nas gestantes com câncer ficam voltados para os aspectos da doença em relação à gravidez.

Reconhecer a ambivalência de sentimentos é uma competência psicológica adquirida no desenvolvimento humano que acompanha todos os 
relacionamentos afetivos. Identificar os sentimentos ambivalentes é sinal de disponibilidade emocional para interpretar os próprios sentimentos e que está a serviço de um mecanismo de adaptação ${ }^{233}$.

Alguns discursos das gestantes enfocaram somente aspectos positivos. Nestes, o conteúdo das falas teve um sentido de que a gratificação com relação à gravidez compensou o sofrimento causado pela doença e enalteceram os aspectos positivos desta situação. Assim, apesar de não verbalizarem os aspectos negativos em si, demonstraram a ideia de contradição de sentimentos.

Algumas gestantes, em contrapartida, conseguiram expressar claramente o fato de não terem gostado de ficar grávidas, denotando sentimentos de tensão e choque.

Ambas as situações precisam ser observadas, uma vez que 0 reconhecimento dos sentimentos contraditórios é necessário para a adaptação à condição vivenciada.

É importante que estes sentimentos sejam detectados durante o prénatal e que seja oferecido um espaço de intervenção psicológica para que as gestantes possam explorar estes sentimentos facilitando o processo de integração e adaptação e, com isso, lidar de maneira mais saudável com aquela condição.

Algumas gestantes ficaram focadas em respostas que descreveram de maneira mais concreta a maneira como descobriram a gestação, como por exemplo, por meio de sinais característicos da gestação, dentro de exames de rotina ou em seu tratamento. Muitas vezes a dificuldade de reconhecer os sentimentos e lidar com os aspectos ambivalentes e/ou negativos existentes favorecem as respostas descritivas. Ao serem perguntadas sobre a descoberta da gestação, no repertório de ideias e pensamentos sobre o fato, escolheram descrever o fato em si, não tendo, assim, que lidar com os sentimentos associados.

No que se refere à vivência do pré-natal, a maiorias das mulheres, independentemente de terem câncer ou não, em seus relatos deram um enfoque positivo ao programa, denotando satisfação. 
O que se observa no relato das gestantes com câncer é que elas referem, como positivo, conteúdos relacionados à proteção, apoio dos profissionais e à possibilidade de realização de exames que acabaram por deixá-las mais tranquilas com relação às preocupações que tinham sobre a saúde do feto.

Quando os pacientes sentem segurança no profissional e percebem que o serviço esclarece as suas dúvidas, isto oferece um conforto psicológico ${ }^{18}$.

Estes dados fornecem informações sobre a importância que os serviços de pré-natal têm para as mulheres que enfrentam adversidades em sua gestação. A literatura destaca a questão do apoio dos profissionais como um fator importante para diminuição de sentimentos de depressão, ansiedade ou qualquer outro sofrimento psicológico ${ }^{18,23}$.

Capelozza et al. ${ }^{19}$ concordam com a ideia de que a gestação é um momento de muitas dúvidas e questionamentos e que a adesão ao pré-natal depende da gestante se sentir cuidada e ter seus questionamentos respondidos.

Especificamente nas gestantes com câncer, alguns estudos ${ }^{20,21}$ relatam a importância que os pacientes atribuem à qualidade das informações recebidas, uma vez que a falta de informações ou informações confusas e contraditórias acabam por aumentar o desgaste emocional.

O enfoque negativo atribuído ao pré-natal estava relacionado à rotina do programa, pela distância percorrida e pela quantidade de consultas que tiveram que participar. Demonstram, portanto, de uma forma realista, as dificuldades impostas pelo fato de terem que conciliar o pré-natal com o tratamento para o câncer.

Os significados atribuídos à gravidez, em ambos os grupos, foram relacionados a ideias de transformação, divino, milagre, completude e continuidade da existência.

Esses relatos demonstram sentidos idealizados da gravidez que fazem parte do imaginário popular. Uma representação social é uma simbologia referente a determinado tema de acordo com um conhecimento que é construído e compartilhado em um grupo social. São ideias, valores ou teorias internalizadas pelos indivíduos e repetidas nos círculos sociais ${ }^{234}$. 
As representações sociais sobre a maternidade são idealizadas ${ }^{235}$. A idealização é um mecanismo psicológico de defesa em que os aspectos positivos são enaltecidos como uma forma de não entrar em contato com os aspectos ruins da mesma situação ${ }^{127}$.

Os significados encontrados nos discursos deste estudo têm consonância com dois estudos que também utilizaram entrevistas qualitativas e obtiveram ideias de milagre, transformação e cura $^{8}$; ou presente de vida, realização como mulher, vitória alcançada e dádiva divina ${ }^{23}$.

Algumas gestantes com câncer descreveram a possibilidade de ocupar a mente para não pensar na doença. Esta ideia também é encontrada no estudo de Capelozza et al. ${ }^{19}$ em que os relatos afirmam que a gravidez atenuou os sentimentos negativos por causa do diagnóstico de câncer.

Sobre a descoberta do câncer, as narrativas descreveram o momento do diagnóstico como um sentimento de choque.

O momento do diagnóstico representa um importante impacto psicológico por ser um período de intenso sofrimento, uma vez que faz o indivíduo pensar na questão da morte, gerando uma série de incertezas quanto ao futuro ${ }^{121}$.

Diante do diagnóstico de uma doença grave, a primeira reação do indivíduo é um estado temporário de choque. Este sentimento é esperado diante de situações de impacto emocional e dará início a um processo de reorganização psicológica gradual, em que será colocada à prova a maior ou menor capacidade de assimilar o acontecimento ${ }^{236}$.

Nos relatos obtidos neste estudo, o que levou ao sentimento de abalo emocional descrito como choque foram as seguintes ocorrências: o inesperado da situação, o fato de estarem sozinhas no momento do diagnóstico e o significado atribuído ao câncer relacionado à morte.

Isto se confirma na literatura, onde os significados associados ao câncer estão relacionados às ideias de morte, dor e sofrimento ${ }^{105}$.

Os estudos que tratam da questão do momento do diagnóstico orientam os profissionais com relação a alguns passos que devem ser respeitados, para que o paciente possa ter condições de assimilar uma notícia impactante do 
ponto de vista emocional e possa ser reorganizar, na medida do possível, para enfrentar todas as dificuldades impostas pela doença ${ }^{237}$.

Uma das condições a serem consideradas neste momento é a possibilidade do sujeito estar acompanhado de algum familiar. Receber a notícia sozinho e ter que se organizar para voltar para casa, por exemplo, pode ser perturbador e colocar a pessoa em risco ${ }^{237}$.

Em relação ao inesperado da situação, ninguém espera, em seu ritmo habitual de vida, receber um diagnóstico de câncer. O imprevisto, conforme foi descrito pelas mulheres deste estudo, dão ao evento uma conotação de traumático.

O trauma corresponde a um excesso de excitação que sobrecarrega emocionalmente o indivíduo de forma que os mecanismos psicológicos não conseguem assimilar aquela situação de maneira imediata. Representa um acúmulo de emoções em nível exacerbado em que o individuo não está possibilitado de organizá-las ${ }^{238}$.

O contexto do diagnóstico merece atenção especial da equipe de saúde, uma vez que as dificuldades inerentes a este processo podem representar complicações futuras com relação à aceitação da doença e ao tratamento ${ }^{237}$.

Outro padrão de respostas demonstrou relatos em que a forma de descoberta do câncer se deu a partir da percepção de algo diferente em seu corpo que as direcionou para uma investigação médica. Muitas delas relataram terem percebido um caroço no seio e isto as levou a procurar um médico.

Munhoz ${ }^{239}$, em um estudo que teve como objetivo descrever as características de serviços públicos ambulatoriais que atendem mulheres com câncer de mama, identificou que 65,38\% das mulheres perceberam algum problema mamário pelo autoexame em relação a 34,62\% que foram percebidos pelo médico.

O hábito do autoexame de mamas e da realização de exames de rotina são importantes questões de saúde pública e precisam estar no foco das práticas assistenciais para que as mulheres sejam incentivadas e conscientizadas com relação à relevância destas práticas.

Com relação ao tratamento, a maioria das gestantes conferiu uma conotação negativa. Estes estavam relacionados à dificuldade em conciliar o 
acompanhamento pré-natal e o tratamento para o câncer, o cansaço derivado desta situação, o sofrimento causado pelo tratamento em si e as incertezas que permeiam este momento.

O acúmulo de consultas médicas e exames que são esperados em uma gravidez de alto risco ficam intensificados com a rotina do tratamento para 0 câncer. Além disso, o tratamento é sofrido, invasivo e tem efeitos colaterais. Assim como o momento do diagnóstico, o tratamento para o câncer também é considerado um evento traumático ${ }^{240}$, pela intensidade emocional que ele representa ao indivíduo.

As incertezas descritas nos relatos estavam relacionadas à qualidade da informação médica.

Informações claras e precisas auxiliam os pacientes a conhecerem as possibilidades e limitações do tratamento, e, ainda que existam incertezas, quando estas são explicadas, é possível estabelecer uma relação de confiança com o profissional e a insegurança pode ficar diminuída ${ }^{240}$.

O apoio recebido pela equipe foi um aspecto positivo relatado em relação ao tratamento.

Fica claro que a atitude da equipe pode colaborar de forma positiva com o enfrentamento dos obstáculos provenientes da doença e do tratamento.

Quando questionadas sobre a adaptação ao adoecimento, a aceitação foi a ideia mais veiculada nos relatos obtidos.

A partir do momento que o sujeito se vê diante do câncer e suas implicações, ele não tem alternativas a não ser encontrar uma forma de seguir o seu caminho. A maneira como cada indivíduo vai seguir em frente vai depender de sua história pessoal e da maneira com que costuma enfrentar as situações adversas em sua vida ${ }^{240}$.

Os argumentos para a aceitação nos relatos obtidos estavam relacionados a aspectos de adaptação à doença, ao apoio recebido por parte dos familiares, ao desafio enfrentado, à fé, ao foco no bebê, e à esperança de cura.

Os sentimentos que demonstram o aprendizado com a experiência, a aceitação do diagnóstico, a crença nas possibilidades do tratamento e na cura, o apoio recebido dos familiares, o foco no feto, são condições que diminuem o 
sofrimento causado pelo diagnóstico de câncer e facilitam às mulheres encontrar mecanismos positivos de adaptação e de enfrentamento da doença.

A negação foi uma forma de lidar com a doença conforme alguns relatos.

A negação é uma estratégia de defesa utilizada por muitos indivíduos que recebem o diagnóstico de uma doença grave. É um mecanismo esperado para lidar com uma situação dolorosa emocionalmente, funcionando como se fosse um anteparo que possibilita a assimilação da experiência aos poucos, conforme a capacidade emocional individual permitir. Quando utilizado, trata-se de um mecanismo necessário para a adaptação ${ }^{236}$.

$\mathrm{O}$ medo foi um sentimento frequentemente relatado. Medo com relação às incertezas do tratamento, por causa de experiências ruins vivenciadas na família, medo de que alguma coisa acontecesse com o feto.

A raiva também apareceu nos discursos das pacientes, sendo relatada como revolta. A raiva foi descrita como um sentimento advindo da perda de esperança em alguns momentos e também dirigida a outras pessoas que relacionam o fato de estarem doentes com a possibilidade de morte.

Diante de uma notícia grave, vários mecanismos de defesa estão ativados e estes aparecem sob a forma de estágios. Quando não é mais possível manter o mecanismo de defesa da negação, ele pode ser substituído por estágios de revolta e ressentimento. Mas, como a negação, ele também é um dos passos a caminho da elaboração.

No que se refere aos significados atribuídos ao câncer, os discursos consistiram em ideias morte, mutilação, estigma e sofrimento. Estes sentidos têm respaldo na representação construída socialmente sobre o câncer.

No imaginário social as teorias desenvolvidas são levadas para o pensamento individual. Enquanto a ideia está no contexto do grupo social, ela é, na maioria das vezes, engessada. Somente quando a ideia vai para o campo individual subjetivo é possível fazer uma reflexão sobre ela ${ }^{241}$.

Portanto, uma alternativa para a conotação negativa da doença é poder subjetivá-la. Ou seja, retirá-la do campo coletivo e discorrer sobre o que realmente significa, e o que pensa sobre, como a vivência. Para isso o indivíduo tem que fazer uso da reflexão e sair de uma ideia mais superficial, 
localizando-a em sua própria história pessoal. Com relação ao câncer, a doença pode ser compreendida a partir de sua experiência particular e não baseada num pensamento coletivo ${ }^{241}$.

Em alguns discursos, os temas relacionados à cura e possibilidade de tratamento também aparecem. Nestes, há uma menção ao tempo cronológico, como por exemplo: "Hoje, é cura". Estes discursos fazem menção ao tempo atual e ao progresso da ciência e tecnologia para os tratamentos de câncer viabilizando a possibilidade de cura.

Outra ideia trazida pelas mulheres foi a de superação. Neste pensamento percebe-se também a possibilidade de uma reflexão maior sobre o tema, veiculando o adoecimento ao aprendizado que ele promove, apesar do sofrimento. Nestes discursos pode-se observar a capacidade humana de ressiginificar experiências dolorosas. O sofrimento humano é passível de transformação.

No que se refere ao relacionamento com o feto, o enfoque positivo foi o mais explorado em ambos os grupos. Das seis categorias definidas para a questão, quatro delas fazem referência a conteúdos positivos: "Conversa", "Bom relacionamento", "Alegria" e "Milagre". Estas foram separadas para poder dar uma melhor compreensão de qual o enfoque positivo foi atribuído pelas pacientes.

No discurso de algumas gestantes estas referem que ao conversar com o feto eles mexem mais. Também associaram outras características afetivas, como por exemplo, acariciar a barriga.

Conversar com o bebê denota uma expressão da vinculação com o feto. Está relacionado a um mecanismo de personificação do feto, atribuindo a ele características que lhe dão uma identidade, tornando-o mais real e conhecido $^{242}$.

Em relação às gestantes com câncer pode-se perceber que apesar das dificuldades relacionadas ao diagnóstico e tratamento do câncer, as mulheres conseguem estabelecer uma relação com o feto.

Analisar a forma como se estabelece o vínculo com o feto é relevante, uma vez que dificuldades neste processo podem interferir na vinculação posterior com o bebê ${ }^{36}$. Além disso, os agravos da doença podem levar a um 
aumento da depressão e ansiedade que também podem comprometer 0 vínculo ${ }^{14,16}$ posterior.

As gestantes com câncer atribuíram mais frequentemente ideias de medo e milagre do que as gestantes sem a doença. $O$ medo relacionado às possíveis consequências para o feto é relatado na literatura ${ }^{19,21}$.

Atribuir ao feto uma condição de milagre foi uma forma de expressar um sentimento de que o filho Ihes dá forças para enfrentar as adversidades. Também tem uma conotação de que algo que elas consideravam impossível, que era uma gravidez estando doentes de câncer, realmente aconteceu.

Em outro momento das entrevistas somente as gestantes com câncer foram questionadas se acreditavam que haveria mudanças no relacionamento com o feto por causa do diagnóstico do câncer.

As gestantes acreditam que ocorrem mudanças pelo fato de estarem grávidas com câncer. Isto pode ser percebido nos relatos que afirmam que os fetos passam a dar um sentido às suas vidas. Referem que eles thes dão mais força para lutar, para enfrentar a doença e que representam um milagre. Demonstração de um vínculo maior também foi percebida nos discursos de mulheres que relataram ter mais carinho.

Isto se confirma na literatura. Hsieh et al. ${ }^{24}$, por meio de entrevistas em um estudo qualitativo, estudaram as percepções sobre a gravidez em 16 mulheres após um câncer de mama e identificaram relatos que afirmavam que elas acreditavam que ter um bebê daria um novo significado às suas vidas $e$ que a possibilidade de ter um filho representava uma esperança.

Ao mesmo tempo têm mais preocupações do que teriam se não estivessem doentes. As preocupações com o feto estão relacionadas ao tratamento e ao medo de que este possa prejudicar a saúde do feto e o medo de malformação.

Segundo os discursos, o que ajuda nesta experiência é o apoio do companheiro, da família e da equipe.

Perceber um vínculo estabelecido com o feto é importante uma vez que este pode ser um fator de ajuda para o enfrentamento da doença como aparecem diversas vezes nos relatos das mulheres. Porém é necessário um 
acompanhamento por parte da equipe de saúde para que nada coloque em risco esta condição.

As narrativas obtidas neste estudo fornecem informações mais aprofundadas sobre os conteúdos psicológicos da vivência do câncer na gestação e que estão relacionados aos sintomas de depressão, ansiedade e autoestima rebaixada observados nos resultados quantitativos. Ambos os resultados se complementam e permitem inferir sobre os possíveis riscos para o desenvolvimento de transtornos emocionais na associação da gestação com o câncer.

A assistência às gestantes com câncer deve ser subsidiada por um psicólogo. A inserção de um psicólogo na equipe multidisciplinar, quando possível, auxilia os profissionais a compreender algumas nuances relacionadas à maneira como cada paciente vivencia esta situação e também oferece um espaço de escuta aos pacientes para que eles possam encontrar maneiras de lidar com este evento traumático.

Quando o evento tem implicações psicológicas que são mais intensas do que a capacidade psíquica do indivíduo pode suportar, gerando um sentimento de impotência, o auxílio psicoterapêutico pode ajudar a dar um novo significado para a sua vivência ${ }^{240}$.

A possibilidade de falar sobre si e sua doença, e com isso sobre o seu sofrimento e suas esperanças abre a possibilidade de lutar por si mesmo e visualizar perspectivas futuras. É por meio do discurso que a experiência pode ser subjetivada e encontrar um caminho para dar um novo significado a experiências tão dolorosas ${ }^{243}$.

Também com relação à depressão, quando é possível uma intervenção psicológica, apesar de toda complexidade existente, a depressão pode servir de motor para a recuperação de um sentido da vida que pode ter-se perdido frente à doença ${ }^{65}$. $O$ que pode ser feito em relação à dor emocional de estar doente é repensar de maneira criativa e aceitar as limitações impostas por ela. É claro que este é um processo complexo e que necessita da ajuda de profissionais preparados para isso ${ }^{65}$.

Capelozza et al. ${ }^{19}$ observaram que, ao serem questionadas sobre sua opinião a respeito do atendimento psicológico recebido, algumas gestantes 
com câncer relataram, em entrevistas semidirigidas, que as intervenções propiciaram um espaço seguro para a expressão de sentimentos e ajudaram a encontrar meios para a diminuição da ansiedade e da depressão. Consideraram que o atendimento psicológico foi importante, pois as ajudou a lidar com o processo do diagnóstico e tratamento.

Este estudo constitui uma contribuição significativa para a literatura, identificando variáveis associadas ao aumento da depressão e ansiedade, diminuição da autoestima em gestantes com câncer quando comparadas às gestantes sem câncer. É relevante, pois pode subsidiar o planejamento de ações voltadas para atenção em saúde coletiva minimizando os efeitos danosos desta problemática para a saúde mental das mulheres e sua família.

Uma limitação deste estudo refere-se ao fato do grupo controle ser composto por funcionárias de um hospital de nível terciário, não sendo possível fazer o pareamento por escolaridade, mas somente por idade gestacional. 


\section{CONCLUSÕES}

Este estudo constatou a presença de sintomatologia de depressão em $33,3 \%$ das gestantes com diagnóstico de câncer e em 18,1\% das gestantes sem diagnóstico de câncer, tendo sido evidenciado diferença estatística significativa $(p=0,041)$

No que diz respeito à ansiedade constatou-se que o grupo com diagnóstico de câncer apresentou, em média, maiores escores para ansiedade $(p=0,039)$.

$\mathrm{Na}$ avaliação de autoestima evidenciou-se mediana de escore menor no grupo de gestantes com câncer evidenciando autoestima rebaixada $(p<0,001)$.

$\mathrm{Na}$ análise feita por meio da combinação de diagnóstico de câncer e de depressão, evidenciou-se que a ansiedade estava associada à depressão e não com o diagnóstico de câncer. Com relação à autoestima, na combinação dos grupos evidenciou-se que o rebaixamento da autoestima está relacionado à presença de câncer e não com a depressão.

$\mathrm{Na}$ análise qualitativa, constatou-se que com relação ao relacionamento com 0 feto foram identificadas as seguintes categorias: Conversa, Bom relacionamento, Medo, Alegria, Milagre e Não se relaciona. Com relação à Vivência do câncer na gestação foram evidenciadas as categorias: Enfoque negativo, Enfoque positivo, Dualidade e Normal. Sobre o significado da gravidez, as categorias foram: Enfoque positivo, Responsabilidade e Não sabe explicar. Em relação ao significado atribuído ao câncer, as categorias demonstradas foram: Morte/sofrimento, Cura/tratamento, Superação e Causa. 


\section{ANEXOS}

Anexo A - ROTEIRO SOCIODEMOGRÁFICO

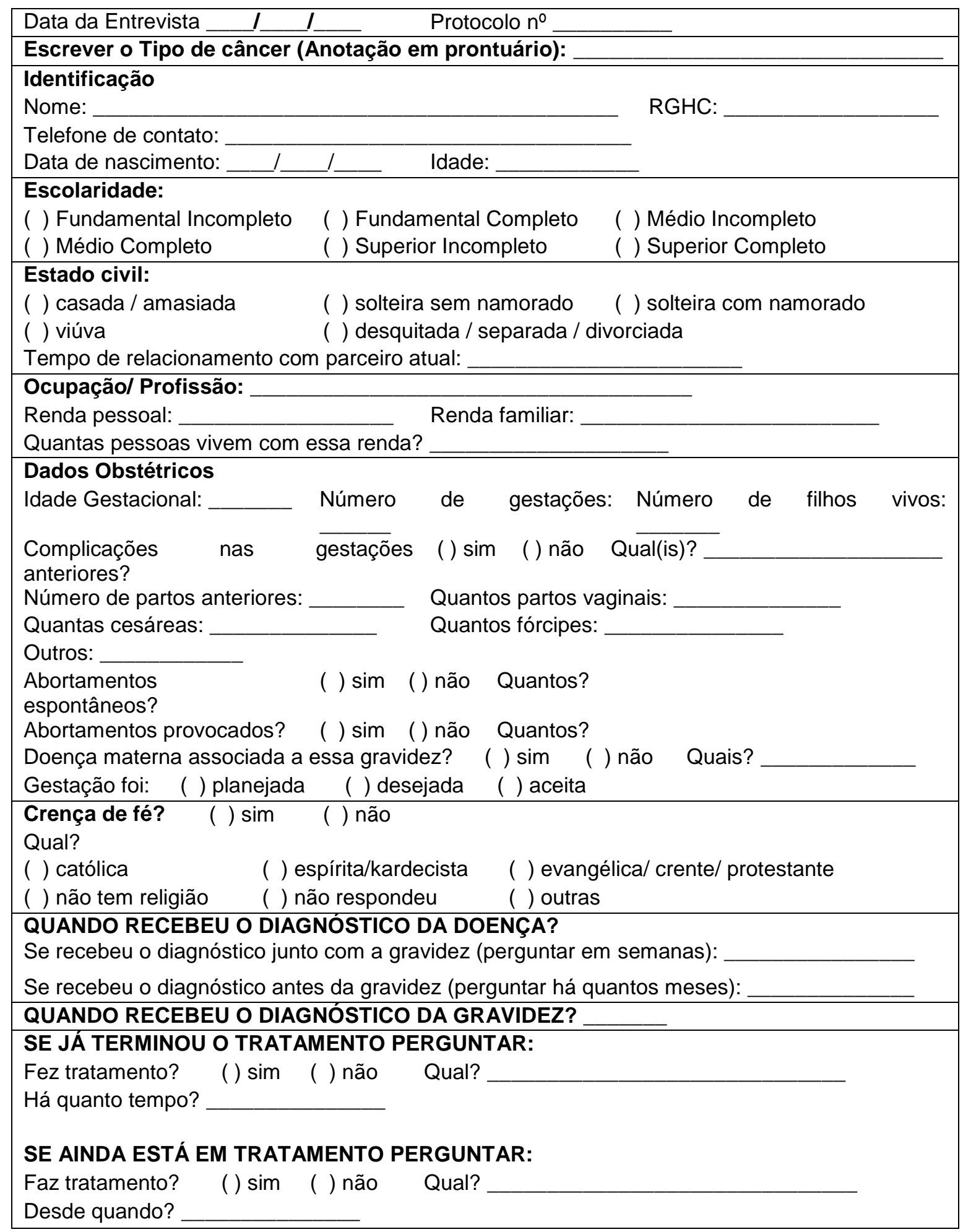




\section{Anexo B - Entrevista semidirigida}

\section{Entrevista - Gestantes com diagnóstico de câncer materno}

1. Conte-me como foi a descoberta da sua gestação.

2. Como está sendo o pré-natal?

3. Como você tem se relacionado com o bebê?

4. O que significa gravidez pra você?

5. Conte-me como foi a descoberta do câncer.

6. Como está sendo o tratamento do câncer?

7. Como você tem se relacionado com a doença?

8. Você acredita que as mulheres que tem câncer junto com a gravidez se relacionam com o bebê de forma diferente?

9. Como está a vivência do câncer com a gestação?

10. O que significa câncer pra você?

\section{Entrevista - Gestantes sem diagnóstico de câncer}

1. Conte-me como foi a descoberta da sua gestação.

2. Como está sendo o pré-natal?

3. Como você tem se relacionado com o bebê?

4. O que significa gravidez pra você? 


\section{Anexo C - Escala de apego materno-fetal}

Por favor, responda às perguntas seguintes sobre você e o bebê que você está esperando. Não existem respostas certas ou erradas. Sua primeira impressão é que mostra melhor seus sentimentos. Marque apenas uma resposta por pergunta.

Eu penso ou faço o seguinte

\begin{tabular}{|c|c|c|c|c|}
$\begin{array}{c}\text { quase } \\
\text { sempre }\end{array}$ & $\begin{array}{c}\text { freque } \\
\text { ntemen } \\
\text { te }\end{array}$ & $\begin{array}{c}\text { às } \\
\text { vezes }\end{array}$ & $\begin{array}{c}\text { rara } \\
\text { men } \\
\text { te }\end{array}$ & nunca \\
\hline & & & & \\
\hline
\end{tabular}

1. Eu converso com o meu bebê na barriga

2. Eu acho que apesar de toda dificuldade, a gravidez vale a pena

3. Eu gosto de ver minha barriga se mexer quando o bebê chuta

4. Eu me imagino alimentando o bebê

5. Eu realmente estou ansiosa para ver como vai ser o meu bebê

6. Eu me pergunto se o bebê se sente apertado lá dentro

7. Eu chamo o meu bebê por um apelido

8. Eu me imagino cuidando do bebê

9. Eu quase posso adivinhar qual vai ser a personalidade do meu bebê pelo modo como ele se mexe

10. Eu já decidi que nome eu vou dar se for uma menina

11. Eu faço coisas para manter a saúde que eu não faria se não estivesse grávida

12. Eu imagino se o bebê pode ouvir, dentro de mim

13. Eu já decidi que nome eu vou dar se for um menino

14. Eu imagino se o bebê pensa e sente "coisas" dentro de mim

15. Eu procuro comer o melhor que eu posso, para o meu bebê ter uma boa dieta

16. Parece que o meu bebê chuta e se mexe para me dizer que é hora de comer

17. Eu cutuco meu bebê para que ele me cutuque de volta

18. Eu mal posso esperar para segurar o bebê

19. Eu tento imaginar como o bebê vai se parecer

20. Eu acaricio minha barriga para acalmar o bebê quando ele chuta muito

21. Eu posso dizer quando o bebê tem soluço

22. Eu sinto que meu corpo está feio

23. Eu deixo de fazer certas coisas, para o bem do meu bebê

24. Eu tento pegar o pé do meu bebê para brincar com ele 


\section{Anexo D - Escala ‘Hospital Anxiety and Depression' - HAD}

\author{
A (1) Eu me sinto tenso ou contraído: \\ 3 ( ) A maior parte do tempo \\ 2( ) Boa parte do tempo \\ 1 ( ) De vez em quando \\ 0 ( ) Nunca
}

D (2) Eu ainda sinto gosto pelas mesmas coisas de antes:

0 ( ) Sim, do mesmo jeito que antes

1 ( ) Não tanto quanto antes

2( ) Só um pouco

3 ( ) Já năo sinto mais prazer em nada

A (3) Eu sinto uma espécie de medo, como se alguma coisa ruim fosse acontecer:

3( ) Sim, e de um jeito muito forte

2 ( ) Sim, mas nāo tāo forte

1 ( ) Um pouco, mas isso não me preocupa

0 ( ) Năo sinto nada disso

D (4) Dou risada e me divirto quando vejo coisas engraçadas:

0 ( ) Do mesmo jeito que antes

1 ( ) Atualmente um pouco menos

2 ( ) Atualmente bem menos

3 ( ) Não consigo mais

A (5) Estou com a cabeça cheia de preocupaçōes:

3 ( ) A maior parte do tempo

2 ( ) Boa parte do tempo

1 ( ) De vez em quando

o( ) Raramente

D (6) Eu me sinto alegre:

0 ( ) A maior parte do tempo

1 ( ) Muitas vezes

2 ( ) Poucas vezes

3( ) Nunca

A (7) Consigo ficar sentado a vontade e me sentir relaxado: 0 ( ) Sim, quase sempre

1( ) Muitas vezes

2( ) Poucas vezes

3( ) Nunca
D (8) Eu estou lento para pensar e fazer as coisas:
3( ) Quase sempre
2( ) Muitas vezes
1 ( ) De vez em quando
0 ( ) Nunca

A (9) Eu tenho uma sensação ruim de medo, como um frio na barriga ou um aperto no estômago:
0 ( ) Nunca
1( ) De vez em quando
2 ( ) Muitas vezes
3() Quase sempre

D (10) Eu perdi o interesse em cuidar da minha aparência: 3( ) Completamente

2 ( ) Nāo estou mais me cuidando como deveria

1 ( ) Talvez não tanto quanto antes

0 ( ) Me cuido do mesmo jeito que antes

A (11) Eu me sinto inquieto, como se eu năo pudesse ficar parado em lugar nenhum:
3 ( ) Sim, demais
2 ( ) Bastante
1 ( ) Um pouco
0 ( ) Nāo me sinto assim

D (12) Fico esperando animado as coisas boas que estão por vir: 0 ( ) Do mesmo jeito que antes

1 ( ) Um pouco menos do que antes

2 ( ) Bem menos do que antes

3( ) Quase nunca

A (13) De repente, tenho a sensaçăo de entrar em pânico:
3 ( ) A quase todo momento
2 ( ) Várias vezes
1 ( ) De vez em quando
0 ( ) Năo sinto isso

D (14) Consigo sentir prazer quando assisto a um bom programa de televisão, de rádio ou quando leio alguma coisa:
0( ) Quase sempre
1 ( ) Várias vezes
2 ( ) Poucas vezes
3( ) Quase nunca 


\section{Anexo E - Prenatal Psychosocial Profile - PPP}

\section{PPP - Avaliação de autoestima}

Todos nós carregamos conosco algum tipo de imagem de nós mesmos. As frases abaixo são frases que geralmente as pessoas usam para se descreverem. Por favor, leia cada uma e marque abaixo o número que indica o quanto você concorda ou não se a frase descreve você, conforme os números abaixo:
(1) Concordo completamente
(2) Concordo
(3) Discordo
(4) Discordo completamente

\begin{tabular}{|l|c|c|c|c|}
\hline & $\begin{array}{c}\text { Concordo } \\
\text { completa- } \\
\text { mente }\end{array}$ & Concordo & Discordo & $\begin{array}{c}\text { Discordo } \\
\text { comple- } \\
\text { tamente }\end{array}$ \\
\hline $\begin{array}{l}\text { A. Você sente que é uma pessoa } \\
\text { de valor, ou pelo menos que é } \\
\text { igual aos outros. }\end{array}$ & 1 & 2 & 3 & 4 \\
\hline $\begin{array}{l}\text { B. Você sente que tem um } \\
\text { grande número de qualidades. }\end{array}$ & 1 & 2 & 3 & 4 \\
\hline $\begin{array}{l}\text { C. No final das contas, você } \\
\text { sente que é um fracasso. }\end{array}$ & 1 & 2 & 3 & 4 \\
\hline $\begin{array}{l}\text { D. Você se sente capaz de fazer } \\
\text { as coisas pelo menos tão bem } \\
\text { quanto a maioria das pessoas. }\end{array}$ & 1 & 2 & 3 & 4 \\
\hline $\begin{array}{l}\text { E. Você sente que não tem } \\
\text { muito do que se orgulhar. }\end{array}$ & 1 & 2 & 3 & 4 \\
\hline $\begin{array}{l}\text { F. Você tem uma atitude } \\
\text { positiva consigo mesma. }\end{array}$ & 1 & 2 & 3 & 4 \\
\hline $\begin{array}{l}\text { G. De modo geral, você se } \\
\text { sente satisfeita consigo } \\
\text { mesma. }\end{array}$ & 1 & 2 & 3 & 4 \\
\hline $\begin{array}{l}\text { H. Você queria ter mais } \\
\text { respeito por si mesma. }\end{array}$ & 1 & 2 & 3 & 4 \\
\hline $\begin{array}{l}\text { I. Às vezes, você se sente } \\
\text { inútil. }\end{array}$ & 1 & 2 & 3 & 4 \\
\hline $\begin{array}{l}\text { J. Às vezes, você acha que } \\
\text { não é suficientemente boa. }\end{array}$ & 1 & 2 & 3 & 4 \\
\hline $\begin{array}{l}\text { K. Você acha que controla a sua } \\
\text { vida. }\end{array}$ & 1 & 2 & 3 & 4 \\
\hline
\end{tabular}

VALORIGU

NUMQUALI

SENTFRAC

TBEQMAIO

NAOTEORG

ATITUPOS

SATICONS

MARESPCM

SENTEINU

NAOBOAQC

CONTSUVI 
Anexo F - Aprovação CAPPesq no 279.127

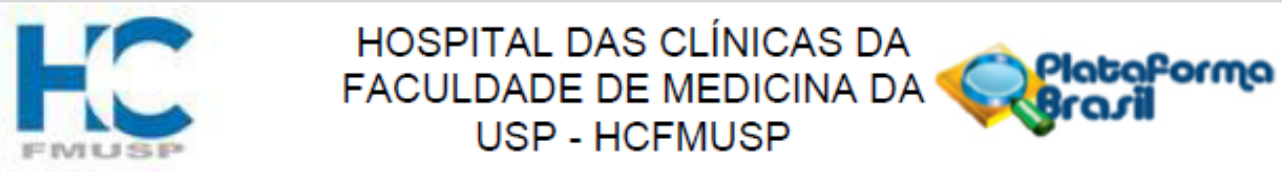

\section{PARECER CONSUBSTANCIADO DO CEP}

\section{DADOS DO PROJETO DE PESQUISA}

Título da Pesquisa: Gestação e câncer: representação social, estresse, depressão, ansiedade e vínculo materno fetal

Pesquisador: Gláucia Rosana Guerra Benute

Área Temática:

Versão: 2

CAAE: 02161713.8 .0000 .0068

Instituição Proponente: Hospital das Clínicas da Faculdade de Medicina da USP

Patrocinador Principal: Financiamento Próprio

DADOS DA NOTIFICAÇÃO

Tipo de Notificação: Outros

Detalhe: "Informação sobre Sub-Projeto e Relatório Parcial"

Justificativa: O Protocolo de Pesquisa Gestação e câncer. representação social, estresse,

Data do Envio: 10/10/2014

Situação da Notificação: Parecer Consubstanciado Emitido

\section{DADOS DO PARECER}

Número do Parecer: 835.540

Data da Relatoria: $15 / 10 / 2014$

Apresentação da Notificação:

É apresentado informe do andamento do Protocolo de Pesquisa CAPPesq n ${ }^{\circ} 279.127-$ Gestação e câncer: representação social, estresse, depressão, ansiedade e vínculo materno fetal e comunicado que o subprojeto intitulado "Associação entre depressão e vínculo materno fetal: um studo comparativo entre gestantes com diabetes pré e pós-gestacional" será tese de doutorado da aluna SOLIMAR FERRARI

Objetivo da Notificação:

Trata-se de apresentação de relatório parcial e comunicado que o sub-projeto intitulado "Associação entre depressão e vínculo materno fetal: um studo comparativo entre gestantes com diabetes pré e pósgestacional" será tese de doutorado da aluna SOLIMAR FERRARI

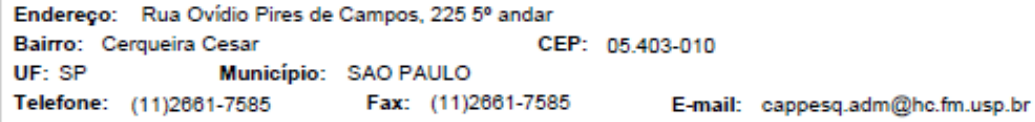




\section{HOSPITAL DAS CLÍNICAS DA \\ FACULDADE DE MEDICINA DA USP - HCFMUSP}

Continuação do Parecer: 835.540

Avaliação dos Riscos e Benefícios:

Os dados fornecidos não são suficientes para a análise; entretanto, como o protocolo foi definido como risco mínimo (entrevistas com gestantes) e não foram relatados problemas na condução da pesquisa de campo (entrevistas), entende-se que o mesmo segue o que foi inicialmente delineado.

Comentários e Consideraçöes sobre a Notificação:

Foi apresentado apenas informe (carta) explicitando o andamento da pesquisa.

Consideraçōes sobre os Termos de apresentação obrigatória:

Nenhum

Recomendações:

Assim que possivel apresentar detalhamento das informações contidas na carta-informe

Conclusões ou Pendências e Lista de Inadequaçöes:

Ver as recomendações

Situação do Parecer:

Aprovado

Necessita Apreciação da CONEP:

Não

Consideraçöes Finais a critério do CEP:

SAO PAULO, 17 de Outubro de 2014

Assinado por:

ALFREDO JOSE MANSUR

(Coordenador)

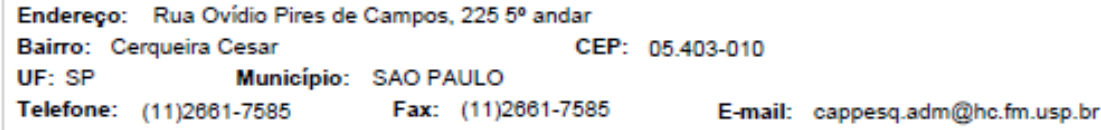




\section{REFERÊNCIAS BIBLIOGRÁFICAS}

1. World Health Organization. http://www.who.int/. Acesso em 2017.

2. Peccatori FA, Azim HA Jr., Orecchia R, Hoekstra HJ, Pavlidis N, Kesic V, Pentheroudakis G. Cancer, pregnancy and fertility: ESMO Clinical Practice Guidelines for diagnosis, treatment and follow-up. Annals of Oncology. 2013 Jun;24(6):vi160-170.

3. Zagouri F, Dimitrakakis C, Marinopoulos S, Tsigginou A, Dimopoulos M. Cancer in pregnancy: disentangling treatment modalities. ESMO Open. 2016;1(3):e000016.

4. Mitrou S, Zarkavelis G, Fotopoulos G, Petrakis D, Pavlidis N. A mini review on pregnant mothers with cancer: A paradoxical coexistence. Journal of Advanced Research. 2016 Jul;7(4):559-563.

5. Stensheim H, Møller B, van Dijk T, Fosså SD. Cause-specific survival for women diagnosed with cancer during pregnancy or lactation: a registrybased cohort study. Journal of clinical oncology. 2009 Jan;27(1):45-51.

6. Cardonick E, Usmani A, Ghaffar S. Perinatal outcomes of a pregnancy complicated by cancer, including neonatal follow-up after in utero exposure to chemotherapy: results of an international registry. American journal of clinical oncology. 2010 Jun;33(3):221-228.

7. Brasil. Ministério da Saúde. Gestação de Alto Risco - Manual Técnico. Brasília: Editora MS; 2012.

8. Achette D, Fregonese AA. Gestação e câncer: convivendo com os paradoxos. Boletim Eletrônico da Sociedade Brasileira de PsicoOncologia. 2009 Abr-Jun; Ano IV, edição 3.

9. Benute GRG, Nomura RMY, Reis JS, Junior RF, de Lucia MCS, Zugaib $M$. Depression during pregnancy in women with a medical disorder: risk factors and perinatal outcomes. Clinics. 2010; 65(11):1127-1131.

10. Molina KM, Kiely M. Understanding depressive symptoms among highrisk, pregnant, African-American women. Women's Health Issues. 2011 Jul-Aug;21(4):293-303.

11. Thiagayson $P$, Krishnaswamy G, Lim ML, Sung SC, Haley CL, Fung DSS, Allen Jr JC, Chen H. Depression and anxiety in Singaporean highrisk pregnancies - prevalence and screening. General hospital psychiatry. 2013 Mar-Apr;35(2):112-116.

12. Juhas TR, Benute GRG, de Lucia MCS, Francisco RPV. Major depression in high-risk obstetric inpatients and outpatients. Medical Express. 2014;1(2):87-90.

13. Bretherton I, Munholland KA. Internal working models in attachment relationships. In: Cassidy J, Shaver PR, editors. Handbook of attachment: Theory, research and clinical applications. New York: Guilford; 1999. p. 89-111. 
14. Lefkovics E, Baji I, Rigó J. Impact of maternal depression on pregnancies and on early attachment. Infant Mental Health Journal. 2014 JulAug;35(4):354-365.

15. Hart R. McMahon CA. Mood state and psychological adjustment to pregnancy. Archives of Women's Ment Health. 2006 Nov;9(6):329-337.

16. Dubber S, Reck C, Müller M, Gawlik S. Postpartum bonding: the role of perinatal depression, anxiety and maternal-fetal bonding during pregnancy. Archives of Women's Mental Health. 2015 Apr;18(2):187195.

17. Henry M, Huang LN, Sproule BJ, Cardonick EH. The psychological impact of a cancer diagnosed during pregnancy: determinants of longterm distress. Psycho-Oncology. 2012 Apr;21(4):444-450.

18. Vandenbroucke T, Han SN, Van Calsteren K, et al. Psychological distress and cognitive coping in pregnant women diagnosed with cancer and their partners. Psycho-Oncology. 2017;26:1215-1221.

19. Capelozza MLSS, Peçanha DL, Mattar R, Sun SY. (2014). A dinâmica emocional de mulheres com câncer e grávidas. Boletim - Academia Paulista de Psicologia, 34(86):151-170.

20. Hammarberg K, Sullivan E, Javid N, Duncombe G, Halliday L, Boyle F, Saunders C, Ives A, Dickinson JE, Fisher J. Health care experiences among women diagnosed with gestational breast cancer. Eur J Cancer Care (Engl). 2018 Mar;27(2):e12682. doi: 10.1111/ecc.12682. Epub 2017 Mar 24.

21. Ives A, Musiello T, Saunders C. The experience of pregnancy and early motherhood in women diagnosed with gestational breast cancer. PsychoOncology. 2012 Jul;21(7):754-761.

22. Rees S, Young A. The experiences and perceptions of women diagnosed with breast cancer during pregnancy. Asia Pac J Oncol Nurs 2016;3:252-8.Stewart BW, Wild CP. World Cancer Report. Lyon: IARC; 2014.

23. Vieira RJS, Gomes R, Trajano AJB. Câncer de mama e gravidez subsequente: um olhar sociocultural. Revista Brasileira de Cancerologia. 2005; 51(2):101-110.

24. Hsieh PL, Huang SM, Chien LY, Lee CF, Hsiung Y, Tai CJ. Risk-benefit perception of pregnancy among breast cancer survivors. Eur $\mathrm{J}$ Cancer Care (Engl). 2018 Mar;27(2):e12696.

25. Curry MA, Campbell RA, Christian M. Validity and reliability testing of the prenatal psychosocial profile. Research in Nursing \& Health, Hoboken, NJ, 1994;17:127-135.

26. Maçola L, Vale IN, Carmona EV. Avaliação da autoestima de gestantes com uso da Escala de Autoestima de Rosenberg Revista da Escola de Enfermagem da USP. 2010;44(3):570-577.

27. Terra FS, Marziale M, Robazzi HP. Avaliação da autoestima em docentes de enfermagem de universidades públicas e privadas. Revista 
Latino-Americana de Enfermagem, Ribeirão Preto. Jan./fev. 2013;21(n.esp):71-78.

28. Sebastián J, Manos $\mathrm{D}$, Bueno MJ, Mateos $\mathrm{N}$. Imagen corporal y autoestima en mujeres con cáncer de mama participantes en un programa de intervención psicossocial. Clínica y Salud. 2007;18(2):137161.

29. Vera B, Roselló J, Toro-Alfonso J. Autoestima y juventud puertorriqueña: eficácia de un modelo de intervención para mejorar la autoestima y disminuir los síntomas de depresión. Revista Puertorriqueña de Psicología. 2010;21(1):35-61.

30. Erdogan B, Bauer TN, Truxillo DM, Mansfield LR. Whistle while you work: a review of life satisfaction literature. J Manag [Internet]. 2012 [cited 2014 Mar 10]; 38(4):1038-83.

31. Gomes NS, Silva SR. Avaliação da autoestima de mulheres submetidas à cirurgia oncológica mamária. Texto Contexto Enferm, Florianópolis, 2013 Abr-Jun; 22(2):509-16.

32. Ramos M. Adaptação para uma população de estudantes universitários portugueses da escala de autoestima de estado de Heatherton e Policy. Psicologia. 2014;28(1):32-8.

33. Leite MAC, Alves Nogueira D, Souza Terra F. Avaliação da autoestima em pacientes oncológicos submetidos a tratamento quimioterápico, Revista Latino-Americana de Enfermagem. Noviembre-diciembre, 2015;23(6):1082-1089.

34. Righetti PL, Dell'Avanzo M, Grigio M, Nicolini U. Maternal/paternal antenatal attachment and four-dimensional ultrasound technique: a preliminary report. British Journal of Psychology. 2005 Feb;96(1):129137.

35. Brandon AR, Pitts S, Denton WH, Stringer CA, Evans HM. A history of the theory of prenatal attachment. Journal of prenatal \& perinatal psychology \& health. 2009 Apr;23(4):201-222.

36. Sroufe LA. Attachment and development: a prospective, longitudinal study from birth to adulthood. Attachment \& human development. 2005 Dec;7(4):349-67.

37. Alhusen JL. A Literature update on maternal-fetal attachment. Journal of Obstetric, Gynecologic, and Neonatal Nursing. 2008 Jan;37(3):315-328.

38. Ramires VRR, Schneider MS. Revisitando alguns Conceitos da Teoria do Apego: Comportamento versus Representação? Psicologia Teoria e Pesquisa. 2010 Jan-Mar;26(1):25-33.

39. Brockington I. Postpartum psychiatric disorders. Lancet. 2004 Jan;363(9405):303-310.

40. Faisal-Cury A, Menezes PR. Ansiedade no puerpério: prevalência e fatores de risco. Revista Brasileira de Ginecologia e Obstetrícia. 2006 Mar;28(3):171-178. 
41. Gomes AG, Piccinini CA. Malformação no bebê e maternidade: aspectos teóricos e clínicos. Psicologia Clínica. 2010 Jun;22(1):15-38.

42. Winnicott DW. Os bebês e suas mães. São Paulo: Martins Fontes; 1999.

43. Drake EE, Humenick SS, Amankwaa L, Younger J, Roux G. Predictors of maternal responsiveness. J Nurs Scholarsh. 2007;39(2):119-25.

44. Falcone VM, Mader CV, Nascimento CF, Santos JM, Nobrega FJ. Atuação multiprofissional e a saúde mental de gestantes. Rev Saúde Pública. 2005;39(4):612-8.

45. Parazzini F, Franchi M, Tavani A, Negri E, Peccatori FA. Frequency of pregnancy related cancer: a population based linkage study in Lombardy, Italy. International Gynecological Cancer Society. 2017 Mar;27(3):613619.

46. Lee YY, Roberts CL, Dobbins T, Stavrou E, Black K, Morris J, Young J. Incidence and outcomes of pregnancy-associated cancer in Australia, 1994-2008: a population-based linkage study. BJOG. 2012 Dec;119(13):1572-1582.

47. Amant F, Loibl S, Neven P, Van Calsteren K. Breast Cancer in Pregnancy. Lancet. 2012 Feb;379(9815):570-79.

48. Litton JK, Theriault RL. Breast cancer and pregnancy: current concepts in diagnosis and treatment. The Oncologist. 2010 Dec;15(12):1238-1247.

49. Wielowieyska-Szybińska DK, Spałkowska M, Wojas-Pelc A. Melanoma in pregnancy: a case report and review of the literature. Advances in Dermatology and Allergology/Postępy Dermatologii i Alergologii. 2015 Dec;32(6):483-487.

50. Pentheroudakis G, Pavlidis N. Cancer and pregnancy: poena magna, not anymore. European journal of cancer. 2006 Jan;42(2):126-140.

51. Hecking T, Abramian A, Domröse C, Engeln T, Thiesler T, Leutner C, Gembruch U, Keyver-Paik MD, Kuhn W, Kübler K. Individual management of cervical cancer in pregnancy. Archives of Gynecology and Obstetrics. 2016 Jan;293:931-939.

52. Lavi N, Horowitz NA, Brenner B. An update on the management of hematologic malignancies in pregnancy. Womens Health. 2014 May;10(3):255-266.

53. Sekine M, Kobayashi $Y$, Tabata T, Sudo T, Nishimura R, Matsuo K, Grubbs BH, Enomoto T, Ikeda T. Malignancy during pregnancy in Japan: an exceptional opportunity for early diagnosis. BMC Pregnancy Childbirth;18(1):50, 2018.

54. de Haan J, Verheecke M, Van Calsteren K, Van Calster B, Shmakov RG, Mhallem Gziri M, Halaska MJ, Fruscio R, Lok CAR, Boere IA, Zola P, Ottevanger PB, de Groot CJM, Peccatori FA, Dahl Steffensen K, Cardonick EH, Polushkina E, Rob L, Ceppi L, Sukhikh GT, Han SN, Amant F. Oncological management and obstetric and neonatal outcomes for women diagnosed with cancer during pregnancy: a 20-year international cohort study of 1170 patients. Journal of Gynecology 
Obstetrics and Human Reproduction. Volume 47, Issue 5, May 2018, p.205-207.

55. de Haan J, Lok CAR, Schutte JS, van Zuylen L, de Groot CJM. Cancer related maternal mortality and delay in diagnosis and treatment: a case series on 26 cases. BMC Pregnancy Childbirth;18(1):10.

56. Lu D, Ludvigsson JF, Smedby KE, Fall K, Valdimarsdóttir U, Cnattingius S, Fang F. Maternal Cancer During Pregnancy and Risks of Stillbirth and Infant Mortality. J Clin Oncol. 2017 May 10;35(14):1522-1529.

57. Yu HH, Cheung PS, Leung RC, Leung TN, Kwan WH (2017) Current management of pregnancy-associated breast cancer. Hong Kong Med $\mathrm{J}$ 23(4):387-394.

58. Cardonick E, lacobucci A. Use of chemotherapy during human pregnancy. Lancet Oncol 2004; 5:283-291.

59. Al-Amri AM. Clinical presentation and causes of the delayed diagnosis of breast cancer in patients with pregnancy associated breast cancer. $J$ Family Community Med. 2015;22(2).

60. Kessler RC, Birnbaum HG, Shahly V, Bromet E, Hwang I, McLaughlin KA, Sampson N, Andrade LH, de Girolamo G, Demyttenaere K, Haro JM, Karam AN, Kostyuchenko S, Kovess V, Lara C, Levinson D, Matschinger $\mathrm{H}$, Nakane Y, Browne MO, Ormel J, Posada-Villa J, Sagar R, Stein DJ. Age differences in the prevalence and co-morbidity of DSM-IV major depressive episodes: results from the WHO World Health Survey Initiative. Depression and anxiety. 2010 Apr;27(4):351-364.

61. Bromet E, Andrade LH, Hwang I, Sampson NA, Alonso J, Girolamo G, Graaf R, Demyttenaere K, Hu C, Iwata N, Karam AN, Kaur J, Kostyuchenko S, Lépine JP, Levinson D, Matschinger $\mathrm{H}$, Mora MHM, Browne MO, Posada-Villa J, Viana MC, Williams DR, Kessler RC. Crossnational epidemiology of DSM-IV major depressive episode. BMC Medicine. 2011; 9(90).

62. Instituto Brasileiro de Geografia e Estatística. Pesquisa Nacional por Amostra de Domicílios. Um panorama da saúde no Brasil: acesso e utilização dos serviços, condições de saúde e fatores de risco e proteção à saúde 2008. Rio de Janeiro: IBGE; 2010.

63. World Health Organization. Global burden of mental disorders and the need for a comprehensive, coordinated response from health and social sectors at the country level: report by the Secretariat. Geneva; 2011. Disponível em: http://apps.who.int/gb/ebwha/pdf_files/EB130/B130_9en.pdf.

64. American Psychiatric Association. Manual Diagnóstico e Estatístico de Transtornos Mentais 5aㅡ ed. Porto Alegre: Artmed; 2014.

65. Freud S. Luto e Melancolia. In: Escritos sobre a psicologia do inconsciente. Obras Psicológicas de Sigmund Freud. Rio de Janeiro: Imago; 2006;2:99-122. (Trabalho original publicado em 1917[1915]). 
66. Winnicott DW. O valor da depressão: Tudo começa em casa. Trad. Sandler P. São Paulo: Martins Fontes. (1999). (p. 59-68). 3 ed. (Trabalho original publicado em 1964. Título original: The value of depression.).

67. Cabreara CC. Sponholz Jr A. Ansiedade e insônia. In: Botega JN (org). Prática psiquiátrica no hospital geral. Interconsulta e emergência. $3^{\text {a }}$ edição. Porto Alegre: Artmed. 2012.

68. Andrade LHSG, Viana MC, Silveira CM. Epidemiologia dos transtornos psiquiátricos na mulher. Revista de Psiquiatria Clínica. 2006;33(2):43-54.

69. Kinrys G, Wygant LE. Transtornos de ansiedade em mulheres: gênero influencia 0 tratamento. Revista Brasileira de Psiquiatria. 2005 Out;27(2):43-50.

70. Charney DS, Reynolds CF, Lewis L, Lebowitz BD, Sunderland T, Alexopoulos GS, Blazer DG, Katz IR, Meyers BS, Arean PA, Borson S, Brown C, Bruce ML, Callahan CM, Charlson ME, Conwell Y, Cuthbert BN, Devanand DP, Gibson MJ, Gottlieb GL, Krishnan KR, Laden SK, Lyketsos CG, Mulsant BH, Niederehe G, Olin JT, Oslin DW, Pearson J, Persky T, Pollock BG, Raetzman S, Reynolds M, Salzman C, Schulz R, Schwenk TL, Scolnick E, Unutzer J, Weissman MM, Young RC. Depression and Bipolar Support Alliance consensus statement on the unmet needs in diagnosis and treatment of mood disorders in late life. Archives of general psychi. 2003 Jul;60(7):664-672.

71. Freud S. Inibições, sintomas e ansiedade. In: Edição Standard Brasileira das Obras de Sigmund Freud, vol. 20. Originalmente publicado em 1926 [1925]. Rio de Janeiro: Imago, 1966.

72. Rodrigues MES, Silveira TB, Jansen K, Cruzeiro, ALS, Ores L, Pinheiro RT, Silva RA, Tomazi E, Souza LDM. Risco de suicídio em jovens com transtornos de ansiedade: estudo de base populacional. Psico-USF. 2012Jan-Apr;17(1):53-62.

73. Escribà-Agüir V, Royo-Marqués $M$, Artazcoz L, Romito $P$, Ruiz-Pérez I. Longitudinal study of depression and health status in pregnant women: incidence, course and predictive factors. European Archives of Psychiatry and Clinical Neuroscience. 2013 Mar;263(2):143-151.

74. Aliane PP, Ronzani TM, Silva CS, Silva GR, Miranda DB, Oliveira PF, Mendes AF, Furtado E. (2008). Avaliação de Saúde Mental em Gestantes. Revista Interinstitucional de Psicologia. 2008;JulDez1(2):113-122.

75. Grigoriadis S, Vonder Porten EH, Mamisashvili L, Tomlinson G, Dennis CL, Koren G, Koren G, Steiner M, Mousmanis P, Cheung A, Radford K, Martinovic J, Ross LE. The impact of maternal depression during pregnancy on perinatal outcomes: a systematic review and metaanalysis. The Journal of clinical psychiatry. 2013 Apr; 74(4):321-341.

76. Earls MF. Incorporating recognition and management of perinatal and postpartum depression into pediatric practice. Committee on Psychosocial Aspects of Child and Family Health American Academy of Pediatrics. Pediatrics. 2010 Nov;126(5):1032-1039. 
77. Thiengo DL, Santos JFC, Fonseca DL, Abelha L, Lovisi GM. Depressão durante a gestação: um estudo sobre a associação entre fatores de risco e de apoio social entre gestantes. Cadernos de Saúde Coletiva. 2012;20(4):416-426.

78. Munk-Olsen T, Laursen TM, Pedersen CB, Mors O, Mortensen PB. New parents and mental disorders: a population-based register study. JAMA. 2006 Dec;296(21):2582-2589.

79. Lindahl V, Pearson JL, Colpe L. Prevalence of suicidality during pregnancy and the postpartum. Archives of Women's Mental Health. 2005 Jun;8(2):77-87.

80. Palladino CL, Singh V, Campbell J, Flynn H, Gold KJ. Homicide and suicide during the perinatal period: findings from the National Violent Death Reporting System. Obstetrics and gynecology. 2011 Nov;118(5):1056-1063.

81. Waldie KE, Peterson ER, D'Souza S, Underwood L, Pryor JE, Carr PA, Grant C, Morton SMB. Depression symptoms during pregnancy: Evidence from Growing Up in New Zealand. Journal of Affective Disorders. 2015 Nov;186:66-73.

82. Alvarado R, Rojas M, Monardes J, Perucca E, Neves E, Olea E, Vera A. Cuadros depresivos en el postparto en uma cohorte de embarazadas: Construcción de un modelo causal. Revista Chilena de NeuroPsiquiatria. 2000 Abr;38(2):84-93.

83. Yedid Sion M, Harlev A, Weintraub AY, Sergienko R, Sheiner E. Is antenatal depression associated with adverse obstetric and perinatal outcomes? The Journal and Maternal Fetal \& Neonatal Medicine. 2016 Mar;29(6):863-867.

84. Pereira PK, Lovisi GM. Prevalência da depressão gestacional e fatores associados. Revista de Psiquiatria Clínica. 2008;35(4):144-153.

85. Spoozak L, Gotman N, Smith MV, Belanger K, Yonkers K. Evaluation of a social support measure that may indicate risk of depression during pregnancy. Journal of Affective Disorders. 2009 Apr;114(1-3):216-223.

86. Senturk V, Abas M, Berksun O, Stewart R. Social support and antenatal depression in extended and nuclear family environments in Turkey: a cross-sectional survey. BMC Psychiatry. 2011 Mar;11:1-10.

87. Waters CS, Hay DF, Simmonds JR, Van Goozen SHI. Antenatal depression and children's developmental outcomes: potential mechanisms and treatment options. European Child \& Adolesc Psychiatry. 2014 Jul;23(10):957-971.

88. Schwartz L, Bowen A, Muhajarine N. The effects of episodic versus continuous and major versus mild depression and anxiety symptoms on pregnancy and labour complications. Archives of Depression and Anxiety. 2015;1(1):10-18. 
89. Bowen A. Muhajarine N. Prevalence of antenatal depression inwomenenrolled in an outreach program in Canada. Journal of Obstetrics \& Gynecology Neonatal Nursing. 2006 Jul-Aug;35(4):491-498.

90. Vythilingum B, Roos A, Faure SC, Geerts L, Stein DJ. Risk factors for substance use in pregnant women in South Africa. The South African Medical Journal. 2012;102(11):851-854.

91. Olhaberry M, Zapata J, Escobar M, Mena C, Farkas C, Santelices MP, Krause M. Antenatal depression and its relationship with problem-solving strategies, childhood abuse, social support, and attachment styles in a low-income Chilean sample. Mental Health \& Prevention. 2014 Dec;2(34):86-97.

92. Lancaster CA, Gold KJ, Flynn Ha, Yoo H, Marcus SM, Davis MM. Risk factors for depressive symptoms during pregnancy: a systematic review. American journal of obstetrics and gynecology. 2010 Jan;202(1):5-14

93. Kohlhoff J, Hickinbotham R, Knox C, Roach V, Barnett Am B. Antenatal psychosocial assessment and depression screening in a private hospital. The Australian \& New Zealand journal of obstetrics \& gynaecology. 2016 Apr;56(2):173-178.

94. Saviani-Zeoti F, Petean EBL. Apego materno-fetal, ansiedade e depressão em gestantes com gravidez normal e de risco: estudo comparativo. Estudos de Psicologia. 2015 Out-Dez; 32(4):675-683.

95. Andersson L, Sundström-Poromaa, Wulff $M$, Aström $M$, Bixo $M$. Implications of antenatal depression and anxiety for obstetric outcome. Obstetrics \& Gynecology. 2004 Sep 104(3), 467-476.

96. Bodecs T, Horváth B, Szilagyi E, Gonda X, Rihmer Z, Sandor J. (2011). Effects of depression, anxiety, self-esteem, and health behaviour on neonatal outcomes in a population-based Hungarian sample. European Journal of Obstetrics, Gynecology, and Reproductive Biology. 2011 Jan; 154(1):45-50.

97. Rubertsson C, Hellström J, Cross M, Sydsjö G. Anxiety in early pregnancy: Prevalence and contributing factors. Archives of Women's Mental Health. 2014 Jun;17(3):221-228.

98. Ross LE, McLean LM. Anxiety disorders during pregnancy and the postpartum period: a systematic review. Journal of Clinical Psychiatry. 2006 Aug;67(8):1285-1298.

99. Britton JR. Infant temperament and maternal anxiety and depressed mood in the early postpartum period. Womens Health. 2011 Jan;51(1):55-71.

100. Andersson L, Sundström-Poromaa I, Wulff M, Aström M, Bixo M. Depression and anxiety during pregnancy and six months postpartum: a follow-up study. Acta obstetricia et gynecologica Scandinavica. 2006;85(8):937-44. 
101. Figueiredo B, Costa R (2009) Mother's stress, mood and emotional involvement with the infant: 3 months before and 3 months after childbirth. Archives of women's mental health. 2009 Mar;12(3):143-153.

102. Moon EH, Kim JY, Jeung MK, Son HJ, Oh JN. Anxiety, depression and maternal fetal attachment behaviors of pregnant women with preterm labor and normal pregnant women. Korean Journal of Parent-Child Health. 2007; 9(2):128-139.

103. Couto ER, Couto E, Vian B, Gregório Z, Nomura ML, Zaccaria R, Passini $\mathrm{R}$ Jr. Quality of life, depression and anxiety among pregnant women with previous adverse pregnancy outcomes. São Paulo Medical Journal. 2009 Jul;127(4):185-189.

104. Remen RN. O paciente como ser humano. Summus Editorial. São Paulo. 1993 3aㅡ edição.

105. Kuhnt S, Brähler E, Faller H et al. Twelve-Month and Lifetime Prevalence of Mental Disorders in Cancer Patients. Psychotherapy and Psychosomatics. 2016;85(5):289-296.

106. Arrieta $O$, Angulo LP, Nunez-Valência $C$ et al. Associação de depressão e ansiedade na qualidade de vida, adesão ao tratamento e prognóstico em pacientes com câncer avançado de pulmão de não pequenas células. Ann Surg Oncol. 2013; 20: 1941-1948.Schmidt EB, Argimon II. Vinculação da gestante e apego materno-fetal. Paidéia. 2009 MaiAgo;19(43):211-220.

107. Cook SA, Salmon P, Hayes G, Byrne A, Fisher PL. Predictors of emotional distress a year or more after diagnosis of cancer: A systematic review of the literature. Psycho-Oncology (2018).

108. Gerbi GB, Ivory S, Archie-Booker E, Claridy MD, Miles-Richardson S.. Factors associated with self-reported history of depression diagnosis among cancer survivors aged 18 years and over in the united states. Psycho-Oncology. Advance online publication. (2018).

109. Subramaniam S, Kong YC, Chinna K, Kimman M, Ho YZ, Saat N, BhooPathy N. (2018). Health-related quality of life and psychological distress among cancer survivors in a middle-income country. Psycho-Oncology

110. Muzzatti B, Mella S, Bomben F, Flaiban C, Gipponi K, Piccinin M, Annunziata MA. Intensity and prevalence of depressive states in cancer inpatients: A large sample descriptive study. European Journal of Cancer Care, 27(1):1-5.

111. Bhattacharyya S, Bhattacherjee S, Mandal T, Das DK. Depression in Cancer Patients Undergoing Chemotherapy in a Tertiary Care Hospital of North Bengal, India. Indian J Public Health. 2017 Jan-Mar;61(1):14-18. doi: 10.4103/0019-557X.200252.

112. Heo J, Chun M, Oh Y.-T, Noh OK, Kim L. Psychiatric comorbidities among ovarian cancer survivors in south korea: A nationwide populationbased, longitudinal study. Psycho-Oncology. Advance online publication. (2018). 
113. Kagee A, Roomaney R, Knoll N. Psychosocial predictors of distress and depression among south african breast cancer patients. 2017.

114. Tas F, Karabulut S, Guveli H, Kurul S, Erturk K, Guveli M, Kinik H. Assessment of Anxiety and Depression Status in Turkish Cutaneous Melanoma Patients . Asian Pac J Cancer Prev. 2017 Feb 1;18(2):369373.

115. Nayyereh Aminisani, Hosseinali Nikbakht, Mohammad Asghari Jafarabadi, Seyed Morteza Shamshirgaran Depression, anxiety, and health related quality of life among colorectal cancer survivors. Vol 8, No 1 (February 2017).

116. Thalén-Lindström A, Glimelius B, Johansson B. Development of anxiety, depression and health-related quality of life in oncology patients without initial symptoms according to the Hospital Anxiety and Depression Scale: a comparative study. 2017

117. Jung, JY, Lee JM, Kim MS, Shim YM, Zo JI, Yun YH. (2018). Comparison of fatigue, depression, and anxiety as factors affecting posttreatment health-related quality of life in lung cancer survivors. Psycho-Oncology, 27(2):465-470.

118. Choi, S., \& Ryu, E. (2018). Effects of symptom clusters and depression on the quality of life in patients with advanced lung cancer. European Journal of Cancer Care, 27(1):1-8.

119. Gonzalez-Saenz de Tejada M, Bilbao A, Baré M, Briones E, Sarasqueta C, Quintana JM, Escobar A. Association between social support, functional status, and change in health-related quality of life and changes in anxiety and depression in colorectal cancer patients. Psychooncology. 2017 Sep;26(9):1263-1269.

120. Vogel RI, Strayer LG, Engelman L, Nelson HH, Blaes AH, Anderson KE, Lazovich D. Comparison of quality of life among long-term melanoma survivors and non-melanoma controls: a cross-sectional study. Qual Life Res. 2017 Jul;26(7):1761-1766. doi: 10.1007/s11136-017-1532-6.

121. Eichler, M, Hechtner, M, Wehler, B, Buhl, R, Stratmann, J, Sebastian, M, Singer, S. Psychological distress in lung cancer survivors at least 1 year after diagnosis-results of a german multicenter cross-sectional study. Psycho-Oncology. (2018)

122. S. Swartzman JN, Booth A, Munro F, Sani. Posttraumatic stress disorder after cancer diagnosis in adults: a meta-analysis. Depression and Anxiety, 2016.

123. Carlson LE, Bultz BD. Efficacy and medical cost offset of psychosocial interventions in cancer care: making the case for economic analyses. Psychooncology. 2004;13(12):837-849.

124. Bultz BD, Carlson LE. Emotional distress: the sixth vital sign: future directions in cancer care. Psychooncology. 2006;15(2):93-95.

125. Gobitta M, Guzzo RSL. (2002) Estudo inicial do inventário de AutoEstima (SEI): Forma A. Psicologia Reflexão Critica, vol.15, no.1. 
126. Rosenberg M. Society and the adolescent self-image. Princeton, NJ: Princeton University Press; 1965.

127. Freud S. Sobre o narcisismo: uma introdução. In: Edição standard brasileira das obras psicológicas completas de Sigmund Freud, vol. XIX. Rio de Janeiro: Imago; 1996.

128. Hornstein L. Introdução à psicanálise. São Paulo: Escuta; 1989.

129. Lacan J. O estádio do espelho como formador da função do eu. In: Lacan J, Escritos. Rio de Janeiro: Zahar; 1998. Trad. do original de 1966 por Ribeiro V; p. 96-103.

130. Ranña W. Psicossomática e infantil: uma abordagem através da pulsão e da relação objetal. In: Ferraz FC, Volich RM (org.). Psicossoma: psicossomática psicanalítica. Casa do Psicólogo; 1997.

131. Zacharias J, Mosquera JJM, Stobäus CD. Autoimagem, Autoestima e Autoconceito: contribuições pessoais e profissionais na docência. In: IX ANPED SUL: Seminário de Pesquisa em Educação da Região Sul [Internet]. 2012.

132. Furegato AR et al. Depressão e autoestima entre acadêmicos de enfermagem. Revista de Psiquiatria Clínica, São Paulo 2006;33(5):239244.

133. Sampaio F. M. C. A autoestima na pessoa portadora de ostomia de eliminação intestinal. Revista Portuguesa de Enfermagem de Saúde Mental, Porto, dez. 2010;(3):31-37.

134. Branden N. Autoestima: como aprender a gostar de si mesmo. Saraiva.

135. Schultheisz TSV, Aprile MR. Autoestima, conceitos correlatos e avaliação. Rev Equil Corp Saúde[Internet]. 2013 [cited 2014 Aug 16];5(1):36-48.

136. Moreira NS, Sousa CS, Poveda VDB, Turrini RNT. Self-esteem of cancer patients' caregivers with reduced functional capacity, Esc. Anna Nery 19 (2015) p. 316-322.

137. Silva RA, Ores LC, Mondin TC, Rizzo RN, Moraes IGS, Jansen K et al . Transtornos mentais comuns e auto-estima na gestação: prevalência e fatores associados. Cad. Saúde Pública [Internet]. 2010; 26(9):18321838.

138. Maia JMD, Williams B, Albuquerque LC. Fatores de risco e fatores de proteção ao desenvolvimento infantil: uma revisão da área. Temas em psicologia 2005; 13(2):91-103.

139. Santos AB, Santos KEP, Monteiro GTR, Prado PR, Amaral TLM. Autoestima e qualidade de vida de uma série de gestantes atendidas em rede pública de saúde. Cogitare Enferm. 2015 Abr/Jun; 20(2):392-400.

140. Machado CD, Vinholes DB, Feldens VP. Avaliação da autoestima de gestantes atendidas em um ambulatório no município de Tubarão, SC. Arq Catarin Med. 2013 abr-jun; 42(2):50-55. 
141. Dias MS, Silva RA, Souza LDM, Lima RC, Pinheiro RT, Moraes IGS. (2008). Auto-estima e fatores associados em gestantes da cidade de Pelotas, Rio Grande do Sul, Brasil. Cadernos de Saúde Pública, 24(12), 2787-2797.

142. Morandin KMM. Avaliação do perfil psicossocial das gestantes atendidas na rede básica de saúde do município de Catanduva-SP. 2010. Tese de Doutorado. Escola de Enfermagem da Universidade de São Paulo e Escola de Enfermagem de Ribeirão Preto da Universidade de São Paulo.

143. van Scheppingen MA, Denissen JJA, Chung JM, Tambs K, Bleidorn W. Self-esteem and relationship satisfaction during the transition to motherhood. Journal of Personality and Social Psychology, 2018;114(6): 973-991.

144. Erol RY, Orth U. Self-esteem development from age 14 to 30 years: A longitudinal study. Journal of Personality and Social Psychology (2011).

145. Robins RW, Trzesniewski, KH.. Self-esteem development across the lifespan. Current Directions in Psychological Science. 2005;14:158-162.

146. Jesse DE, Kim H, Herndon C. Social support and self-esteem as mediators between stress and antepartum depressive symptoms in rural pregnant women. Res Nurs Health. 2014 Jun;37(3):241-52.

147. Carvalho MP, Oliveira Filho RS, Gomes HC, Veiga DF, Juliano Y, Ferreira LM. Auto-estima em pacientes com carcinomas de pele. Rev. Col. Bras. Cir. [Internet]. 2007 Dec; 34(6):361-366.

148. Oliveira MCM, Oliveira TC, Schnaider TB. Autoestima, espiritualidade e depressão em pacientes de neoplasia colorretal. Revista do médico residente. 2012;14(4).

149. Mohd-Sidik S, Akhtari-Zavare M, Periasamy U, Rampal L, Fadhilah SI5, Mahmud R. Effectiveness of chemotherapy counselling on self-esteem and psychological affects among cancer patients in Malaysia: Randomized controlled trial. Patient Educ Couns. 2018 May;101(5):862871.

150. Cieślak K, Golusiński W. Coping with loss of ability vs. emotional control and self-esteem in women after mastectomy. Rep Pract Oncol Radiother. 2017 May-Jun; 22(3):231-236.

151. Fernandes MMJ, Cândido Alves P, Lavinas Santos MC, Moreira Mota E, Carvalho Fernandes AF. Autoestima de mulheres mastectomizadas: aplicação da escala de Rosenberg. Revista da Rede de Enfermagem do Nordeste. 2013;14(1):101-108.

152. Ortiz E, Méndez L, Camargo J, Chavarro S, Toro G, Vernaza M. (2014). Relación entre las estrategias de afrontamiento, ansiedad, depresión y autoestima, en un grupo de adultos con diagnóstico de cáncer. Psychologia. Avances de la Disciplina, 8(1):77-83.

153. Zornig SMAJ. Tornar-se pai, tornar-se mãe: o processo de construção da parentalidade. Tempo psicanalítico. 2010;42(2):453-470. 
154. Scavone L. A maternidade e o feminino: diálogo com as ciências sociais. Cadernos Pagu - desdobramentos do feminino. 2001;16:137-150.

155. Benute, GRG. Abortamento como um processo psicossocial: uma interpretação junguiana; perda e culpa, depressão e ansiedade. São Paulo. [Dissertação de mestrado]. Faculdade de Medicina da USP; 2002.

156. Piccinini CA, Gomes AG, De Nardi T, Lopes RS. Gestação e a constituição da maternidade. Psicologia em Estudo. 2008 JanMar;13(1):63-72.

157. Caron, N. O ambiente intra-uterino e a relação materno-fetal. In: Caron $\mathrm{N}$, org. A relação pais-bebê: Da observação à clínica. São Paulo: Casa do Psicólogo; 2000. p.119-134.

158. Aulagnier P. Um intérprete em busca de sentido. São Paulo: Escuta; 1990.

159. Thompson RA. The legacy of early attachments. Child development. 2000 Jan-Feb;71(1):145-152.

160. Condon JT. The assessment of antenatal emotional attachment: Development of a questionnaire instrument. The British journal of medical psychology. 1993 Jun;66(2):167-183.

161. Shin H, Park YJ, Kim MJ. (2006). Predictors of maternal sensitivity during the early postpartum period. Issues and Innovations in Nursing Practice. 2006 Aug;55(4):425-434.

162. Bowlby J. Apego: A natureza do vínculo. São Paulo: Martins Fontes; 1984.

163. Bowlby J. Uma base segura: Aplicações clínicas da teoria do apego. Porto Alegre: Artes Médicas; 1989.

164. Lecannelier F. Apego e intersubjetividad: influencia de los vínculos tempranos en el desarrollo humano y la salud mental. Santiago: Editorial LOM; 2006. p.23-25.

165. Bowlby J. Formação e rompimento dos laços afetivos. 3aㅗ ed. São Paulo: Martins Fontes; 1997.

166. Bowlby J. Attachment theory and its therapeutic implications. Adolescent Psychiatry. 1978;6:5-33.

167. Cranley MS. Development of a tool for the measurement of maternal attachment during pregnancy. Nursing research. 1981 Set-Out, 30(5):281-284.

168. Salisbury A, Law K, LaGrase L, Lester B. Maternal-fetal attachment. Journal of the American Medical Association. 2003 Apr;289(13):1701.

169. Ainsworth MD. Attachments beyond infancy. The American Psychologist. 1989;44(4):709-716.

170. Canella BL. Maternal-fetal attachment: an integrative review. Journal of Advanced Nursing. 2005 Apr;50(1),60-68. 
171. Yarcheski A, Mahon NE, Yarcheski TJ, Hanks MM, Cannella BL. (2009). A meta-analytuc study of predictors of maternal-fetal attachment. International Journal of Nursing Studies. 2009 May;46(5):708-715.

172. Hepper P. Behavior During the Prenatal Period: Adaptive for Development and Survival. Child Development Perspectives. 2015 Mar;9(1):38-43

173. Eswaran H, Lowery CL, Wilson JD, Murphy P, Preissl H. Functional development of the visual system in human fetus using magnetoencephalography. Experimental Neurology. 2004 Nov, 190(1):52-58.

174. Hepper PG, Shahidullah S. The development of fetal hearing. Archives of disease in childhood. 1994 Sep; 71(2):81-87.

175. Klaus $\mathrm{MH}$, Klaus $\mathrm{PH}$. Seu surpreendente recém nascido. Porto Alegre: Artmed; 2001.

176. Seimyr L, Sjögren B, Welles-Nystrom B, Nissen E. (2009). Antenatal maternal depressive mood and parental-fetal attachment at the end of pregnancy. Archives Women's Ment Health. 2009 Oct;12(5):269-279.

177. Alhusen JL, Hayat MJ, Gross D. A longitudinal study of maternal attachment and infant developmental outcomes. Archives of women's mental health . 2013 Dec; 16(6):521-529.

178. Winnicott DW. A criança e seu mundo. 6ed. Rio de Janeiro: LTC; 2008.

179. Pisoni C, Garofoli F, Tzialla C, Orcesi S, Spinillo A, Politi P, Balottin U, Manzoni $P$, Stronati M. Risk and protective factors in maternal-fetal attachment development. Early human development. 2014 Sep;90(2):4546.

180. Clauson MI. Uncertainty and stress in women hospitalized with high risk pregnancy. Clinical Nursing Research. 1996 Aug;5(3):309-325.

181. Silva MRC, Vieira BDG, Alves VH, Rodrigues DP, Vargas GS, Sá AMP. A percepção de gestantes de alto risco acerca do processo de hospitalização. Revista de enfermagem. 2013 Dez; 21(2):792-797.

182. Fonagy $\mathrm{P}$, Steele $\mathrm{H}$, Steele $\mathrm{M}$. Maternal representations of attachment during pregnancy predict the organization of infant-mother attachment at one year of age. Child development. 2008 Oct;62(5):891-905.

183. Moehler E, Brunner R, Wiebel A, Reck C, Resch F. Maternal depressive symptoms in the postnatal period are associated with long-term impairment of mother-child bonding. Archives of Women's Mental Health. 2006 Sep;9(5):273-278.

184. Tronick E, Reck C. Infants of depressed mothers. Harvard Review of Psychiatry. 2009;17(2):147-156.

185. Field T. Postpartum depression effects on early interactions, parenting, and safety practices: A review. Infant Behavior and Development. 2010 Feb;33(1):1-6. 
186. Waxler E, Thelen K, Muzik M (2011). Maternal perinatal depression Impact on infant and child development. European Psychiatric Review. 2011 May;4(1):41-47.

187. Kwon MK, Bang KS. (2011). Relationship of prenatal stress and depression to maternal-fetal attachment and fetal growth. Journal of Korean Academy of Nursing. 2011 Apr;41(2):276-283.

188. Parsons CE, Young KS, Rochat TJ, Kringelbach ML, Stein A. Postnatal depression and its effects on child development: A review of evidence from low- and middle-income countries. British Medical Bulletin. 2011 Nov;101(1):57-79.

189. Sohr-Preston SL, Scaramella LV. Implications of maternal depressive symptoms for early cognitive language development. Clinical Child and Family Psychology Review. 2006 Mar; 9(1):65-83.

190. Stein A, Craske MG, Lehtonen A, Harvey A, Savage-McGlynn E, Davies B, Goodwin J, Murray L, Cortina-Borja M, Counsell N. (2012). Maternal cognitions and mother-infant interaction in postnatal depression and generalized anxiety disorder. Journal of Abnormal Psychology. 2012 Nov;121(4):795-809.

191. Bansil P, Kuklina EV, Meikle SF, Posner SF, Kourtis AP, Ellington SR, Jamieson DJ. Maternal and fetal outcomes among women with depression. Journal of Women's Health. 2010 Feb;19(2):329-334.

192. Moehler E, Kagan J, Parzer P, Brunner R, Reck C,Wiebel A, Poustka L, Resch F. Childhood behavioral inhibition and maternal symptoms of depression. Psychopathology. 2007 Aug;40(6):446-452.

193. Kingston D, Tough S, Whitfield H. (2012). Prenatal and postpartum maternal psychological distress and infant development: A systematic review. Child Psychiatry and Human Development. 2012 Oct;43(5):683714.

194. Deave T, Heron J, Evans J, Emond A. The impact of maternal depression in pregnancy on early child development. BJOG: An International Journal of Obstetrics and Gynaecology. 2008 Jul;115(8):1043-1051.

195. Aceti F, Baglioni V, Ciolli P, De Bei F, Di Lorenzo F, Ferracuti S, Giacchetti N, Marini I, Meuti V, Motta P, Roma P, Zaccagni M, Williams R. Maternal attachment patterns and personality in post partum depression. Rivista di psichiatria. 2012 May-Jun;47(3):214-20.

196. Feldman R, Eidelman Al, Rotenberg N. Parenting stress, infant emotion regulation, maternal sensitivity, and the cognitive development of triplets: A model for parent and child influences in a unique ecology. Child Development. 2004 Nov-Dec;75(6):1774-1791.

197. Milgrom J, Westley DT, Gemmill AW. The mediating role of maternal responsiveness in some longer-term effects of postnatal depression on infant development. Infant Behavior and Development .2004 Dec;27(4):443-454. 
198. Diego MA, Field T, Hernandez-Reif M, Schanberg S, Kuhn C, GonzalezQuintero VH. Prenatal depression restricts fetal growth. Early Human Development. 2009 Jan;85(1):65-70.

199. McGrath JM, Records K, Rice M. Maternal depression and infant temperament characteristics. Infant Behavior and Development. 2008 Jan;31(1):71-80.

200. Tikotzky L, Chambers AS, Gaylor E, Manber R. Maternal sleep and depressive symptoms: Links with infant negative affectivity. Infant Behavior and Development. 2010 Dec;33(4):605-612.

201. Olhaberry Huber M, Romero Jiménez M y Miranda Largo M. Depresión materna perinatal y vínculo madre-bebé: consideraciones clínicas. SUMMA psicológica UST. 2015;12(1):77-87.

202. Yedid Sion M, Harlev A, Weintraub AY, Sergienko R, Sheiner E. Is antenatal depression associated with adverse obstetric and perinatal outcomes? The journal of maternal-fetal \& neonatal medicine. 2016 Mar;29(6):863-867.

203. Marcus SM. (2009). Depression during pregnancy: Rates, risks and consequences-Motherisk Update 2008. Canadian Journal of Clinical Pharmacology. 2009 Jan;16(1)15-22.

204. Alder J, Fink N, Bitzer J, Hösli I, Holzgreve W. Depression and anxiety during pregnancy: A risk factor for obstetric, fetal and neonatal outcome? A critical review of the literature. Journal of Maternal-Fetal \& Neonatal Medicine. 2007 Mar;20(3):189-209.

205. Bahri MRZ, Hosseinian S, Afrooz G, Hooman HA. The relationship between mothers' biological and psychological characteristics and their babies' levels of low birth weight. Australian Journal of Basic and Applied Sciences. 2011 Oct;5(10):848-854.

206. Smith MV, Shao L, Howell H, Lin H, Yonkers KA. Perinatal depression and birth outcomes in a healthy start project. Matern Child Health Journal. 2011 Apr; 15(3):401-409.

207. Tse AC, Rich-Edwards JW, Rifas-Shman SL, Gillman MW, Oken. Association of maternal prenatal depressive symptoms with child cognition at age 3 years. Paediatric and Perinatal Epidemiology. 2010 May;24(3):232-240.

208. Evans J, Melotti R, Heron J, Ramchandani P, Wiles N, Murray L, Stein A. The timing of maternal depressive symptoms and child cognitive development: a longitudinal study. Journal of child psychology and psychiatry. 2012 Jun;53(6):632-640.

209. Stein A, Pearson RM, Goodman SH, Rapa E, Meaghan McCallum AR, Howard LM, Pariante CM. Effects of perinatal mental disorders on the fetus and child. Lancet. 2014 Nov;384(9956):1800-1819.

210. Ocampo MLS, Arzeno MEG. A entrevista inicial. In: Ocampo MLS, Arzeno MEG, Piccolo, EG e colabs. O processo psicodiagnóstico e as técnicas projetivas. 5.ed. São Paulo: Martins Fontes; 1987. p.23-43. 
211. Feijó MC. Validação brasileira da Maternal-Fetal Attachment Scale. Arquivos Brasileiros de Psicologia. 1999;51(4):52-62.

212. Botega NJ, Bio MR, Zomignani MA, Garcia JRC, Pereira WAB. Transtornos do humor em enfermaria de clínica médica e validação da escala de medida (HAD) de ansiedade e depressão. Revista de Saúde Pública. 1995;29(5):355-63.

213. Weissheimer AM. Tradução, adaptação transcultural e validação para uso no Brasil do instrumento Prenatal Psychosocial Profile. Ribeirão Preto. Tese [Doutorado em Enfermagem em Saúde Pública] - Escola de Enfermagem de Ribeirão Preto da USP; 2007.

214. Bardin L. Análise de conteúdo. 4.ed. Portugal: Edições 70, 2007. 223p.

215. Ferrari F, Faccio F, Peccatori F, Pravettoni G. Psychological issues and construction of the mother-child relationship in women with cancer during pregnancy: a perspective on current and future directions. BMC Psychology 2018;6:10.

216. Instituto Nacional do Câncer José Alencar Gomes da Silva. Estimativa 2018: incidência do câncer no Brasil. Rio de Janeiro. 2018. http://www.inca.gov.br/estimativa/2018/

217. Merluzzi TV, Philip EJ, Heitzmann Ruhf CA, Liu H, Yang M, Conley CC. Self-efficacy for coping with cancer: Revision of the Cancer Behavior Inventory (Version 3.0). Psychological Assessment 2018;30(4):486-499.

218. American College of Obstetricians and Gynecologists Committee on Health Care for Undeserved Women. ACOG Committee Opinion No. 343: psychosocial risk factors: perinatal screening and intervention. Obstet Gynecol. 2006;108:469-77.

219. Royal College of Obstetricians and Gynaecologists. Antenatal care. Routine care for the healthy pregnant woman. London: RCOG Press; 2008.

220. Harrison P. Psychosocial Impact of a Cancer Diagnosis During Pregnancy. Nurs Womens Health 2013;17(5):437-42.

221. Lindgren K. Relationships among maternal-fetal attachment, prenatal depression, and health practices in pregnancy. Research in Nursing \& Health. 2001 Jun, 24(3):203-217.

222. Stern D. A constelação da maternidade: o panorama da psicoterapia pais/bebê. (Trad. Veronese MAV). Porto Alegre: Artes Médicas,1997.

223. Van den Bergh BRH, Mulder EJH, Mennes M, Glover V. Antenatal maternal anxiety and stress and the neurobehavioural development of the fetus and child: links and possible mechanisms. A review. Neurosci Biobehav Rev. 2005;29:237-258.

224. Herba CM, Glover V, Ramchandani PG, Rondon MB. (2016). Maternal depression and mental health in early childhood: An examination of underlying mechanisms in low-income and middle-income countries. The Lancet Psychiatry, 3(10):983-992. 
225. Biaggi A, Conroy S, Pawlby S, Pariante CM. Identifying the women at risk of antenatal anxiety and depression: A systematic review. J Affect Disord. 2016 Feb;191:62-77.

226. van de Loo KFE, Vlenterie R, Nikkels SJ, Merkus PJFM, Roukema J, Verhaak CM, Gelder MMHJ. Depression and anxiety during pregnancy: The influence of maternal characteristics. J Mood Disord Ther. 2017;1(1):1-16.

227. Woolhouse H, Brown S, Krastev A, Perlen S, Gunn J (2009) Seeking help for anxiety and depression after childbirth: results of the maternal health study. Arch Womens Ment Health 12:75-83.

228. Howard LM, Goss C, Leese M, Appleby L, Thornicroft G (2004) The psychosocial outcome of pregnancy in women with psychotic disorders. Schizophr Res 71:49-60.

229. Heyningen TV, Myer L., Onah M., Tomlinson M, Field S, Honikman S. Antenatal depression and adversity in urban South Africa. Journal of Affective Disorders, 2016;203:121-129.

230. Elmberger E, Bolund C, Magnusson A, Lützén K, Andershed B. Being a mother with Cancer. Cancer Nurs. 2008;31:58-66.

231. Turato ER. Métodos qualitativos e quantitativos na área da saúde: definições, diferenças e seus objetivos de pesquisa. Revista de Saúde Pública. 2005; 39(3):507-514.

232. Darvill R, Skirton H, Farrand P. Psychological factors that impact on women's experiences of first-time motherhood: a qualitative study of the transition. Midwifery. 2010 Jun;26(3):357-66.

233. Winnicott DW O ambiente e os processos de maturação: estudos sobre a teoria do desenvolvimento emocional. Porto Alegre: Artes Médicas,1983. (Trabalho original publicado em 1965b).

234. Moscovici S. Representações sociais: investigações em psicologia social. Rio de Janeiro, Vozes, 2003.

235. Maldonado MT. Psicologia da gravidez, parto e puerpério. 17ª ed. São Paulo: Saraiva, 1997. 229p.

236. Kübler-Ross. Sobre a morte e o morrer: o que os doentes terminais têm para ensinar a médicos, enfermeiros, religiosos e aos seus próprios parentes. Martins Fontes, São Paulo. 8a edição. 1998.

237. Noninol A, Magalhães AG, Falcão DP. Treinamento Médico para Comunicação de Más Notícias: Revisão da Literatura. Rev Bras Educ Med [Internet]. 2012.

238. Freud S. Além do princípio de prazer.1920.

239. Munhoz CAS. Câncer de mama e organização de serviços: do atendimento básico à referência na Casa de Saúde Santa Marcelina Itaquera no município de São Paulo. Dissertação apresentada ao Programa de Pós Graduação em Saúde Pública para obtenção do título 
de Mestre em Saúde Pública. Universidade de São Paulo. Faculdade de Saúde Pública. São Paulo. 2009.

240. Ferreira DM, Castro-Arantes JM. Câncer e corpo: uma leitura a partir da psicanálise. Analytica. São João del-Rei. Julho/dezembro de 2014;3(5):37-71.

241. Rasia JM. Imaginário e simbólico em pacientes com câncer: análise de duas narrativas. Revista Mediações. Londrina. Julho/dezembro de 2006;11(2):65-82.

242. Piccinini CA, Gomes AG, Moreira LE, Lopes RS. (2004). Sentimentos e expectativas da gestante em relação ao seu bebê. Psicologia: Teoria e Pesquisa, 20 (3), 233-240.

243. Lerner K, Vaz P. Minha história de superação: sofrimento, testemunho e práticas terapêuticas em narrativas de câncer. Interface 21 (60) Jan-Mar 2017. 